\title{
Customer System Efficiency Improvement Assessment: Description and Examination of System Characterization Data
}

J. W. Callaway

J. G. DeSteese

December 1986

Prepared for the

Bonneville Power Administration under a Related Services Agreement with the U.S. Department of Energy Contract DE-AC06-76RLO 1830

Pacific Northwest Laboratory Operated for the U.S. Department of Energy by Battelle Memorial Institute 


\title{
DISCLAIMER
}

This report was prepared as an account of work sponsored by an agency of the United States Government. Neither the United States Government nor any agency thereof, nor Battelle Memorial Institute, nor any of their employees, makes any warranty, expressed or implied, or assumes any legal liability or responsibility for the accuracy, completeness, or usefulness of any information, apparatus, product, or process disclosed, or represents that its use would not infringe privately owned rights. Reference herein to any specific commercial product, process, or service by trade name, trademark, manufacturer, or otherwise, does not necessarily constitute or imply its endorsement, recommendation, or favoring by the United States Government of any agency thereof, or Battelle Memorial Institute. The views and opinions of authors expressed herein do not necessarly state or reflect those of the United States Government or any agency thereof, or Battelle Memorial Institute.

\author{
PACIFIC NORTHWEST LABORATORY \\ operated by \\ BATTELLE \\ for the \\ UNITED STATES DEPARTMENT OF ENERGY \\ under Contract DE-ACO6-76RLO 1830
}

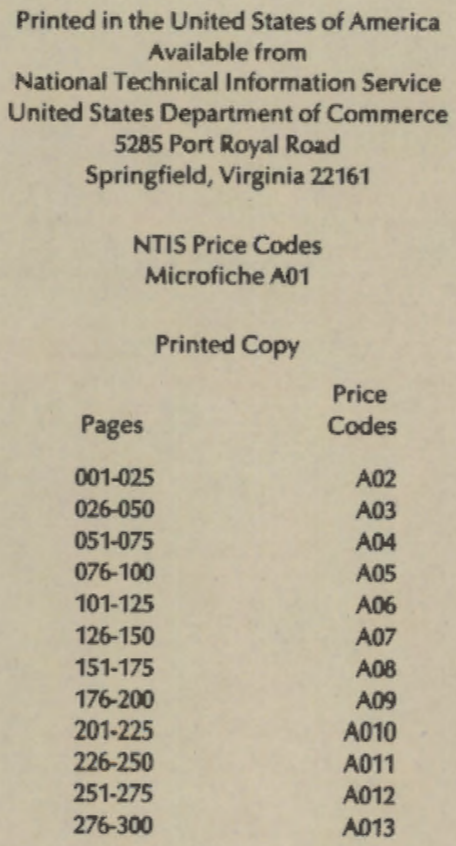


J. W. Callaway

J. G. DeSteese

December 1986

Prepared for

the Office of Conservation

Bonneville Power Administration under a Related Services Agreement with the U.S. Department of Energy under Contract DE-AC06-76RL0 1830

Pacific Northwest Laboratory

Richland, Washington 99352 
SUMMARY

This report describes three data bases that were developed in the Customer System Efficiency Improvement (CSEI) Assessment Project to help characterize transmission and distribution (T\&D) system losses experienced hy utility customers in the Pacific Northwest. The CSEI Project is being conducted by the Pacific Northwest Laboratory (PNL) for the Bonneville Power Administration (BPA), Office of Conservation. A principal objective of this project is to assess the potential for electric energy conservation in the T\&D systems of BPA's utility customers.

The three data bases provide essential input on the number and operating characteristics of T\&D component stocks that was used in another task of the CSEI Project to estimate the conservation supply functions that result from replacing existing stocks with more efficient components (Tepel et a1. 1986). This document describes the three data bases, provides a guide to their use, and presents a summary characterization of the principal lossagenerating components ( 1 ines and transformers) of the region's T\&D systems.

The first data base (called INVTRY) contains time series data for the annual power requirements and sectoral and total sales of electricity for all customers (utilities and other primary users of electrical power) in the BPA region. Data are for the years 1976 through 1983. The second data base, called QUEST, contains general information about loss recovery practices and other system loss-related features for about half of the approximately 140 electrical utilities in the region. This information was collected in a voluntary survey conducted by PNL in Tate 1984. Finally, SYSTEMS, the third data base, contains extensive and detailed data on the T\&D component characteristics. This information was provided by a subset of the utilities that responded to the survey. These three data bases are described in greater detail below.

First, the requirement and sales data base INVTRY was developed from data provided by BPA's Power Requirement Branch. Using a standard definition of energy losses as the difference between annual requirements and annual sales (in megawatt hours), this data base was used to determine both the magnitude 
and distribution, by customer type, of the energy losses that occur on the nonfederal portion of the region's T\&D network. Annual energy losses at the utility level were also calculated to identify possible loss patterns of individual utility systems. Demand, or peak, losses were not examined in this part of the CSEI Assessment.

Analysis of these data shows the following relationships between requirements and losses for each utility class:

- Investor-owned utilities (IOUs) require approximately $48 \%$ of the region's electricity, but their systems are responsible for over $60 \%$ of the region's total losses (in megawatt hours). This disproportionality can be explained, at least in part, by the fact that these utilities maintain extensive high voltage transmission systems that supplement the federally-owned transmission system operated by BPA. Losses for this category of utility therefore reflect the combined inefficiencies of both the T\&D system and a substantial transmission network.

- Nongenerating public utilities (NGUs), by contrast, require $15 \%$ of the region's electricity, but contribute only $10 \%$ of regional losses. The losses that occur on these systems generally do not include much high voltage transmission loss, as most NGUs rely on the federal network to deliver power to their bulk delivery points. Therefore, their distribution systems, on average, contain only short stretches of transmission line. Losses for this group of utilities are typically attributable to line loss on feeders and load losses on transformers.

- Generating public utilities (GPUS) have T\&D losses approximately proportional to their loads (21\% of regional load, $22 \%$ of regional losses).

- Direct service industries (DSIS), requiring about $15 \%$ of the region's power in 1983, were responsible for only $7 \%$ of the regional losses. 
This is consistent with DSIs typically having points of delivery near. site boundaries and very compact distribution systems within the site.

The second data base QUEST provides loss recovery information for about half of the utilities in the Pacific Northwest region. However, this information may not be statistically representative of Northwest utilities, because the utilities that volunteered this information may have greater-than-average interest in loss analysis and recovery. The general survey data do provide a representative description of current utility activities that deal with system losses. Moreover, the technical component data collected in the survey are some of the most detailed and comprehensive ever obtained for a regional system.

The information in the QUEST data base indicates the following trends:

- On average, utilities' own estimates of the distribution of their Tosses by component closely match the loss allocations in published research.

- Northwest utilities appear to be installing a substantial number of T\&D system efficiency improvements. These improvements are probably the result of normal system maintenance and growth requirements, and any loss reduction is viewed as a secondary benefit.

- Reconductoring, transformer replacement (to increase efficiency), and capacitance additions are the most frequent improvements reported by the utilities.

The third data base SYSTEMS was used to estimate the total regional stock of four basic distribution system components, and to determine potential resource recovery from improving the efficiency of these components through replacement or other modifications. Analyzing the sample data revealed a number of interesting operating characteristics:

- The average age of distribution system components is estimated to be about 13 to 14 years. 
- Many components were apparently oversized when installed, probably because the utilities expected that the high-demand growth rates experienced during the 1970 s would continue into the $1980 \mathrm{~s}$. As a result, current peak loads on substation transformers are, on the average, only about $60 \%$ of installed capacity; distribution transformers show a similar, but less dramatic, under-loading. In comparison, the national average for peak-to-installed capacity is over $100 \%$ for distribution transformers.

- The regional load factor for the distribution system network is about 0.4 , well below the reported national average of over 0.6 . A wide range of load factors exists over the various sizes of each component. Load factors also varied widely among different utility categories.

The information contained in SYSTEMS was used to estimate the regional stock of four principal loss generating components (substation transformers, distribution transformers, primary feeders, and transmission lines). These estimates were then used as input to other analytical tasks of the CSEI Project. Estimates of substation transformers and transmission line stocks in the region are easy to obtain because these components are relatively few in number, and are easily inventoried. However, adequate estimates of the existing distribution transformer stock by size and feeder circuit miles have not been available previously. The resulting estimates of the region's stock of these four components were determined to contain:

- about 1.3 million distribution transformers, ranging in size from Tess than 7.5 kVA to over 500 kVA

- about 1,200 substation transformers, ranging in size from about 1.0 MVA to over 60 MVA

- about 60,000 circuit miles of primary feeder, with nominal voltages ranging from about $11 \mathrm{kV}$ to $33 \mathrm{kV}$

- about 24,000 circuit miles of nonfederal transmission lines, with operating voltages of $34.5 \mathrm{kV}$ to $230 \mathrm{kV}$. 
The development of these three data bases was essential for estimating regional supply functions for T\&D conservation measures. Despite variations in data quality and consistency, the data bases provide the most accurate and detailed basis for assessing regional $T \& 0$ system characteristics yet available. The initial purpose of these data bases was to provide inputs for estimating conservation supply curves for region-wide T\&D equipment upgrading. However, the information developed for this effort regarding T\&D losses and component stocks has the potential for much broader use in future assessments of T\&D system conservation options, plans, and policies. 
ACKNOWLEDGMENTS

The authors acknowledge and appreciate the efforts of the many individuals in the Pacific Northwest utility industry who responded to the system characterization surveys and members of BPA's Area 0ffice staff, who facilitated these contacts.

A number of PNL staff made significant contributions to this work. Mike King participated in early task planning activities. As Task Leader for the initial portion of the study, Lisa Skumatz helped to develop the questionnaire and conduct the survey of utilities. Audrey Lyke collected information from representatives of the direct service industries. Jim Johnston provided the cluster analysis that guided the conduct of the utility survey in this and a previous task of the CSEI Assessment Project. Annet Dittmer and Elinor Edin performed much of the data entry and computer manipulation of the data bases. Bill Doggett reviewed the databases, eliminated data of doubtful validity, and performed the calculations that resulted in the figures in Section 5.0 . Finally, but not the least in importance, Donna Debrodt and Cary Counts edited the manuscript.

Several members of BPA's Headquarters staff greatly assisted this research by providing data and advice. Camilla Downing, in particular, played an important role in supplying basic sales and requirements data and in assisting PNL staff in its interpretation. Barry Kennedy and Clair Loosli provided much helpful information. The authors also thank the BPA Project Manager, Mike Warwick, for his interest and encouragement during the course of the study. 

. 


\section{CONTENTS}

SUMMARY

ACKNOWLEDGMENTS

ix

1.0 INTRODUCTION

1.1

2.0 CSEI DATA MANAGEMENT SYSTEM AND BACKGROUND INFORMATION

2.1

2.1 RELATIONAL DATA BASES $\ldots \ldots \ldots \ldots \ldots \ldots \ldots \ldots \ldots \ldots \ldots \ldots \ldots \ldots \ldots \ldots \ldots$

2.2 RBASE 4000 SYSTEM CHARACTERISTICS $\ldots \ldots \ldots \ldots \ldots \ldots \ldots \ldots \ldots \ldots .2 . \ldots \ldots$

2.3 LOTUS $1-2-33^{\circ}$ USES $\ldots \ldots \ldots \ldots \ldots \ldots \ldots \ldots \ldots \ldots \ldots \ldots \ldots \ldots \ldots \ldots . . \ldots \ldots$

2.4 BACKGROUND INFORMATION ON CSEI DATA BASES $\ldots \ldots \ldots \ldots \ldots \ldots \ldots . . . . . . .$.

2.4.1 The CSEI Data Bases ...................... 2.3

2.4.2 Use of the CSEI Data Bases .................. 2.4

3.0 THE SALES AND REQUIREMENTS DATA BASE $\ldots \ldots \ldots \ldots \ldots \ldots \ldots \ldots \ldots \ldots \ldots \ldots \ldots$

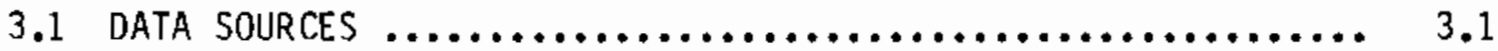

3.1 .1 Data Received from BPA ..................... 3.1

3.1.2 Supplemental Data $\ldots \ldots \ldots \ldots \ldots \ldots \ldots \ldots \ldots \ldots \ldots \ldots \ldots . \ldots . \ldots . \ldots . \ldots$

3.2 DATA MODIFICATION EFFORTS $\ldots \ldots \ldots \ldots \ldots \ldots \ldots \ldots \ldots \ldots \ldots \ldots \ldots \ldots$

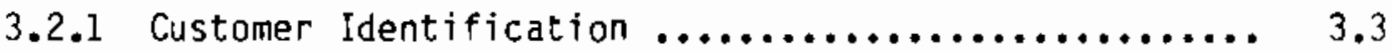

3.2.2 Error Correction ........................ 3.4

3.2 .3 Data Merges .............................. 3.5

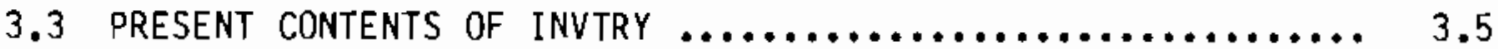

3.3.1 Group 1: Identification Relations ............ 3.5

3.3.2 Group 2: Original Data Relations $\ldots \ldots \ldots \ldots \ldots \ldots \ldots .3 .5$

3.3.3 Group 3: Sales and Requirements Relations ........ 3.6

3.3.4 Group 4: Supplementary Data Relations ........... 3.9

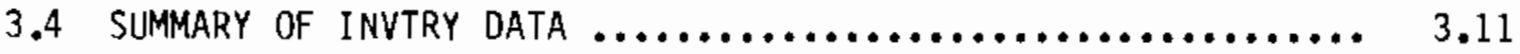


4.0 SURVEY PART 1: DATA BASE $\ldots \ldots \ldots \ldots \ldots \ldots \ldots \ldots \ldots \ldots \ldots \ldots, 4.1$

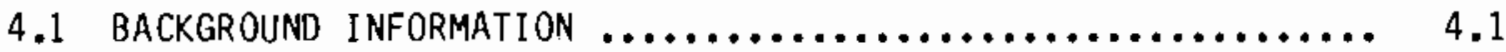

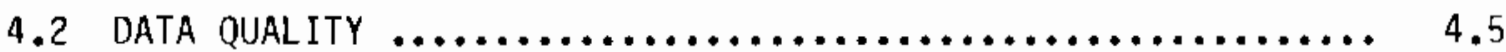

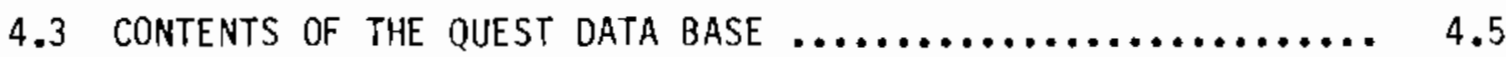

4.4 HIGHLIGHTS OF QUEST DATA $\ldots \ldots \ldots \ldots \ldots \ldots \ldots \ldots \ldots \ldots \ldots, 4.7$

4.4.1 Estimated Losses by Component $\ldots \ldots \ldots \ldots \ldots \ldots \ldots \ldots, 4.7$

4.4.2 Power Factor and Equipment Replacement ........... 4.10

5.D SURVEY PART 2: THE SYSTEMS DATA BASE $\ldots \ldots \ldots \ldots \ldots \ldots \ldots \ldots \ldots . \ldots . \ldots \ldots$

5.1 CONTENTS OF THE SYSTEMS DATA BASE $\ldots \ldots \ldots \ldots \ldots \ldots \ldots \ldots \ldots . . . \ldots .1$

5.2 DATA QUALITY $\ldots \ldots \ldots \ldots \ldots \ldots \ldots \ldots \ldots \ldots \ldots \ldots \ldots \ldots \ldots \ldots \ldots \ldots . .2$

5.2 .1 Background $\ldots \ldots \ldots \ldots \ldots \ldots \ldots \ldots \ldots \ldots \ldots \ldots \ldots, \quad 5.2$

5.2.2 Evaluation of 1984 Survey Data ................. 5.5

5.3 SUMMARY HIGHLIGHTS OF THE SYSTEMS DATA BASE $\ldots \ldots \ldots \ldots \ldots \ldots .5 .7$

6.0 CONCLUSIONS $\ldots \ldots \ldots \ldots \ldots \ldots \ldots \ldots \ldots \ldots \ldots \ldots \ldots \ldots \ldots \ldots \ldots \ldots, 6.1$

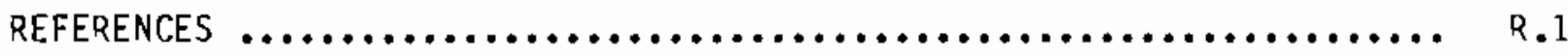

APPENDIX A--REQUEST FOR INFORMATION FORM SENT TO UTILITIES $\ldots \ldots \ldots \ldots$ A.1

APPENDIX B-BPA REgION UTILITIES BY CLUSTER $\ldots \ldots \ldots \ldots \ldots \ldots \ldots \ldots \ldots$ B.I

APPENDIX C--NAMES OF VARIABLES OR ATTRIBUTES USED IN DATA BASES $\ldots \ldots . c .1$

APPENDIX D--CLUSTER ANALYSIS $\ldots \ldots \ldots \ldots \ldots \ldots \ldots \ldots \ldots \ldots \ldots \ldots \ldots \ldots \ldots \ldots \ldots \ldots \ldots$ 


\section{FIGURES}

3.11983 Requịrements and Losses by Customer Type .............. 3.12

4.1 Utilities Estimates of Losses $\ldots \ldots \ldots \ldots \ldots \ldots \ldots \ldots \ldots \ldots \ldots \ldots . \ldots . \ldots$

5.1 Portion of Corrected Transmission Line Worksheet with Loss Calculation ................................ 5.8

5.2 Distribution of Distribution Transformers by Size Category ..... 5.9

5.3 Detail from Figure 5.2 for Distribution Transformers

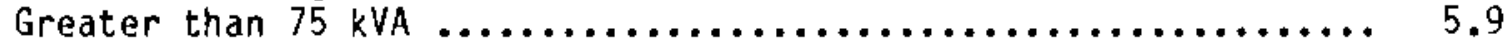

5.4 Distribution of Substation Transformers by Size Category ...... 5.10

5.5 Distribution of Feeders by Size Category $\ldots \ldots \ldots \ldots \ldots \ldots \ldots \ldots \ldots . \ldots \ldots$

5.6 Distribution of Transmission Lines by Size Category .......... 5.11

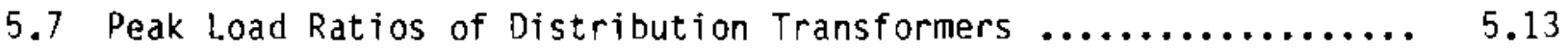

5.8 Peak Load Ratios of Substation Transformers .............. 5.13

5.9 Comparison of Average Loads to Peak Loads for Substation Transformers, 1984 .................................. 5.14

5.10 Comparison of Average Loads to Peak Loads for Distribution Transformers, 1984 ................................. 5.15

5.11 Comparison of Average Loads to Peak Load for Feeders, 1984 .... 5.16

5.12 Comparison of Average Loads and Peak Loads for Transmission

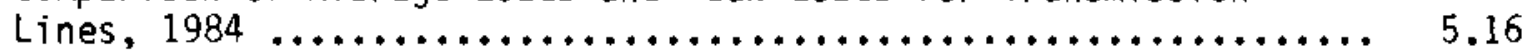

5.13 Comparison of System and Components Load Factors by Utility Cluster, 1984 



\section{$\underline{\text { TABLES }}$}

3.1 Identification Relations in INVTRY $\ldots \ldots \ldots \ldots \ldots \ldots \ldots \ldots \ldots . .6 .6$

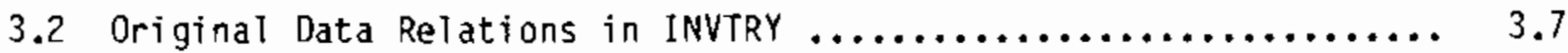

3.3 Sales and Requirements Relations $\ldots \ldots \ldots \ldots \ldots \ldots \ldots \ldots \ldots \ldots, 3.8$

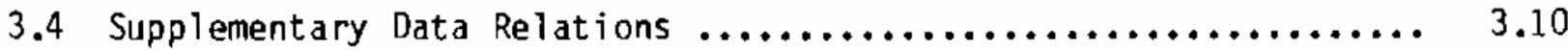

4.1 Response to Request for Information, by Type of Information and Utility Cluster $\ldots \ldots \ldots \ldots \ldots \ldots \ldots \ldots \ldots \ldots, 4.2$

4.2 Utilities' Estimates of Loss Reduction Potential .............. 4.9

4.3 Distribution of Utility Responses: Efficiency Improvements

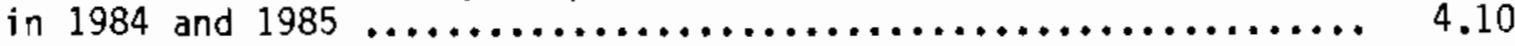

4.4 Summary of Power Factor by Point of Delivery $\ldots \ldots \ldots \ldots \ldots \ldots \ldots . . .11$

5.1 Matrix of Files and Variables in SYSTEMS Data Base........ .5 .3$

5.2 Estimated Number of Components in the BPA Region ............. 5.12

5.3 Distribution Transformers: Categories and Estimated Operating Characteristics of Regional Stock $\ldots \ldots \ldots \ldots \ldots \ldots \ldots \ldots \ldots \ldots . . .6 .18$

5.4 Substation Transformers: Categories and Operating Characteristics ........................................ 5.19

5.5a Primary Feeders: Operating Characteristics of Sample Data ..... 5.20

5.5b Primary Feeders: Categories and Estimated Operating

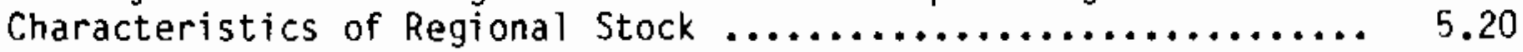

5.6a Transmission Lines: Operating Characteristics of Sample Data ............................................. 5.21

5.6b Transmission Lines: Categories and Estimated Operating Characteristics of Regional Stock 


\subsection{INTRODUCTION}

This report describes the results of one part of the CSEI Assessment Project. The project is being conducted by PNL for the BPA Office of Conservation. A principal objective of the CSEI Assessment Project is to assess the potential for conservation in the T\&D systems of BPA's customers. By focusing on customer power systems, the CSEI project complements BPA's ongoing assessments of conservation potential in the residential, commercial, agricultural, and industrial sectors and in its own electric power T\&D system. The project's other objective is to respond to Action Item 11.2 in the 1983 Northwest Conservation and Electric Power Plan issued by the Northwest Power Planning Council. In Action Item 11.2, the Council requested that BPA study ways to improve the efficiency of electric power generation, transmission, and distribution. The CSEI project thus focuses on all T\&D systems in the Pacific Northwest except systems owned by the federal government.

Determining the magnitude of reducing T\&D losses for individual utility systems and for the region's nonfederal transmission and distribution network involves developing conservation supply curves for loss reduction options. These supply curves represent the amount of energy that could be recovered at various economic costs to the region by reducing energy losses on the T\&D network. Estimating this conservation resource requires several types of information:

- an inventory of various T\&D loss-generating components in the region by component size

- an adequate characterization of existing components stock to determine current energy losses for each size of each component

- a characterization of more efficient components to estimate the loss reduction potential for each size of each component 
- an estimation of the costs (capital and labor) to replace inefficient equi pment

- an estimation of the age distribution of T\&D components.

Most of this information did not exist for the regional system before the CSEI Assessment Project began. Data were available for portions of a limited number of utility systems as a result of utility-sponsored engineering studies and construction plans. However, a characterization of the larger regional network had never been attempted. In addition, while estimates of the quantity of transmission line and substation transformers had been made, they were of questionable reliability and were generally nonspecific. For example, no data existed on the number and sizes of distribution transformers, or on feeder mileage in the region. Therefore, the primary data needed for generating supply curves were not available prior to this study.

These data gaps were filled by collecting a large quantity of data from regional utilities. Initial plans called for a pilot survey to determine the capability of utilities to supply detailed component descriptions and lossrelated operating data. This survey was to have been followed by a stratified random sample of utilities or components based on the results of the pilot survey. However, before the latter survey was conducted, nontechnical policy considerations by $B P A$ resulted in a decision to postpone any attempts to develop region-wide T\&D efficiency improvement programs. Accordingly, the need for highly detailed cost and conservation potential information diminished. The supply curve estimation proceeded, but was based instead on the data acquired in the pilot survey that are subsequently integrated into two of the three data bases described in this report.

This report presents descriptions and a guide to the use of the data bases developed to support the CSEI Assessment Project. The three data bases, which were developed for use on an IBM microcomputer, contain 1) extensive sales and energy requirement data for all BPA customer utilities for the years 1976 through 1983, and 2) detailed system component characterization information for a large, nonstatistical sample of customer distribution systems in the BPA service area. 
This document consists of five sections. Section 2.0 provides an introduction to the characteristics and use of the relational data base system that was used to organize and provide access to the data. General background information on the three data bases developed in this task is also discussed. The data base created to examine the trend of sales, requirements, and losses of BPA customers is described in Section 3.0. The two remaining data bases contain information derived from data that were provided by regional utilities. These two data bases are discussed in Sections 4.0 and 5.0 , respectively. 


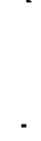




\subsection{CSEI DATA MANAGEMENT SYSTEM AND BACKGROUND INFORMATION}

The first phase of the CSEI analysis drew upon three large data bases of information about the 170 BPA customers and the components in their distribution systems. These data bases (called INVTRY, DUEST, and SYSTEMS) are discussed in detail in Sections $3.0,4.0$, and 5.0 of this report. At the time this report was written, these data bases required about seven megabytes of storage on a personal computer and contain information for approximately 80 variables. The sales data base (described below) contains time series data for eight years (1976-1983). This data base was developed on IBM personal computers using an RBASE $4000^{\circledR}$ relational data base system and LOTUS 1-2-3 spreadsheets. These software systems are briefly discussed below.

\subsection{RELATIONAL DATA BASES}

In general terms, a relational data base is a system for organizing and storing information so that it can be displayed in two-dimensional tables, or relations, that consist of horizontal rows and vertical columns. Tables within a relational data base can be compared, combined, and manipulated for a broad range of uses. Information (records) within a single table also can be sorted or extracted in a variety of ways.

A fundamental concept of relational information management is that while no two rows of data are identical within a given relation, there must be a field or combination of fields with values that will uniquely identify each row. The value of the characteristic (or attribute) contained in this field is labeled a "key" variable. This key feature makes it possible for relations containing rows of different kinds of information to be electronically manipulated a number of different ways.

RBASE 4000 is a trademark of Microrim, Inc.

- LOTUS $1-2-3$ is a trademark of Lotus Development Corporation. 


\subsection{RBASE $4000^{\circ}$ SYSTEM CHARACTERISTICS}

The RBASE $4000^{\circ}$ series is a relational data base system for microcomputers that is produced and distributed by Microrim, Inc., a Seattle-based software company. RBASE $4000^{\circ}$ has a number of features that made it desirable for managing the CSEI Assessment data bases. These features include:

- an ability to manage large quantities of data

- high transportability of data between RBASE $4000^{\circ}$ and other data base systems, including DBase II and III*, spreadsheet software packages such as LOTUS 1-2-3\%, and other microcomputer, minicomputer and mainframe systems

- ease of use due to logical structure, format and language syntax

- extensive report writing capabilities

- an ability to interface with programming languages such as FORTRAN and BASIC to increase data manipulation options.

As with any software, there are also certain disadvantages with RBASE $4000^{2}$ that were encountered in the CSEI analysis. Two problems were identified, but both were easily solved by using the inherent flexibility and high degree of data transportability found in RBASE $4000^{\circ}$. First, RBASE $4000^{\circ}$ can perform only limited calculations within the data base. Energy losses for system components using sample data were calculated with other software (primarily LOTUS 1-2-3 and APL). Second, RBASE $4000^{\circ}$ limits each defined data base to 400 attribute columns, no matter how many relations are contained in that data base. For those CSEI data bases that contain relations holding large numbers of attributes, this limitation made it difficult to perform manipulations such as appending, intersecting, or similar operations (that resulted in additional relations) after a certain number of relations had been created. This problem was dealt with by periodic "housecleaning" of the data base to eliminate relations that were duplicative or were not needed as a permanent grouping of information.

DBase II and III are trademarks of Ashton-Tate. 


\subsection{LOTUS 1-2-3 USES}

LOTUS 1-2-3 is a multi-use, spreadsheet-type data analysis and management tool created by LOTUS Development Corporation. It has become one of the leading personal computer business software programs, with application in a wide variety of settings in business, industry, and research. In addition to the use of RBASE 4000 to create the CSEI data base, extensive portions of the data base technical (component) information also reside in LOTUS 1-2-3 spreadsheet files. The LOTUS 1-2-3 format allowed more extensive data manipulation to estimate component loss recovery potential than RBASE $4000^{*}$.

More detailed descriptions of the software used for the three data bases are provided in Sections 3.0 through 5.0. Additional information on the software systems used for the CSEI data bases can be obtained from the RBASE $4000^{\circledR}$ and the LOTUS 1-2- User's Manuals. The current version of RBASE $5000^{\circledR}$ can also be consulted, as this version is compatible with the RBASE $4000^{\circledR}$ version used to create the CSEI data bases.

\subsection{BACKGROUND INFORMATION ON CSEI DATA BASES}

The three data bases created to support the conservation assessment tasks of the project are introduced in this section, accompanied by a brief description of their use in the CSEI analysis. In subsequent sections of this report, each data base is presented in greater detail, with examples of the type of information each contains and descriptions of the manner in which it was manipulated and used in the CSEI Assessment Project.

\subsubsection{The CSEI Data Bases}

The first data base (called INVTRY) was developed to scope the current magnitude of distribution system losses in BPA's Pacific Northwest region. Historical sales and energy requirements data for approximately 170 regional utilities and other direct service customers were received from BPA on magnetic IBM tape. These data, in conjunction with utility identification attributes added by PNL, formed the basis of the first data base. The INVTRY data

(8) RBASE 5000 is a trademark of MICRORIM, Inc. 
base was used to identify historical levels of annual system losses for each BPA customer utility for which matching annual sales (or use) and requirements information were available.

The second and third data bases were created from a voluntary questionnaire sent by PNL to regional utilities to obtain information about the quantity and operating characteristics of components in their distribution systems. The second data base, called QUEST, contains general system operation and los $\mathrm{s}$ information obtained from the first portion of the questionnaire. Data that described the important technical specifications and operating characteristics of the key elements in utility distribution systems were obtained in the second portion of the questionnaire and were stored in a third data base (called SYSTEMS). Appendix A contains a copy of the questionnaire that was used. This information was used to help bracket the range of potential loss reduction in the early stages of the project. This third data base contains more extensive technical data on four key distribution system elements: distribution transformers, distribution substation transformers, primary level feeders, and utility-owned transmission lines. The SYSTEMS data base, was used to estimate the number of distribution system components (by size) for the entire region, and to estimate average energy losses of those components.

\subsubsection{Use of the CSEI Data Bases}

The flexibility and transportability inherent in the RBASE $4000^{3}$ data base management system allows relations or attributes in any of these three data bases to be exported to other data bases or to other software to facilitate analysis. While each data base had its own particular use in the project, data from all three data bases were used in Tater stages of the project.

The supplementation, correction, and manipulation of the INVTRY data base provided the information necessary to scope the magnitude and distribution of regional losses experienced by various classes of utilities and to investigate whether sectoral sales could be used to predict utility loss levels. The other two data bases were used primarily to estimate the numbers, current efficiency levels, and loss reduction potentials of the four distribution system components for the region's utilities. These estimates were used to develop a supply curve describing the expected costs and savings of various region-wide 
system improvement schemes. Current CSEI analyses of load management approaches were also based in part on these data bases. 


\section{D THE SALES AND REQUIREMENTS DATA BASE (INVTRY)}

This section describes the development of the INVTRY sales and requirements data base. This data base represents an eight-year history of the purchases (and/or the levels of self-generated power for those utilities with their own generating resources) and sales by each utility to five consumer sectors for the years from 1976 to 1983. Once they had heen checked and apparent errors corrected, these data were used to estimate system losses for each individual customer and for the region as a whole. For those customers that do not have "sales" [i.e., direct service industries (DSIs) and federal agency customers], losses were estimated using a different approach that is described in Section 3.1.2.

\subsection{DATA SOURCES}

Average regional electrical losses on the T\&D systems of BPA's customers have been estimated by BPA and others for demand forecasts and similar purposes, but comprehensive data on the historical levels and trends of losses for each customer have not been generally available. Although the data needed to estimate losses have existed at BPA in the form of sales and requirements records, these data have not been used previously in a systematic manner to identify individual utility loss patterns or loss recovery potential.

\subsubsection{Data Received from BPA}

The data provided by BPA were received in the form of four magnetic tapes containing information for the years 1976 through 1982. Sales data for 1983 were also provided when they became available in 1985. The general contents of each tape are described below:

Tape 1--Contains annual sales and number of customers by consumer sector for all BPA customers, including direct service industries (DSIs) and federal customers, for 1976 through 1982. This information was provided to BPA by each customer. Five consumer sectors were represented: domestic, commercial, industrial, irrigation, and "other" (which includes the utility's own usage, municipal uses such as street lighting, and other institutional consumption). The tape files also contained fields with identification information, including 
a BPA-assigned customer number, type of utility (municipal, cooperative, publis utility district, federal or privately owned), the state in which the customer is located, and the name of its BPA area or district office.

Tape 2--Contains monthly sales, as available, by consumer sector for public utilities in the region lexcept those located in the BPA Puget Sound Area Office territory) for the period from 1976 through 1983. The data were taken from utility billing records. The actual reporting periods for this data were unknown, and irrigation data were particularly unreliable. These data were not incorporated into the data base.

Tape 3--Contains monthly deliveries by BPA to nongenerating and small public utilities (preference customers) for the period from 1976 through 1983. These data were from BPA billing records, and included the following information: BPA customer number, year, month, maximum peak (kW), billing peak (kW), energy (MWh), and billing in dollars. A FORTRAN program was written to average this information so annual energy requirements for each utility and year could be produced.

Tape 4--Contains monthly requirement data for the investor-owned utilities (IOUs) and the large generating public utilities in the BPA service area. The data were obtained by BPA from the records submitted by the utilities to the Northwest Power Pool, an organization of nineteen utilities and agencies that voluntarily operate their power systerns on a coordinated basis. The tape contains the following information: BPA customer number, month, year, number of weeks per month, average power (MW), reading period, peak load, and type of load (firm or nonfirm). The average energy requirements were converted to a value compatible with the requirements of nongenerating utilities by summing and averaging the montbly average megawatts; that result was multiplied by 8761$)$ (the number of hours in a year) to produce requirements in MWh for each year. This tape contained both the requirements of the entire utility system, and the requirements for those portions that were within the BPA service area. Only the latter were used in the INVTRY data base.

1983 Sales Tape--Sales information for 1983 was made available by BPA in the spring of 1985. This data tape provided annual sales information for 121 utilities. 


\subsubsection{Supplemental Data}

BPA has approximately 170 customers. Of that number, 144 are utilities that have retail sales of electricity. The remaining customers are either DSIs or federal agencies (ranging from military installations to Bureau of Reclamation irrigation projects). Although these latter customers constitute approximately $16 \%$ of the regional load, little data are available about what portion of the regional loss is attributable to their systems. This information gap was addressed by conducting an informal survey of the 20 OSIs (these industries consumed $14.7 \%$ of the regional electrical load in 1982) to determine an average level of electrical loss between the point of bulk power delivery from BPA and its point of use.

The DSI survey data, which contained both estimates and metered losses, indicated that losses for these customers is very low; on the average it is estimated to be only $1.7 \%$ of the annual load. Some of the federal entities, which together constitute the remaining group of BPA customers, have loads distributed in a manner similar to that of the utilities (for example, the military bases). Other agencies, such as the Bureau of Reclamation and the Army Corps of Engineers, require power for a single purpose (pumping of irrigation water or dam operation); these customers do not maintain distribution systems. CSEI records on these BPA customers include on?y their annual requirements, and presently cover only the five-year period from 1979 through 1983. No effort was made to obtain system loss information from these agencies.

\subsection{DATA MODIFICATION EFFORTS}

Once tape data were transferred to the RBASE 4000 system, several modifications were necessary to facilitate its use in analysis. These modifications are described briefly below.

\subsubsection{Customer Identification}

Each raw data tape from BPA identified customers using a 3-digit numbering system. Most utility customers had three different numbers (one for each data file or tape). To eliminate confusion and to facilitate the relational 
operations of the data hase, a 4-letter (alpha) code was assigned to each of the 170 customers. This code is listed in Appendix $B$ and was used in all three data bases.

\subsubsection{Error Correction}

Three sources of error were possible with the sales and requirement data used for the INVTRY data base. The first two were coding errors made when data were entered on BPA's computer system, and data inaccuracies (errors in the data collected by BPA). Most of these errors were identifiable when anomalous results occurred in preliminary checks. One such check involved summing sales across all consumer sectors and comparing this figure with the amount given for total sales. Another obvious indication of error was when total annual sales exceeded total annual requirements by a significant amount for a given year.

There was some evidence of a third category of possible error that was not addressed. This error is termed the "billing cycle bias," which results because the periods of record for which sales and requirements data are collected do not always coincide. In other words, requirement data may be recorded by calendar weeks or months, while sales are tabulated in 30-day billing periods that may not start at the beginning of the month. These differences can occur because billing periods are often staggered by utilities to make them administratively easier to handle.

To evaluate this error source, time series files were constructed from utility customers' annua? sales, requirements, and apparent losses for the 1975 through 1982 period. These files were examined to identify any cyciical variations in losses that would indicate that the billing cycle bias was an important factor in the variation of losses from year to year. While many utilitiej had loss patterns that showed moderate annual variations (i.e., loss percentages that changed by one or two points) over the eight years, no significant cyclical patterns were apparent. Therefore, while some billing cycle bias is likely to be present in the data, it is assumed that the error introduced by this problem into the gross estimate of losses is small. 


\subsubsection{Data Merges}

In its present form, the INVTRY data base contains information from the tape files, data entered by PNL, and relations (or tables, see Section 2.1) that were the product of relational operations, such as merges or subtractions. These operations are very easily accomplished within RBASE 4000, and were used for loss reports, for sorting and grouping by certain attributes, and for examining utility clusters. The present size of the data base will allow a moderate amount of additional operations to create new relations. As discussed in Section 2.2, such modifications can be made as long as the number of total attribute (or variable) columns for the whole data base doses not exceed 400 . This is accomplished by eliminating superfluous relations or storing them in a new data base.

\subsection{PRESENT CONTENTS OF INVTRY}

The INVTRY data base presently contains four groups of relations. These relations are described below and identified in accompanying tables. In all tables, an ' $X$ ' signifies the presence of the attribute (or variable) in the noted table. Refer to Appendix $C$ for a complete explanation of the variables in all three data bases.

\subsubsection{Group 1: Identification Relations}

The three relations in this group contain identification data for the BPA customers in the CSEI Study. These were used for such activities as crossreferencing in relational operations, for developing mail and phone lists and for storing information on customer contacts. Table 3.1 contains the names and descriptions, data type, formatted field length, and present key designations for attributes in these three relations. The key designation for any attribute can be added or deleted at any time, and is used to facilitate relational operations such as intersects, unions, or subtractions.

\subsubsection{Group 2: Original Data Relations}

These five relations (1isted in Table 3.2) contain data from the tapes in their original form, although FILE3 and ANNGEN data have been converted from monthly to annual requirements. 
TABLE 3.1. Identification Relations in INVTRY

Attributes

\begin{tabular}{|c|c|c|c|c|c|c|}
\hline Name & Type & Length & Key & ALLID & NAMENUMS & CONTACTS \\
\hline CODE & TEXT & 4 characters & Yes & $x$ & $x$ & $x$ \\
\hline CUSTN0.1 & INTEGER & 1 value(s) & & $x$ & $x$ & \\
\hline CUSTNO.2 & INTEGER & 1 value(s) & & $x$ & $x$ & \\
\hline CUSTN0.3 & INTEGER & 1 value(s) & & $x$ & $x$ & \\
\hline CUSTN0.4 & INTEGER & 1 value(s) & & $x$ & $x$ & \\
\hline UTYPE & TEXT & 1 characters & & $x$ & & \\
\hline NUMBER & INTEGER & 1 value(s) & & $x$ & & \\
\hline NAME & TEXT & 40 characters & & $x$ & $x$ & \\
\hline ADDRESS1 & TEXT & 40 characters & & $x$ & & \\
\hline ADDRESS2 & TEXT & 40 characters & & $x$ & & \\
\hline CITY & TEXT & 25 characters & & $x$ & & \\
\hline STATE & TEXT & 2 characters & & $x$ & & \\
\hline ZIPCODE & TEXT & 6 characters & & $x$ & & \\
\hline CONTACT & TEXT & 25 characters & & & & $x$ \\
\hline TITLE & TEXT & 40 characters & & & & $x$ \\
\hline PHONE & TEXT & 12 characters & & & & $x$ \\
\hline SUBJECT & TEXT & 40 characters & & & & $x$ \\
\hline \multicolumn{3}{|c|}{ rent Number of Rows } & & 171 & 171 & 184 \\
\hline
\end{tabular}

\subsubsection{Group 3: Sales and Requirements Relations}

This group consists of four primary relations that contain merged information for each customer. These relations include identifiers, sector data (numbers of consumers and sales by sector), and total annual sales and requirement:s for 1976 through 1983. Three additional relations hold partial data (e.g., sales or requirements combined with identifiers) that were used for repetitive loss analysis operations. Table 3.3 contains the full description of all seven relations. 
TABLE 3.2. Original Data Relations in INVTRY

Attributes

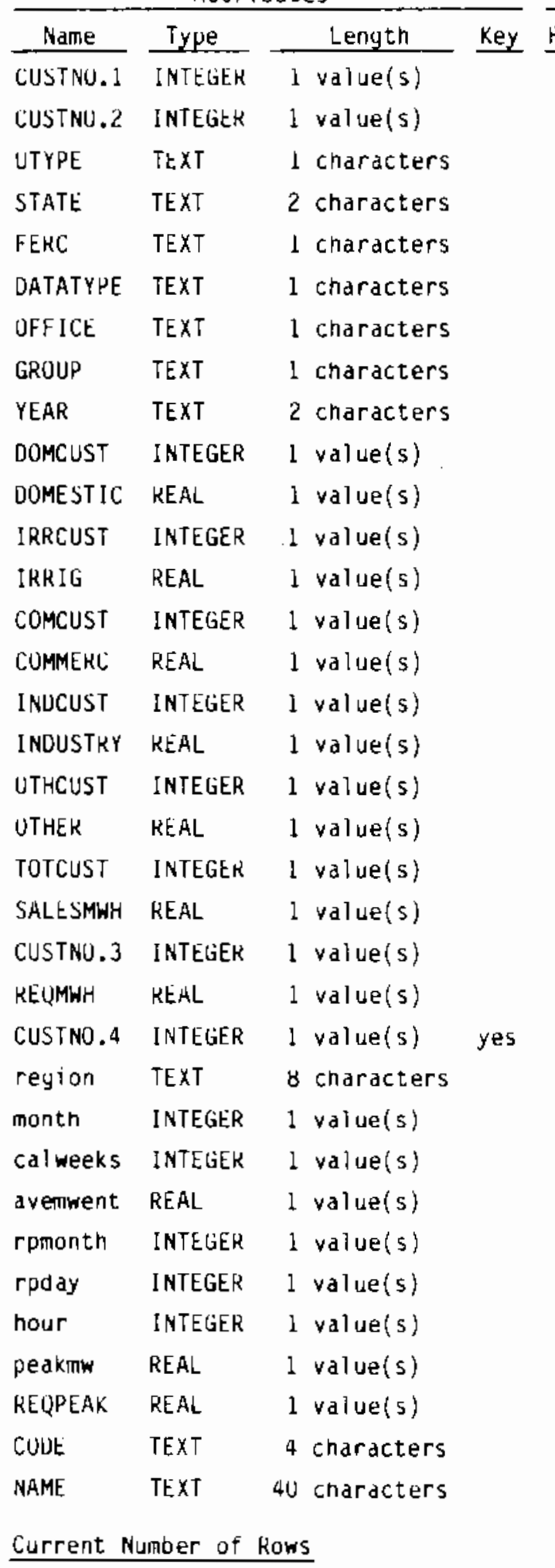

Kelation Names

$\frac{\text { FILE1 }}{x}$ FILE3 FILE4 ANNGEN SALESB3

$x$

$x$

$x$

$x$

$x$

$x$

$x$

$x \quad x \quad x \quad x$

$x$

$X$

$x$

$x$

$x$

$x$

$x$

$x$

$x$

$x$

$x$

$x$

$x$

$x$

$x$

$x$
$x \quad x$
$x$
$x$

$x$

$x$

$\begin{array}{lllll}1068 & 866 & 2442 & 225 & 121\end{array}$ 
TABLE 3.3. Sales and Requirements Relations

Attributes

\begin{tabular}{|c|c|c|c|c|c|c|c|c|}
\hline Name & Type & Length & Key & IOUS\&R & PUBS\&R & PUBS\&R83 & PREQ83 & 10083 \\
\hline CUSTNO.1 & INTEGER & 1 value(s) & & $x$ & $x$ & $x$ & & \\
\hline CUSTNO.? & INTEGER & 1 value(s) & & $x$ & $x$ & $x$ & & \\
\hline CUSTNO.3 & INTEGER & 1 value(s) & & $x$ & $x$ & $x$ & $x$ & \\
\hline CUSTNO.4 & INTEGER & 1 value $(s)$ & yes & $x$ & $x$ & $x$ & & $x$ \\
\hline REGION & TEXT & 8 characters & & $x$ & & & & \\
\hline YEAR & TEXT & 2 characters & & $x$ & $x$ & $x$ & $x$ & $x$ \\
\hline REQMWH & REAL & 1 value(s) & & $x$ & $x$ & $x$ & $x$ & $x$ \\
\hline CODE & TEXT & 4 characters & & $x$ & $x$ & $x$ & & \\
\hline NAME & TEXT & 40 characters & & $x$ & $x$ & $x$ & & \\
\hline UTYPE & TEXT & I characters & & $x$ & $x$ & $x$ & & \\
\hline STATE & TEXT & 2 characters & & $x$ & $x$ & $x$ & & \\
\hline FERC & TEXT & 1 characters & & $x$ & $x$ & $x$ & & \\
\hline DATATYPE & TEXT & I characters & & $x$ & $x$ & $x$ & & \\
\hline OFF ICE & TEXT & 1 characters & & $x$ & $x$ & $x$ & & \\
\hline GROUP & TEXT & 1 characters & & $x$ & $x$ & $x$ & & \\
\hline DOMCUST & INTEGER & 1 value(s) & & $x$ & $x$ & $x$ & & \\
\hline DOMESTIC & REAL & 1 value(s) & & $x$ & $x$ & $x$ & & \\
\hline IRRCUST & INTEGER & 1 value(s) & & $x$ & $x$ & $x$ & & \\
\hline IRR IG & REAL & 1 value(s) & & $x$ & $x$ & $x$ & & \\
\hline COMCUST & I NTEGER & 1 value (s) & & $x$ & $x$ & $x$ & & \\
\hline COMMERC & REAL & 1 value(s) & & $x$ & $x$ & $x$ & & \\
\hline INDCUST & INTEGER & I value(s) & & $x$ & $x$ & $x$ & & \\
\hline INDUSTRY & REAL & 1 value(s) & & $x$ & $x$ & $x$ & & \\
\hline OTHCUST & I NTEGER & 1 value(s) & & $x$ & $x$ & $x$ & & \\
\hline OTHER & REAL & 1 value(s) & & $x$ & $x$ & $x$ & & \\
\hline TOTCUST & INTEGER & 1 value (s) & & $x$ & $x$ & $x$ & & \\
\hline SALESMWH & REAL & I value(s) & & $x$ & $x$ & $x$ & & \\
\hline Current $\mathrm{N}$ & Number of & Rows & & 185 & 912 & 105 & 105 & 20 \\
\hline
\end{tabular}




\subsubsection{Group 4: Supplementary Data Relations}

Group 4 contains three relations with data collected by PNL to supplement the tape data, which as noted above, lacked certain information on several ciasses of BPA customers. The relation DSIREQS contains information callected by BPA on the annual requirements for the 20 DSI customers for the years 1976 through 1983. In addition, this relation contains monthly peak requirement data. The relation SECS\&R contains data for 16 customers that either purchase their requirements from other regional utilities or generate their own supply, and are therefore not served by BPA. These are primarily small municipal systems, and PNL obtained data on their annual sales and requirements by contacting them directly. For eight of these customers, only sales data were obtainable. The final relation in this group is PFEDS\&R, which is a collection of all information available from BPA about distribution of the loads of the six federal agency customers. Table 3.4 lists the contents of these relations.

In addition to sorting utilities by their ownership/generating status, utilities were also categorized by size and sales characteristics. This differentiation was obtained by performing a cluster analysis (described in Appendix 0). Eleven clusters were formed in the original analysis. However, it was found that a less refined level of clustering was more useful for statistical purposes. Therefore, the analysis used a cluster of four types of utilities taken from a point closer to the middle of the cluster analysis "trees." Cluster I contains small utilities (primarily municipal systems with fewer than 5,000 customers) that do not have significant irrigation loads. Cluster 2 utilities are also small utilities (in terms of their total sales and customers), but that do serve sizable irrigation loads. Cluster 3 contains medium-sized utilities with mixed commercial, industrial, and irrigation loads. Utilities in Cluster 4 are the largest in the region and also serve mixed loads. Most generating utilities fall into this latter category. 
TABLE 3.4. Supplementary Data Relations

Attributes

\begin{tabular}{|c|c|c|c|c|c|c|}
\hline Name & Type & Length & Key & DSIREOS & SECS\&R & PFEDS\&R \\
\hline CODE & TEXT & 4 characters & & $x$ & $x$ & $x$ \\
\hline NAME & TEXT & 40 characters & & $x$ & $x$ & $x$ \\
\hline YEAR & TEXT & 2 characters & & $x$ & $x$ & $x$ \\
\hline REQMWH & REAL & 1 value(s) & & $x$ & $x$ & $x$ \\
\hline PEAKMO & TEXT & 3 characters & & $x$ & & \\
\hline PEAKREQ & REAL & 1 value (s) & & $x$ & & \\
\hline CUSTNO.1 & INTEGER & 1 value $(s)$ & & & $x$ & $x$ \\
\hline CUSTNO. 2 & INTEGER & 1 value $(s)$ & & & $x$ & \\
\hline CUSTNO. 3 & INTEGER & 1 value $(s)$ & & & $x$ & \\
\hline CUSTNO. 4 & INTEGER & I value(s) & & & $x$ & \\
\hline UTYPE & TEXT & 1 characters & & & $x$ & \\
\hline STATE & TEXT & 2 characters & & & $x$ & $x$ \\
\hline FERC & TEXT & 1 characters & & & $x$ & \\
\hline DATATYPE & TEXT & 1 characters & & & $x$ & \\
\hline OFFICE & TEXT & 1 characters & & & $x$ & \\
\hline GROUP & TEXT & 1 characters & & & $x$ & \\
\hline DOMCUST & INTEGER & I value(s) & & & $x$ & \\
\hline DOMESTIC & REAL & 1 value(s) & & & $x$ & $x$ \\
\hline IRRCUST & INTEGER & 1 value(s) & & & $x$ & \\
\hline IRRIG & REAL & 1 value(s) & & & $x$ & $x$ \\
\hline COMCUST & INTEGER & 1 value(s) & & & $x$ & \\
\hline COMMERC & REAL & 1 value(s) & & & $x$ & $x$ \\
\hline INDCUST & INTEGER & 1 value(s) & & & $x$ & \\
\hline INDUSTRY & REAL & 1 value(s) & & & $x$ & $x$ \\
\hline OTHCIJST & INTEGER & 1 value(s) & & & $x$ & \\
\hline OTHER & REAL & 1 value(s) & & & $x$ & $x$ \\
\hline TOTCUST & INTEGER & 1 value (s) & & & $x$ & \\
\hline SALESMWH & REAL & I value(s) & & & $x$ & \\
\hline DELPT & TEXT & 20 characters & & & & $x$ \\
\hline Current 1 & umber of & Rows & & 161 & 122 & \\
\hline
\end{tabular}




\subsection{SUMMARY OF INVTRY DATA}

The INVTRY data base was used in the CSEI study for a number of analyses, including the initial assessment of system and regional losses by utility and utility type. Some of the more significant results are depicted in the pie charts shown in Figure 3.1 .

Figure 3.1 shows the proportion of losses and requirements for 1983 by type of utility. In these tables, 100 is an acronym for investor-owned utilities, GP is a generating public utility, NGP is a nongenerating public utility (i.e., its requirements are fully supplied by BPA or another utility), and DSI denotes direct service industries (primarily aluminum smelters). The category of OTHER consists of the federal agencies supplied by BPA (see Section 3.3.4). This group represented too small a portion of the regional losses to be graphically displayed in the loss pie chart.

These graphs show some interesting aspects of distribution system losses in the BPA region. Both the generating public utilities and investor-owned utilities are responsible for a disproportionate amount of regional losses. This discrepancy is particularly noticeable in the latter group, which required $47.5 \%$ of the region's power in 1983, but was responsible for over $60 \%$ of the total 1osses. This situation was not closely analyzed, but the high proportion of losses is probably because these utilities operate extensive transmission facilities that incur losses that are included in this study as "system" losses. Nongenerating utilities and DISS, on the other hand, operate only a very small fraction of the region's transmission system. Power to these utilities is delivered over the BPA-owned transmission grid, and the losses for this part of the regional system were not included in CSEI calculations.

The DSIs show losses that are disproportionately small for a related reason. Because they are typically located very near BPA bulk delivery points, there is no "distribution system," to speak of, for these customers, and thus extremely low distribution system losses occur. 


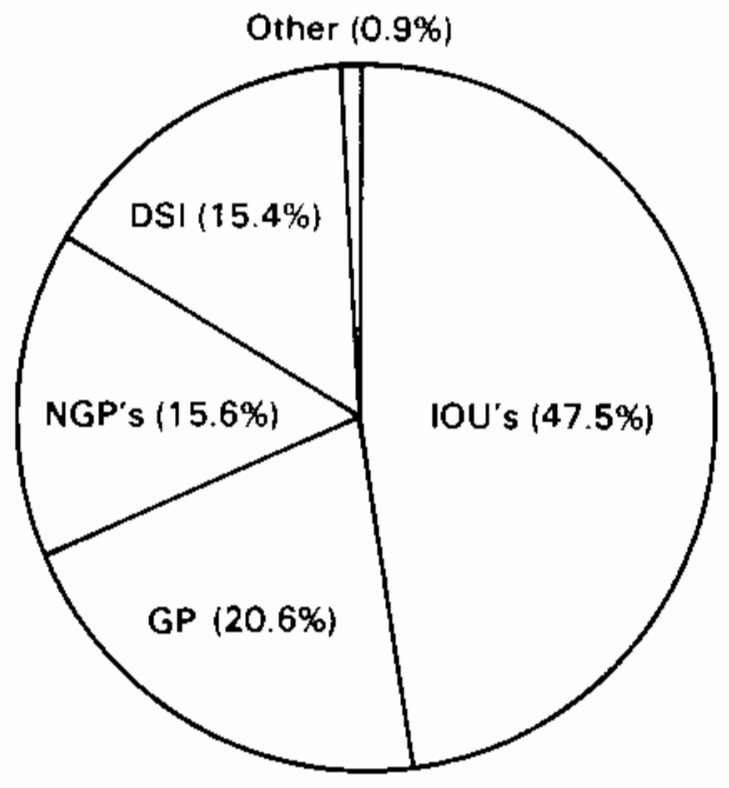

a. Requirement (MWh)

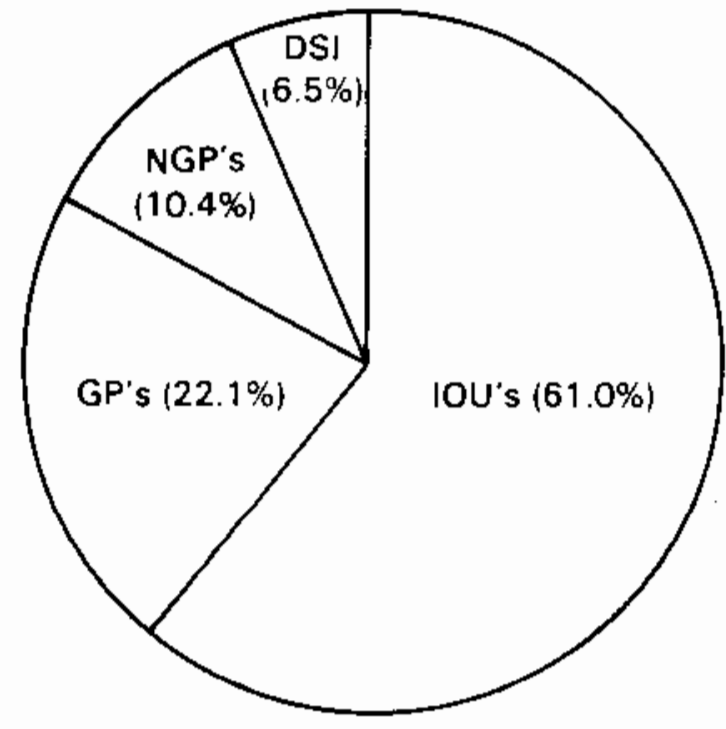

b. Losses (MWh)

FIGURE 3.1. 1983 Requirements and Losses by Customer Type 


\section{D SURVEY PART 1: THE QUEST DATA BASE}

The two remaining data bases were created with information gathered in a survey of utilities conducted in the fall of 1984. This section of the report describes and discusses QUEST, which is the first of these two data bases.

\subsection{BACKGROUND INFORMATION}

During the fall of 1984 , a mailed survey questionnaire was sent to the chief system engineers of BPA's utility customers to request information on the technical and operational characteristics of their distribution systems (see Appendix A). The first portion of the survey was intended to collect general information on utility characteristics and operations that related to system efficiency. This part of the questionnaire was designed to be answered relatively easily by the utility engineers and to not require reference to detailed system records. General information in the following areas was requested:

- requirements information for 1983

- general supply relationships with other utilities

- bulk delivery point power factor information

- estimates of the percent of distribution system losses by component

- estimates of the potential for system loss reductions with efficiency improvements

- average yearly equipment replacement rates and typical costs

- loss studies, work plans, and annual reports as available.

Of the 144 utilities included in the survey, 67 (47\%) provided responses to one or more sections of the questionnaire. Table 4.1 provides an indication of the responses to various segments of questionnaire. A " 0 " indicates that no information was received. The table lists utilities by name and by the alpha code used in the data bases. Headings across the top of the table refer to relations that were created from the data. The clustering system described previously was again found to be helpful in characterizing the types of 
TABLE 4.1. Response to Request for Information, by Type of Information and Utility Cluster

\begin{tabular}{|c|c|}
\hline Cogde (a) & Cluster a \\
\hline $\begin{array}{l}\text { MLSP } \\
\text { RIIRL }\end{array}$ & $\begin{array}{l}1 \\
1\end{array}$ \\
\hline $\begin{array}{l}\text { RIIRL } \\
\text { CCA5 }\end{array}$ & 1 \\
\hline $\begin{array}{l}\text { CCAS } \\
\text { EMQL }\end{array}$ & $\begin{array}{l}1 \\
1\end{array}$ \\
\hline LLRP & $i$ \\
\hline MCLP & 1 \\
\hline $\operatorname{coc} 0$ & 1 \\
\hline CMON & 1 \\
\hline TOM & 1 \\
\hline WORL & i \\
\hline COCE & 1 \\
\hline CDED & 1 \\
\hline CAEB & 1 \\
\hline EPL & 1 \\
\hline PSPR & 1 \\
\hline CDRA & 1 \\
\hline TWAT & 1 \\
\hline PENL & 1 \\
\hline CWSL & 1 \\
\hline CSIIM & 1 \\
\hline $\begin{array}{l}\text { PLIIM } \\
\text { COF }\end{array}$ & $\frac{1}{1}$ \\
\hline SODA & $i$ \\
\hline ALTP & 1 \\
\hline AMLC & \\
\hline $\mathrm{BCL}$ & 1 \\
\hline TOST & 1 \\
\hline REU & 1 \\
\hline WESA & 1 \\
\hline DUPT & 1 \\
\hline MINI & 1 \\
\hline CASH & 1 \\
\hline TANN & 1 \\
\hline PLWC & 1 \\
\hline
\end{tabular}

Sum Cluster $1=4$ n

BREA

LOST

MEC

VEC

VID

WEC

KEC
PACP

2
2
2
2
2
2
2
2
2
2
2

Name (a)

Montana Light and Power

Burley Municipal Distribution System

City of Cascare Locks

Cimhurst Mutual power and Light

Lecleary Ltant and Power

city of Coulee Dam

City of Monmouth

Town of Milton

city of Worley

city of Chewelen

City of Declo

Canby Electric Board

Eatonville Power and Light

Puget Sound Power and Light, PT. ROBE

City of Orain

Tawn of Waterville

Penninsula Lighe Company

Cashmere Water Sewer and Light

City of Suinas

city of plummer

city of Soda Springs

Atlanta Power Company

Alder Mutual Light Compony

Rlaine City Light

Tawn of Steil acsom

Ruston Electric ut ility

City of Weiser

City of

City of Ashiand

Parkland Light and water Company

\begin{tabular}{|c|c|c|c|c|c|c|}
\hline $\operatorname{RTS}(\mathrm{b})$ & OREOS(c) & OSYSCHAR (d) & nLOSS $(e)$ & DEDPREPL $(f)$ & OPARTB (g) & IALLYY \\
\hline 1 & 1 & 1 & 1 & 1 & D & 5 \\
\hline 0 & $i$ & $i$ & l & $i$ & 0 & 4 \\
\hline 1 & 0 & 0 & $i$ & 0 & $i$ & 3 \\
\hline 0 & $!$ & $n$ & 1 & 0 & $n$ & 2 \\
\hline is & $\mathrm{i}$ & 1 & 0 & 0 & 0 & 2 \\
\hline 1 & 1 & 0 & 0 & 0 & 0 & 2 \\
\hline$i$ & 0 & 0 & 0 & 0 & 0 & \\
\hline$i$ & D & 0 & 0 & 0 & 0 & i \\
\hline 0 & 0 & 0 & 0 & 0 & 0 & n \\
\hline 0 & 0 & 0 & 0 & 0 & 0 & 0 \\
\hline 0 & 0 & 0 & 0 & 0 & 0 & 0 \\
\hline 0 & 0 & 0 & 0 & 0 & 0 & 0 \\
\hline 0 & 0 & 0 & 0 & 0 & 0 & 0 \\
\hline (3) & 0 & 0 & 0 & 0 & 0 & 0 \\
\hline 0 & 0 & 0 & 0 & 0 & 0 & 0 \\
\hline 0 & 0 & 0 & 0 & 0 & 0 & 0 \\
\hline 0 & 0 & 0 & 0 & 0 & 0 & 0 \\
\hline 0 & 0 & 0 & 0 & 0 & 0 & 0 \\
\hline 0 & 0 & 0 & 0 & 0 & 0 & i) \\
\hline 0 & 0 & 0 & 0 & 0 & 0 & 0 \\
\hline 0 & 0 & 0 & 0 & 0 & 0 & 0 \\
\hline n & 0 & 0 & 0 & 0 & 0 & 0 \\
\hline 0 & 0 & 0 & 0 & 0 & 0 & 0 \\
\hline$n$ & 0 & 0 & 0 & o & 0 & 0 \\
\hline 0 & 0 & 0 & 0 & 0 & 0 & 0 \\
\hline 0 & n & 0 & 0 & 0 & 0 & 0 \\
\hline 0 & 0 & 0 & 0 & 0 & 0 & 0 \\
\hline in & 0 & 0 & 0 & 0 & 0 & 0 \\
\hline 0 & 0 & 0 & 0 & 0 & 0 & 0 \\
\hline a & 0 & 0 & 0 & 0 & 0 & 0 \\
\hline$n$ & 0 & 0 & 0 & 0 & $n$ & 0 \\
\hline 0 & 0 & 0 & 0 & 0 & 0 & i) \\
\hline 0 & 0 & 0 & 0 & 0 & 0 & 0 \\
\hline 0 & 0 & 0 & 0 & 0 & 0 & 0 \\
\hline
\end{tabular}

Percent Cluster 1 Responding to Part $2=10.0$

Benton Rural Electrification Assoc.

Lost Ryver Electrification Coop.

Cooperative

Electrifycation Cooperative

Vigilante Electric Cooperative

Nespelem Valley Electric Cooperative

Yerd Irrigation ofstrict

Columbia Power Cooperative As5oc.

Hasco Electrification Cooperative

PUD *2 of Pacific County

1
1
1
1
1
0
1
1
0
1
0

(a) See text.

(b) Identification and loss study information.

(c) 1982 and 1983 requirement hy source.

(d) Power fartor characteristics.

(e) It illty loss estimate by component.

(f) Equipment replacemerit inforiliation.

(g) Response to technical component questions. 
TABLE 4.1. (contd)

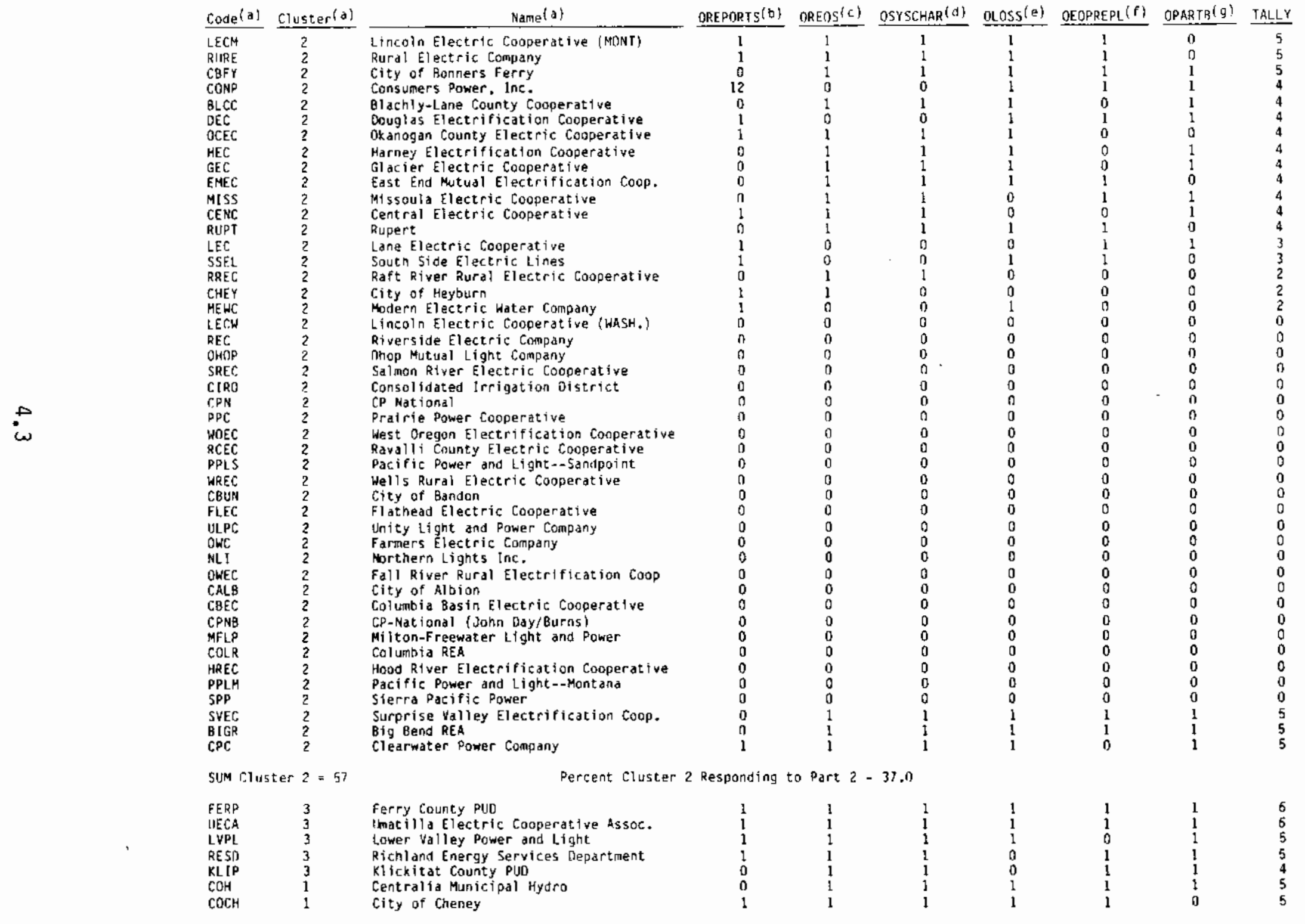


TABLE 4.1. (contd)

\begin{tabular}{|c|c|c|c|c|c|c|c|c|c|}
\hline Codge $(a)$ & Cluster $(a)$ & Name! (a) & OREPORTS(b) & OREOS $(c)$ & OSYSCHAR $(d)$ & Qtoss $(e)$ & DEOPREPL $(f)$ & QPARTB $(y)$ & $\underline{\text { TALLYY }}$ \\
\hline COF & 1 & City of Ellensburg & 1 & 1 & 1 & 1 & 1 & 0 & 5 \\
\hline CFOR & $i$ & City of Forrest Grove & 0 & $\mathrm{j}$ & 1 & 1 & 1 & 1 & 5 \\
\hline MPLC & $i$ & Orcas Power and Light Company & $\mathrm{i}$ & 1 & $i$ & 0 & i & $\mathrm{i}$ & 5 \\
\hline $\mathrm{SE}$ & $i$ & Salem Electric & i & 1 & $i$ & 1 & $i$ & 0 & 5 \\
\hline SXAP & 3 & Skanania County pun & 1 & 0 & 0 & $i$ & i & 0 & 3 \\
\hline GRTP & 3 & Grant County PIID & 0 & 1 & 0 & 1 & 0 & 1 & 3 \\
\hline TILP & 3 & Tillamook pido & 1 & 0 & n & 1 & 1 & 0 & 3 \\
\hline INPL & 3 & Inland Power and Light & i & n & 0 & 0 & $a$ & 1 & $?$ \\
\hline LEWP & 3 & Lewis County PUD & 0 & 0 & 0 & D & 0 & 0 & 0 \\
\hline EMEP & 3 & Emerald PUD & 0 & 0 & n & 0 & 0 & 0 & a \\
\hline WHAP & 3 & Whatcom County PID & i & f) & 0 & 0 & 0 & 0 & 0 \\
\hline CLAP & 3 & Clallam County PUD & 0 & 0 & 0 & 0 & 0 & 0 & 0 \\
\hline MAP1 & 3 & Mason County PII il & 0 & 0 & 0 & 0 & 0 & 0 & 0 \\
\hline POCF & 3 & Pend Oreille County Plo & 0 & 0 & 0 & 0 & 0 & 0 & 0 \\
\hline NWCP & 3 & Northern Wasco County PUD & 0 & 0 & 0 & 0 & 0 & 0 & 0 \\
\hline KITP & 3 & kittitas County PUD & 0 & 0 & 0 & 0 & 0 & 0 & 0 \\
\hline WAHP & 3 & Wahk1 akum County PUl? & 0 & 0 & 0 & 0 & 0 & 0 & 0 \\
\hline $\operatorname{ccec}$ & 3 & Coos-Curry Electrification Cooperative & 0 & D & 0 & 0 & 0 & 0 & 0 \\
\hline $\mathrm{CCH}^{\circ}$ & 3 & Chelan County PUB & 0 & 0 & 0 & 0 & 0 & 0 & 0 \\
\hline
\end{tabular}

Sum Cluster $3=20$

\begin{tabular}{|c|c|c|}
\hline SCL & 4 & Seattle city Light \\
\hline FRAP & 4 & Frank1in County PUD \\
\hline COPA & 4 & City of Port Angeies \\
\hline novp & 4 & Douglas County PUD \\
\hline PSPL & 7 & Puget Sound Power and Light \\
\hline SNOP & 4 & Snchomish PUD \\
\hline OKAN & 4 & Okanogan County PUD \\
\hline CONP & 4 & Cowlitz County PUD \\
\hline CLKP & 4 & Clark County Pun \\
\hline SPUR & 4 & Springfield Utility Board \\
\hline CITI & 4 & Citizens litilities Company \\
\hline RENP & 4 & Benton County PuD \\
\hline CMCM & 4 & Clty of MCMinnutile \\
\hline PGE & 4 & Portland General Electric \\
\hline $\begin{array}{l}\text { CTAC } \\
\text { CLIP }\end{array}$ & 4 & $\begin{array}{l}\text { City of Tacoma } \\
\text { Clatskanie PID }\end{array}$ \\
\hline $\begin{array}{l}\text { CLTP } \\
\text { EWEB }\end{array}$ & $\begin{array}{l}4 \\
4\end{array}$ & $\begin{array}{l}\text { Clatskanie PldD } \\
\text { Eugene Water and Electric Roard }\end{array}$ \\
\hline MPC & 4 & Montand Pawer Company \\
\hline МАP3 & 4 & Mason County PUo $\# 3$ \\
\hline IDFL & 4 & Idaho Falls Electric Light Department \\
\hline PPLO & 4 & Paciftc Power and Light--U-W-\&C \\
\hline GRYP & 4 & Grays Harbor County PUD \\
\hline IPC. & 4 & Idaho Pawer Company \\
\hline UPSLL & 4 & Utah Power and Light \\
\hline WWPC & 4 & Washington Water Power Company \\
\hline CLNP & 4 & Central Lincoln PUD \\
\hline
\end{tabular}

Sum C1 1uster $4=26$

Sum of Responses by Section

Response by Section as Percent of al! letilities
Percent Cluster 3 Responding to Part $2=35.0$

$\begin{array}{lll}1 & 1 \\ 1 & 1 \\ 1 & 1 \\ 1 & 1 \\ 1 & 1 \\ 1 & 1 \\ 0 & 1 \\ 1 & 0 \\ 1 & 1 \\ 1 & 0 \\ 1 & 1 \\ 1 & 0 \\ 1 & 0 \\ 1 & 0 \\ 1 & 0 \\ 1 & 0 \\ 0 & 0 \\ 0 & 0 \\ 0 & 0 \\ 0 & 0 \\ 0 & 0 \\ 0 & 0 \\ 0 & 0 \\ 0 & 0 \\ 0 & 0 \\ 0 & 0\end{array}$

Percent Cluster 4 Responding to Part $2=50.0$
REPORTS
REOS
CHAR
Loss
EQPT
PART B

$\begin{array}{rrrrrr}50 & 53 & 45 & 57 & 50 & 45 \\ 34.97 & 37.05 & 31.47 & 39.85 & 34.97 & 31.47\end{array}$


utilities that responded. The first five headings refer to segments of Part 1 of the questionnaire. The notation "Part 2 " refers to responses obtained in the second, technical portion of the questionnaire. A copy of the information request is included as Appendix $A$ to this report. Most of the information on this portion of the questionnaire was entered into the data base in either RBASE 4000 or LOTUS 1-2-3 form. The general information responses from Part 1 are reviewed in the remainder of this section.

\subsection{DATA QUALITY}

The information collected in Part 1 of the questionnaire was viewed primarily as a general indication of utility concern with system losses and the extent to which their equipment replacement practices were aimed at loss reduction. Much of the information that was obtained on loss allocation was apparently based on opinions of individuals in the utilities surveyed. Therefore, information may be of limited reliability for either definitive loss allocation by component or for estimating the extent that system efficiency improvements are being achieved in the normal course of system maintenance and operations. A comparison of the utilities' responses also indicated that some of the questions may have been misinterpreted by the respondents. However, when used in conjunction with data from the CSEI institutional survey of utilities (Hendrickson and Darwin 1986) this perceptual information helps to illustrate the views that utility staff have of their own systems.

\subsection{CONTENTS OF THE QUEST DATA BASE}

The information obtained from Part 1 of the survey was coded and entered into eight relations that form the QUEST data base. These relations and their contents are summarized below.

Relation QIDENT--This relation contains the name and title of the utility staff member contacted (usualiy the chief engineer) and the date of any loss study, loss-reduction work plan, or other related reports that the utility may have prepared. Of the 67 utilities that provided information in this section, 23 (34\%) had prepared loss studies for some portion of their systems in recent years. Work plans were prepared by 40 utilities for projects where 
efficiencies were improved. Related reports or studies had been conducted by 28 utilities. The fact that on $3 y$ out of 67 utilities indicated that both loss studies and work plans for improvements that addressed those losses were conducted in recent years is open to interpretation; it is possible that this response indicates quite a low level of construction and related activities specifically designed to reduce losses at this time. Reports received in response to this portion of the questionnaire are contained in the CSEI library utility files, which are maintained at PNL.

Relation QREQS--This relation contains 1982 and 1983 data on each utility's requirements, in $M$ Wh and by source (BPA, self, other utility); it also contains MWh supplied by the utility to other utilities for those years.

Relation QPODPF--Information was collected on the average, high, and low power factors at the point of delivery for each utility in 1983. The high and low power factors are accompanied by the month of the year in which they occurred. Data for 45 utilities and their points of delivery were obtained anit entered in this relation.

Relations QLOSSES and QLOSSEST--Questions concerning the estimated allocation of system losses by component, estimates of loss reduction potential, and any comments about loss reduction efforts are coded in QLOSSES. The relation QLOSSEST contains the distribution of estimated losses by component, and the 1982 sales and losses in MWh. Fifty-five utilities responded to this segment of the questionnaire. Utilities were asked to estimate the contribution to their systems' total losses in six categories: feeders, distribution transformers, secondary feeder systems, transmission/subtransmission lines, substation transformers, and other causes. The losses in this set of relations are slightly different from those used for the study in general, in that utilities were asked to estimate losses as a percentage of sales, rather than of requirements. This definition was used because the pretest showed that many utilities commonly use sales, not requirements, as the basis for assessing their loss levels.

Relation QEQREPL--A final portion of the set of general questions in Part 1 dealt with utility equipment replacement. Information was obtained from 50 utilities on the number of components replaced, features of the 
replacements, and approximate costs (both for the component and for the installation). These data were entered into the OUEST data base as text in fixed field format because the data were provided in a variety of forms.

Relations QCOUNT AND OCONTENT--These two relations contain tallies of the utilities that responded to the questionnaire. In QCONTENT, the tally is distributed by the portion of the questionnaire (reports, requirements, power factor characteristics, loss estimates, equipment replacement from Part 1 and component operating characteristics from Part 2).

The relation QCOUNT is simply a listing of all utilities accompanied by a field that indicates whether they responded to the survey.

\subsection{HIGHLIGHTS OF QUEST DATA}

Some of the more interesting highlights of the information obtained in Part 1 of the questionnaire are summarized in the following tables and figures. Caution should be used before assuming that any trends or other implications of these data are truly representative of Pacific Northwest utilities as a whole. Nevertheless this information is valuable in that it provides the most comprehensive characterization of the regional distribution system yet available.

\subsubsection{Estimated Losses by Component}

Utilities were asked to estimate the fraction of their systems' total losses contributed by feeders, distribution transformers, secondary feeder systems, transmission/subtransmission lines, substation transformers, and other causes. Figure 4.1 displays a histogram of these estimates for the responding utilities. Most respondents indicated that these allocations were made by "educated guessing." The next survey question requested the respondent estimate the extent to which total system losses could be reduced by replacing existing components with more efficient components that 1) could be economically justified and 2) could be used if economics (rate of return) were not considered. Table 4.2 lists the loss estimates provided on the questionnaire along with the 1982 calculated losses (requirements minus sales as a percentage of sales, utility's estimate). Table 4.2 also lists the utilities' estimates of potential loss reduction through equipment replacement. On average, the 


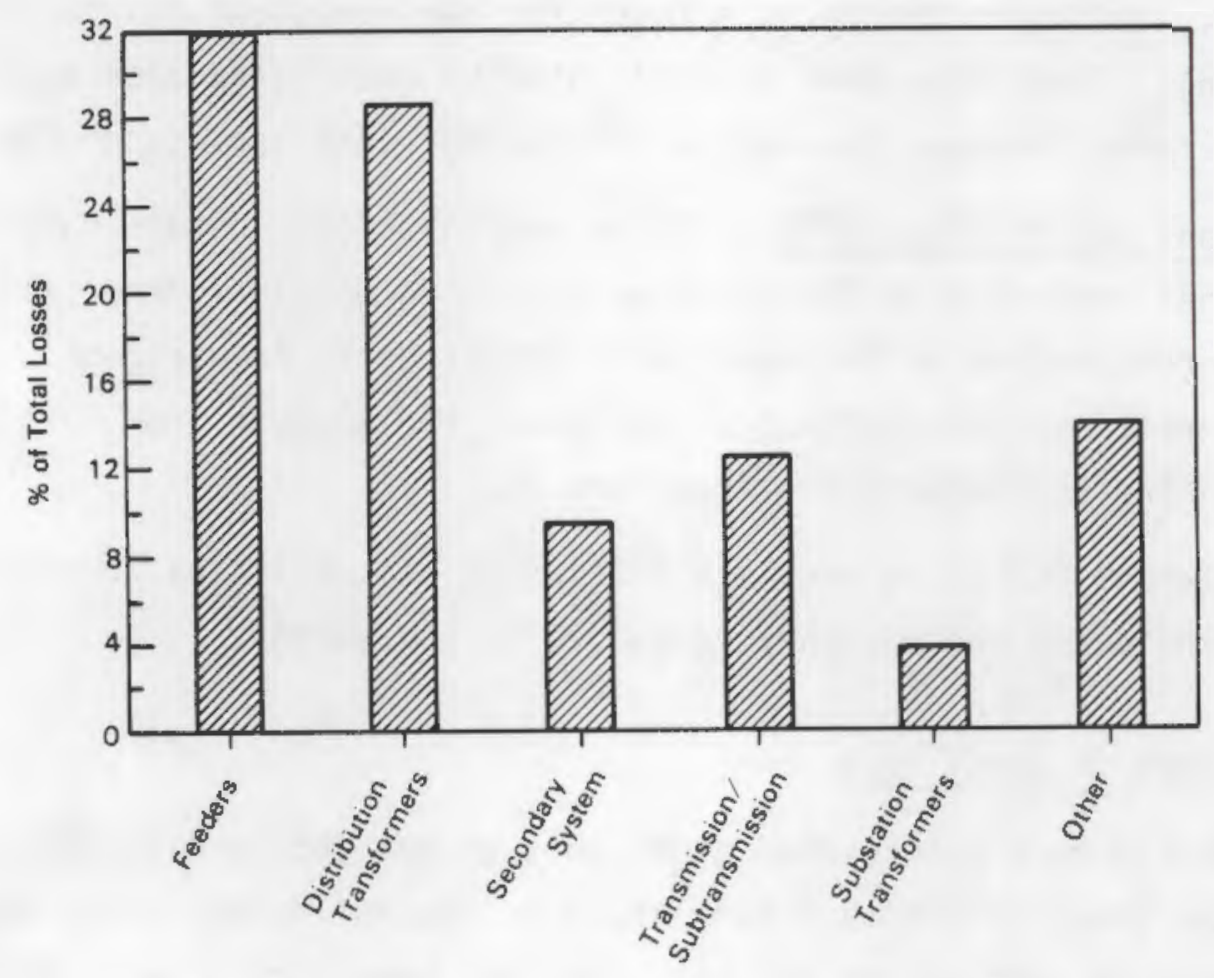

FIGURE 4.1. Utilities' Estimates of Losses

utility engineers that responded to this question felt that loss reductions of 20 to $25 \%$ were economically justifiable, but that far greater reductions (50\% or more) were technically possible.

The corment section provided some of the most interesting information on current utility practices with regard to system efficiency. Fifty-nine util-ities responded to the question, "Are loss reduction measures being systematically installed as part of a regular system improvement plan? If yes, what actions have been taken in 1984 or are planned for 1985?" The distribution of their responses is provided in Table 4.3.

The responses to these questions indicate that a substantial amount of ongoing efficiency improvements are probably being made by a majority of utilities, but it was also clear that many of the component upgrades were typically done as part of a regular replacement schedule, or when costs of losses combined with other problems (e.g., reliability) or system growth justified outright replacement. Whether the response to this question indicates a general 
TABLE 4.2. Utilities' Estimates of Loss Reduction Potential

\begin{tabular}{|c|c|c|c|}
\hline Utility & $\begin{array}{l}1982 \text { Los } \\
\text { (Percent) }\end{array}$ & $\begin{array}{l}\text { Economically } \\
\text { Justifiable } \\
\text { Loss Reduction }(b)\end{array}$ & $\begin{array}{l}\text { Technically } \\
\text { Feasible } \\
\text { Loss } \\
\text { Reduction (b) }\end{array}$ \\
\hline Big Bend REA & 7.9 & 6.0 & 4.5 \\
\hline Blachly-Lane County Coop. & 7.9 & 7.6 & 7.4 \\
\hline $\begin{array}{l}\text { Benton REA } \\
\text { Burley }\end{array}$ & 8.6 & 6.0 & 4.0 \\
\hline $\begin{array}{l}\text { Burley } \\
\text { City of Cascade Locks }\end{array}$ & 7.0 & 4.2 & $\begin{array}{l}3.5 \\
1.8\end{array}$ \\
\hline $\begin{array}{l}\text { City of Cascade Locks } \\
\text { Citizens Utility Company }\end{array}$ & $\begin{array}{l}6.1 \\
7.5\end{array}$ & $\begin{array}{l}2.5 \\
5.5\end{array}$ & $\begin{array}{l}1.8 \\
4.5\end{array}$ \\
\hline Clark County PUD & 7.2 & 4.0 & 3.5 \\
\hline Centralia Municipal Hydro & 6.3 & 4.0 & 2.5 \\
\hline City of Ellensburg & 4.7 & 3.7 & 2.7 \\
\hline Cowlitz County PUO & 1.9 & -- & -- \\
\hline Clearwater Power Co. & 8.4 & 7.4 & 6.4 \\
\hline City of Tacoma & 7.9 & 7.4 & -- \\
\hline Oougl as Elec. Coop. & 10.3 & 9.3 & -- \\
\hline East End Mutual Elec. Coop. & 7.6 & 5.6 & 5.6 \\
\hline Elmhurst Mutual Power and Light & 4.8 & 3.6 & 2.4 \\
\hline Ferry County PUO & 7.9 & 4.0 & 2.0 \\
\hline Franklin County PUD & 6.5 & 5.0 & 3.0 \\
\hline Glacjer Elec. Coop. & 14.4 & 8.8 & 8.5 \\
\hline Idaho County Light and Power & 11.6 & 9.0 & 7.0 \\
\hline Kootenai Elec. Coop. & 9.2 & 9.2 & 8.1 \\
\hline Lincoin Elec. Coop. (MT) & 11.1 & 9.2 & 8.2 \\
\hline Nespelem Valley Elec. Coop. & 7.7 & 7.0 & 4.0 \\
\hline Orcas Power and Light Co. & 13.5 & 12.0 & 10.0 \\
\hline Puget Sound Power and Light & 8.2 & 6.0 & 4.0 \\
\hline Rupert & 10.0 & 5.0 & 4.0 \\
\hline Salem Electric & 5.5 & -- & 4.4 \\
\hline Skamania County PUD & 4.5 & 4.0 & 4.0 \\
\hline Seattle City Light & 7.6 & 5.0 & 3.0 \\
\hline Snohomish County PUD & 4.6 & $\rightarrow$ & 4.0 \\
\hline South Side Elec. Lines & 11.0 & 4.0 & 2.0 \\
\hline Springfield Utility Board & 3.7 & 3.0 & 2.0 \\
\hline Surprise Valley Elec. Coop. & 9.7 & -- & 4.0 \\
\hline Tillimook County PUD & 6.6 & 5.0 & 2.5 \\
\hline Vera Irrigation District & 5.9 & 2.9 & 1.0 \\
\hline
\end{tabular}

(a) Estimated as a percent of sales.

(b) Level to which losses could be reduced, as a percent of sales. 
TABLE 4.3. Distribution of Utility Responses: Efficiency Improvements in 1984 and 1985

Utilities Responding to Question

Utilities with Systematic Loss-Reduction Efforts 48

Utilities with No Systematic Loss-Reduction Efforts 11

Loss Reduction Measure

Reconductoring with Larger Size

Replacement with Higher Efficiency Transformer

Capacitance Added

Voltage Increases

Other Feeder System Improvements $(a)$

Meter Checking or Replacement Program
Number of Times Mentioned

\section{4}

29

14

12

12

6

(a) Includes reconfiguration of feeder system, right-of-way maintenance, adding substations, shortening feeders and secondary lines, installing underground line, and adding phases.

trend among most Pacific Northwest utilities is unclear, because the sample was not statistical and the respondents may have been a self-selected group (i.e., those willing to respond). More information needs to be collected using statistically-appropriate techniques before any conclusions can be reached about voluntary T\&D system efficiency improvements made by regional utilities. 4.4.2 Power Factor and Equipment Replacement

Power factor information was requested so a general idea of the amount of reactive power on the regional system at various times of the year could be obtained. Power factor information at specific points of delivery for all BPA full service customers is also available from BPA's office of Power and Resource Management, where it is used for billing purposes. Table 4.4 shows a summary of the power factor information for 1983 collected by the survey.

Fifty utilities provided information on equipment replacement. The average quantities and costs of each component (feeders, distribution transformer, and substation transformers) stated in the responses varied widely, making it difficult to notice any trends or to identify possible causes of the 
TABLE 4.4. Summary of Power Factor by Point of Delivery

\begin{tabular}{|c|c|c|c|c|}
\hline $\begin{array}{l}\text { Utility } \\
\text { Cluster }\end{array}$ & $\begin{array}{l}\text { Average High } \\
\text { Power Factor }\end{array}$ & Month & $\begin{array}{l}\text { Average Low } \\
\text { Power Factor }\end{array}$ & Month \\
\hline 1 & 0.98 & January & 0.95 & August \\
\hline 2 & 0.99 & January & 0.96 & August \\
\hline 3 & 0.99 & $\begin{array}{l}\text { December, } \\
\text { January }\end{array}$ & 0.96 & August \\
\hline 4 & 0.99 & January & 0.93 & August \\
\hline
\end{tabular}

Al! PODS:

Average High Power Factor $\quad 0.99$

Most Frequently Stated Month of High Power Factor January

$\begin{array}{ll}\text { Average Low Power Factor } & 0.96\end{array}$

Most Frequently Stated Month of Low Power Factors August

variation. The overall impression gained from this response is that equipment replacement is taking place at a relatively slow pace at the present time. In view of the rapid growth of many Pacific Northwest utilities during the 1960 s and 1970s, the current situation of electricity surpluses, and much slower regional growth, this reduced rate of equipment replacement is not surprising. 


\subsection{SURVEY PART 2: THE SYSTEMS DATA BASE}

The second portion of the 1984 survey sent to BPA utility customers requested detailed technical and operational descriptions of four distribution system components: substation transformers, distribution transformers, primary feeders, and utility-owned transmission/subtransmission lines.

This data base was used primarily to estimate the total regional stock of each of the four components. This information was used in the calculation of component replacement supply curves for the Pacific Northwest, which were developed by Tepel et al. (1986). A description of the SYSTEMS data base and a summary of the derived component stock information are provided in this section.

\subsection{CONTENTS OF THE SYSTEMS DATA BASE}

The technical component characteristic and operating information data base was originally created by transferring data from questionnaires onto a series of LOTUS 1-2-3 worksheets to facilitate quality assurance procedures. Once data were checked for accuracy and uniformity (i.e., in terms of the units of measurement used), a relation was created in RBASE 4000 for each of the four components of interest. Utility cluster identity was added to all relations; 1983 sales information was also appended where available.

The data required extensive manipulation, sorting, and, in particular, intermediate calculations to prepare them for use in the supply curve analys is. Data in the component relations were therefore transferred back to the Lotus 1-2-3 spreadsheet format at this point. This intermediate phase of data preparation generally involved the same steps for all components:

1. correcting and checking of second-stage data

2. sorting of data rows by cluster, utility, and component size category

3. calculating the total number of components by size category for each utitity that responded to the survey

4. eliminating rows that lacked information necessary for calculating component efficiency 
5. calculating component efficiency/losses for each row of data

6. calculating weighted averages of efficiency/losses by component size category.

As a result, three categories of data exist in the SYSTEMS data base: 1) the original "raw" data in LOTUS 1-2-3 spreadsheets, 2) the original sorted data in RBASE $4000^{\circ}$ component relations, and 3) the manipulated and corrected data in LOTUS 1-2-3 files. In some cases a single final LOTUS 1-2-3 file contains all the corrected information for all sizes of a given component; in others, separate files were prepared for different size categories. Table 5.1 lists the names of the LOTUS $1-2-3$ or RBASE 4000 files/relations in the latter two categories. The tables are presented in matrix form with an " $X$ " indicating the fields/attributes that each file contains. Description's of the variables (including their units of measurement) appear in Appendix $C$.

\subsection{DATA QUALITY}

The data that were received from respondents were not of uniform quality or consistency in several respects, including the units used and the degree to which components were individually described. Use of the data preparation steps described above resolved most, but not all, of the problems regarding data accuracy and consistency. Therefore, the overall quality of the data used for supply curve estimates is reviewed here.

\section{2 .1 Background}

The data requested from utilities on the four components of interest were used in the loss-estimation methodology developed by Westinghouse, Inc. for the Electric Power Research Institute (EPRI 1983). This relatively simple methodology uses a computer program entitled Simplified Calculation of Loss Equations (SCALE). The loss equations in this program were used to characterize the efficiency of the components described by survey data; the equations were also used in the supply curve calculations to determine the incremental energy loss reductions attributable to replacement or upgrading of distribution system components in the Pacific Northwest. 


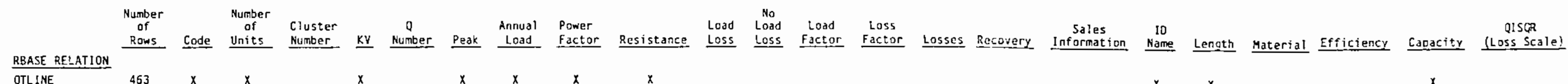

QTLINE

gLATERAL

455
750

QOVERH4

QSTRAN2

1151
405

LOTUS FILE

TLCORR

TLCLOSS

DOVERH4A

DOHALOSS

ST-CORR

ST-EFF

STR 4S

STR4M

STR4L

STES83

ST-LOSS

OTRAN

OT-AVG

OTCORR

$\begin{array}{rlllllll}491 & x & x & x & x & & x & x \\ 286 & x & x & x & x & & x & x \\ 1151 & x & x & x & x & x & x & x \\ 500 & x & & x & x & x & x & x \\ 405 & x & x & x & & & x & x \\ 183 & x & x & x & & & x & x \\ 12 & x & x & x & & & x & x \\ 31 & x & x & x & & & x & x \\ 62 & x & x & x & & & x & x \\ 37 & x & x & x & & & x & x \\ 183 & x & x & x & & & x & x \\ 750 & x & x & x & & x & x & x \\ 750 & x & x & x & & x & x & x \\ 385 & x & x & x & & x & & \end{array}$
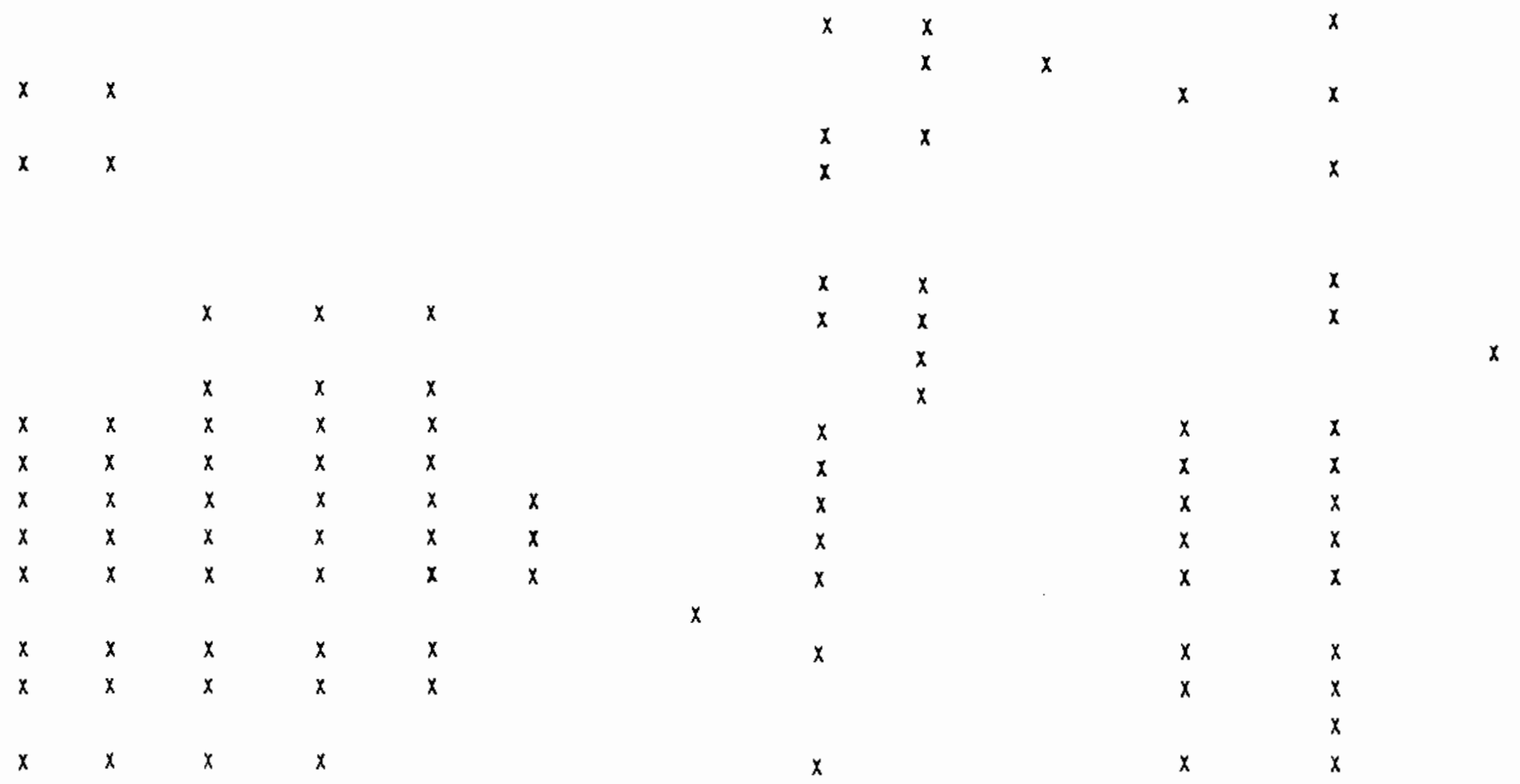

TABLE 5.1. Matrix of Files and Variables in SYSTEMS Data Base 

Although the Westinghouse methodology is considered to be a "simplified" approach, it still requires fairly detailed data about component characteristics. The methodology was developed and tested using data from single utilities that had extensive and precise operational information on components in computerized form (EPRI 1983). There was considerable challenge to applying this methodology (or any other approach requiring detailed component data) to the problem of estimating distribution system loss-reduction potential for an entire region composed of over a hundred utilities of varying sizes. The survey conducted by the CSEI Project staff in 1984 was an exploratory step to gain a better understanding of the degree to which various types of utilities could adequately characterize their distribution system components.

As discussed in Section 1.0, the original project plan called for this survey to be followed by a statistically designed sample survey of regional components. Before this additional survey was conducted, however, BPA made policy decisions that reduced the need for such a detailed effort. Work continued on efforts to estimate supply curves of the T\&D system conservation resource, but the approach was modified to use the data available from the preliminary 1984 survey.

\subsubsection{Evaluation of 1984 Survey Data}

The survey was performed both by mailing questionnaires to utility engineers and by conducting interviews with managers and engineers from a smaller sample. Interviews were conducted with large-, medium-, and smali-sized utilities in conjunction with the survey undertaken in the Institutional Assessment Task of the CSEI study (Hendrickson and Darwin 1986). Questionnaires were administered to a total of 144 utilities by one or the other of the approaches described above. The overall response was surprisingly good, considering the time and effort required to provide some of the information that was requested.

The quality of the characterization data varied by component, presumably because of the effort and the quality of records required to complete the questionnaire. Detailed information on distribution transformers (including peak and average load information necessary to estimate losses) was provided primarily by the medium- to large-sized utilities with mixed loads that included irrigation (utilities in Clusters 2, 3 and 4). Utilities in Cluster 1 (smal1 
municipal utilities with no irrigation load) also provided information about the estimated quantity of distribution transformers in their systems, but few usable data regarding operating characteristics were obtained. Of the 750 rows of raw data for distribution transformers that were entered, approximately 385 rows remained after the data were sorted to eliminate rows with missing critical information. However, in the data entry used, each row potentially represents a large number of individual transformers with identical characteristics. Therefore, the base number of transformers (or other components) used for the regression analysis by Tepel et al. (1986) was much higher. On average, adequate survey data were available for about 25-30\% of the estimated regional stock of distribution transformers.

Adequate substation transformer data, on the other hand, were more uniformly distributed. Utilities in all size/load clusters were represented in the final spreadsheet. Again, a number of rows of data had to be dropped from the original file due to the absence of critical data; 183 rows of complete data remained of the original 405 rows. The "good" data describe, on average, about $25 \%$ of the estimated regional stock of substation transformers.

Feeder data were entered as rows that described segments of line varying from 0.5 mile to over 25 miles in length. Although the average distribution factor was requested from the utilities, this information was generally not supplied, so an average was assumed for the purposes of energy loss calculations (Tepel et al. 1986). The screening process reduced the number of usable rows of data from 1151 to 500 .(a)

Transmission line data were supplied by about half of the regional utilities that maintain their own lines (transmission/subtransmission lines were defined as lines ranging from $34 \mathrm{kV}$ to $230 \mathrm{kV}$ ). Operating characteristics that were used in the loss-reduction and supply-curve calculations relied on the data supplied by the survey. However, the estimate of the total circuit miles at each voltage was derived from Electrical World (1983). Both the current miles estimated for the region and the average operating characteristics of

(a) As was the case for the other components, utilities often provided a single set of operating characteristics that was applicable to a large number of segments of their feeders. 
transmission lines appear to be accurate because good utility records are usually available for transmission facilities. The screening process used to obtain adequately characterized line segments resulted in the reduction of the file from 491 to 286 rows. Loss-related characteristics derived from the corrected file are based on approximately $10 \%$ of the estimated total regional mileage at various voltages.

\subsection{SUMMARY HIGHLIGHTS OF THE SYSTEMS DATA BASE}

This section summarizes the component characterization information contained in the SYSTEMS data base. Tables listing these characteristics were developed to assist in the calcutation of supply curves (Tepel et a1. 1986) and are repeated here to illustrate the results of the data collection, reduction, and manipulation. Other displays, particularly the figures showing distributions and comparisons of components by utility cluster, are presented to show the system characterization capability of the data base.

Figure 5.1 shows a representative portion of a corrected LOTUS 1-2-30 worksheet for transmission lines. Similar worksheets were developed for all components to estimate the average loss-related characteristics that were used to calculate losses of components by size category.

Figures $5.2,5.3,5.4,5.5$, and 5.6 show the component size categories that were used in the supply curve analysis, and the distribution of the sample components by those categories (crosshatched bars). The regional stock (stippled bars) was estimated by regressing the number of units of components (from the sample) against known sales and consumer sector data for each utility that provided component quantity information. Ordinary least squares regression was used for this process, and the resulting coefficients were used to predict regional component stocks in the supply curve analysis. In addition to appearing as percentages on Figures 5.2 through 5.5 , the estimated total regiona1 stock is Tisted in Table 5.2 by component and size category.

Operational data for a majority of all sample components indicated that distribution system transformers are generally somewhat underloaded in terms of their installed capacity. Figures 5.7 and 5.8 illustrate the ratio of the actual reported peaks to the installed capacity (peak loading or peak load 


\begin{tabular}{|c|c|c|c|c|c|c|c|c|c|c|c|c|c|c|c|}
\hline $\begin{array}{l}\text { LOSFES } \\
\text { TJTALS }\end{array}$ & 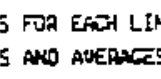 & 5 ARE $F$ & 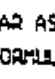 & LAS & alc & MastaI & MILS5 & $\mathbf{M H}$ & KVA & & & $2=0.89$ & ודיה זרסו & Totik & 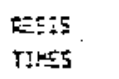 \\
\hline $\cos \equiv$ & io & $x v$ & $t$ & СXT & GAP & $\operatorname{Exi5}$ & 15 & LaAd & FeAx & $D F$ & LDF & LSF & L05站 & 2005 & Banta \\
\hline DEF & 2 D - RB & 12.5 & 1 & \pm & $2 \times 00$ & 1.120 & 13.8 & 11000 & 2279 & 1.00 & 0.531 & 0.341 & 112.1 & :753.s & $: 7.696$ \\
\hline cxt & 1 Suล E & 23 & I & 1 & esso & 0.259 & $=0.0$ & 57000 & 13200 & 0.99 & $0 . \hat{8}: 3$ & $0 .:=0$ & 6i.: & $1 \pi: .9$ & 5.19 \\
\hline CarLC & I EPA SUE 0 & 25 & 1 & $\mathfrak{t}$ & 10700 & 0.257 & 12.3 & 13000 & 9000 & 0.99 & $0.37 !$ & $0 .: 73$ & 10.0 & $1 \geqslant 2.3$ & 2.9957 \\
\hline UEE & ס אובהבם 2 & 34.5 & $!$ & 1 & 13.7 & $0 . \cos$ & 14.4 & $: 5074$ & 4100 & 0.96 & $0.1<0$ & 0.657 & 25.2 & 375.5 & iz. \\
\hline 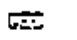 & 2 ATKनOAT 5 & 34.3 & \pm & 1 & 14044 & $0.5 \dot{c} z$ & $\therefore .8$ & $2 \pm \approx 75$ & $7 a 37$ & 0.95 & 0.00 & 0.3 ? & $i E_{.} \rho$ & 100.6 & 1. S6ะ64 \\
\hline ẼE & a DAIN To & 34.5 & 1 & 1 & $: 3 . T$ & 0.803 & 4.4 & Aiżs & $10 \%=0$ & 0.96 & $0 .=0$ & 0.Ė & 172.0 & 756.9 & 3.9072 \\
\hline$\sqrt{c i}$ & 2 Fटनिसा & 34.5 & 1 & 1 & BG6 & E. 290 & 0.5 & $: 310$ & 证舟9 & 0.86 & 0.14 & 0.040 & 1.2 & 0.6 & 1.164 \\
\hline ज: & 2 AIQNOTT 5 & 34.5 & 1 & 1 & 10756 & 1.410 & $\therefore .4$ & $\Xi 1$ โล9 & 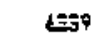 & 0.99 & 0.507 & $0.35 \mathrm{a}$ & 189.4 & 209.2 & 1.974 \\
\hline $\cos$ & 2 AIFPORT 5 & 34.5 & 1 & 1 & 17527 & 0.560 & 8.3 & 2587 & $40 \Omega 2$ & 0.99 & 0.67 & 0.044 & 27.7 & 246.7 & $4.6=0$ \\
\hline 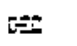 & 2 ST: 2 & 34.5 & 1 & i & ê. 4 & 0.45 & 15.6 & 5097 & 1300 & 0.99 & $0 . \Leftrightarrow$ & 0.257 & 1.3 & 17.9 & 6.052 \\
\hline LEC & $2 \operatorname{Ln} x+10$ & जิ.5 & $!$ & 1 & 15000 & 0.607 & 5.: & 2090 & 700 & 0.99 & 0.526 & 0.139 & 0.3 & 0.9 & 1.5917 \\
\hline ت & E AIRPCORT 5 & 34.5 & : & 1 & 16044 & 0.862 & 4.8 & $30 \pi$ & 1991 & 0.90 & 0.176 & 0.053 & 1.3 & 6.3 & 4.0905 \\
\hline DEA & द & 34.5 & 1 & 1 & 20000 & 0.59 & 14.0 & 43112 & 16000 & 0.90 & 0.293 & 0.117 & 15.7 & 2012.3 & 3.750 \\
\hline LEC & $2 \pi-\infty$ & 34.5 & 1 & 1 & 14000 & 1.120 & 4.3 & 7000 & 2200 & 0.90 & 0.活的 & 0.167 & 6.6 & 29.9 & 5.04 \\
\hline Et & 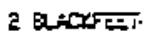 & 34.3 & 1 & 1 & 17927 & 0.560 & 3.2 & azso & 15024 & 0.97 & 0.309 & 0.127 & 129.1 & 406.2 & $\therefore .752$ \\
\hline 吟 & 2 youren $T$ & 34.5 & 1 & 1 & 13.7 & 0.858 & 5.5 & 19152 & $46=0$ & 0.96 & 0.448 & $0 . \overline{E 9}$ & 3.3 & 1묘. 7 & 4.884 \\
\hline GEL & 2 AIR⿴囗十 5 & 34.5 & 1 & 1 & 14044 & 0.862 & 2.8 & 15150 & 3106 & 0.88 & 0.196 & 0.346 & $2 ! .2$ & 59.4 & 6ت 2. \\
\hline Dasp & 4 फت̋VIIL & 34.5 & 1 & 1 & 13740 & 0.898 & 6.5 & 19735 & sór & 0.97 & $0 . \equiv 30$ & 0.167 & 42.9 & 259.0 & $3 . \pi 2$ \\
\hline LE: & $2 \mathrm{TI}-\operatorname{CRCS}$ & 34.5 & 1 & 1 & 10000 & 0.607 & 1.3 & 19000 & 2100 & 0.99 & 0.390 & 0.168 & 14.1 & 18.3 & 0.7892 \\
\hline LE: & 2 פEDE - & 34.5 & 1 & $I$ & 18900 & 0.607 & 2.9 & 17000 & 5600 & 0.99 & 0.347 & 0.154 & 21.6 & 22.6 & $1 . \bar{t}$ and \\
\hline DE & 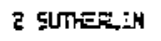 & 54.3 & 1 & 1 & 20.4 & 0.445 & $\$ .2$ & $20 ! 94$ & 2600 & 0.96 & $0.4 \pi$ & 0.37 & 5.3 & 16.8 & 1. $\Rightarrow 24$ \\
\hline$\sqrt{5 L}$ & 2 & 34.5 & 1 & 1 & 10756 & 1.410 & 1.0 & :estis & ב200 & 0.97 & 0.652 & 0.459 & 23.5 & 2.5 & $\therefore 4$ \\
\hline LF & 2 T25 - TI & 34.5 & 1 & \pm & 14000 & 1.120 & 1.8 & 21000 & 6500 & 0.99 & 0.301 & 0.180 & 50.9 & 106.1 & 2.016 \\
\hline 5neA & 2 WOATO- 25 & 34.5 & 1 & 1 & 21000 & 0.552 & 21.4 & 40060 & Te:3 & 0.9 & 0.671 & 0.783 & 104.4 & $\approx 4.4$ & :1. a12s \\
\hline EtEA & 2 SCOTIXY & 34.5 & 1 & 1 & 12000 & 0.893 & 19.0 & 397 & 1400 & 0.98 & 0.75 & 0.139 & 2.9 & 29.1 & $: 1.505$ \\
\hline FEp & 于 & 34.5 & 1 & 1 & 17826 & 0.360 & 9.0 & $320 \mathrm{~s}$ & 1305 & 0.96 & $0 . \approx 73$ & 0.144 & 1.0 & 9.1 & 5.04 \\
\hline ExiA & 2 RIMACXX & 34.5 & $t$ & 1 & 11000 & 1.690 & 23.5 & $189 \mathrm{c}$ & 3120 & 0.79 & 0.670 & 0.988 & 58.4 & 1665.1 & $08 .: 05$ \\
\hline LEt & दे & $=4.5$ & 1 & i & 14000 & 1.120 & 1.0 & $\varepsilon 9000$ & 6400 & 0.90 & 0.517 & 0.305 & 103.0 & 303.0 & $\therefore, i \Xi$ \\
\hline 6 & 2 5AसTA RTT & S4.5 & 1 & 1 & 13744 & $0.8 \mathrm{Eg}$ & 16.1 & 7487 & 1385 & 0.93 & 0.624 & 0.424 & 3.2 & $\$ 3.1$ & 14.2968 \\
\hline$P \mathcal{P R P}$ & 3 GAY KINES & 34.5 & 1 & 1 & 17966 & 0.560 & 2.3 & 7512 & 1440 & 0.96 & 0.395 & 0.391 & 3.3 & 7.7 & 2.208 \\
\hline$x$ & 2 antone & 34.5 & 1 & : & -1 & 0.988 & x.1 & $209^{\circ}$ & 1693 & 0.77 & 0.786 & 0.274 & 2.1 & 128.5 & 20.5138 \\
\hline LE & $250-c a$ & 34.5 & I & 1 & 11000 & 1.670 & 7.0 & 29000 & 600 & 0.99 & 0.517 & 0.305 & 15.4 & i0d. 3 & 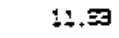 \\
\hline 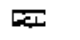 & $2 \operatorname{cog} x \mathrm{MM}$ & 34.5 & $I$ & 1 & 20756 & 1.910 & 1.6 & 17369 & $\operatorname{sac}$ & 0.99 & 0.586 & 0.390 & 4.1 & T.2. & E. 36 \\
\hline Fin & 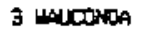 & 34.5 & 1 & 1 & 13740 & $0 . \mathrm{css}$ & 19.0 & 688 & 216 & 0.98 & $0.3 \dot{A}$ & 0.167 & 0.1 & 0.7 & $: 2 . \approx 2$ \\
\hline FEP & 3 SAM FOIL & 34.5 & 1 & 1 & $17 \% 6$ & 0.560 & 16.0 & BS62 & 2700 & 0.96 & 0.362 & 0.266 & 5.0 & $\pi .7$ & 8.96 \\
\hline ceti & 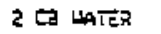 & 34.5 & 1 & 1 & 20756 & :.410 & 4.2 & $=0724$ & SERS & 0.94 & 0.505 & 0.370 & 140.6 & 576.5 & 5.721 \\
\hline$G \Xi$ & 2 אם & +3*.s & 1 & 1 & 10756 & 1.410 & $2.0^{\circ}$ & 18438 & S675 & $0.7 ?$ & 0.560 & 0.391 & 59.2 & 90.4 & 2. $\Xi 2$ \\
\hline FE: & אי & 34.5 & $!$ & 1 & $197=4$ & $\therefore 410$ & 0.0 & 669 & 293 & $0 . \hat{8}$ & 0.261 & 0.097 & จ.: & 0.2 & 0.346 \\
\hline 在 & 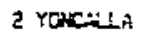 & 34.5 & 1 & 1 & 10.2 & i. 374 & 1.0 & $1 \pi 00$ & 4530 & 0.98 & $0.7 \Rightarrow$ & 0.237 & $\Rightarrow .3$ & 49.3 & 1.374 \\
\hline E: & 290.2341 & 24.5 & : & 1 & 137\%4 & 0.83 & 1.4 & :EIa3 & 2106 & $0.6 B$ & 0.556 & 0.246 & $2: .9$ & 51.4 & 1. ERate \\
\hline SEA & I ALVF= & 34.5 & i & 1 & $\geq 2000$ & 0.306 & 12.9 & यहज 60 & 7293 & $0 . \infty$ & 0.671 & $0 . \approx 99$ & 57.9 & 804.5 & - 2954 \\
\hline קה & 3 & 39.5 & 1 & i & $17 \geqslant 8 b$ & 0.380 & 2.0 & Eota & $5=40$ & 0.96 & $0.7 \leq 0$ & 0.292 & Ė: & 22.: & $: .: 2$ \\
\hline ت & a ALVET - i & 34.5 & $i$ & 1 & 20000 & 0.972 & 5.0 & $\approx 3000$ & 8900 & 0.08 & 0.276 & 0.177 & $=8.6$ & 270.0 & 2.96 \\
\hline 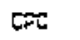 & 2 可暗 & 34.5 & 1 & 1 & -1 & $0 . \approx 0$ & 12.6 & $\exists=9$ & 797 & 0.98 & 0.706 & 0.674 & 1.1 & 13.2 & $: 0.3000$ \\
\hline CE & 2 sUT:CH & 34.5 & 1 & $:$ & 20.4 & 0.46 & 4.4 & 7173 & 1890 & 0.97 & 0.5 & 0.297 & 2.6 & $1: .5$ & 1.958 \\
\hline 哐 & 2 ranctida & 32.5 & $!$ & 1 & 20.4 & 0.45 & 6.7 & i76? & 4500 & 0.96 & 0.40 & $0.3 \mathrm{ET}$ & 15.7 & 105.5 & 2. $98: 5$ \\
\hline$\because$ & 2 HAAIN TO & Z7.5 & 1 & 1 & 10.2 & 1.374 & 4.7 & 5253 & 1370 & 0.97 & 0.30 & 0.387 & 4.3 & 24.3 & a. \\
\hline 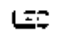 & a LEst IITH & 34.3 & 1 & 1 & 12000 & 0.607 & $i .0$ & 12000 & 3000 & 0.99 & 0.560 & 0.165 & 10.6 & 74.3 & 4.259 \\
\hline 应 & 2 ax $\approx$ & 34.5 & I & 1 & 1544 & 0.68 & 10.5 & 1.569 & 1521 & 0.95 & 0.870 & 0.290 & 4.2 & 44.4 & 29736 \\
\hline
\end{tabular}

\section{FIGURE 5.1. Portion of Corrected Transmission Line Worksheet with Loss Calculation (sample)}




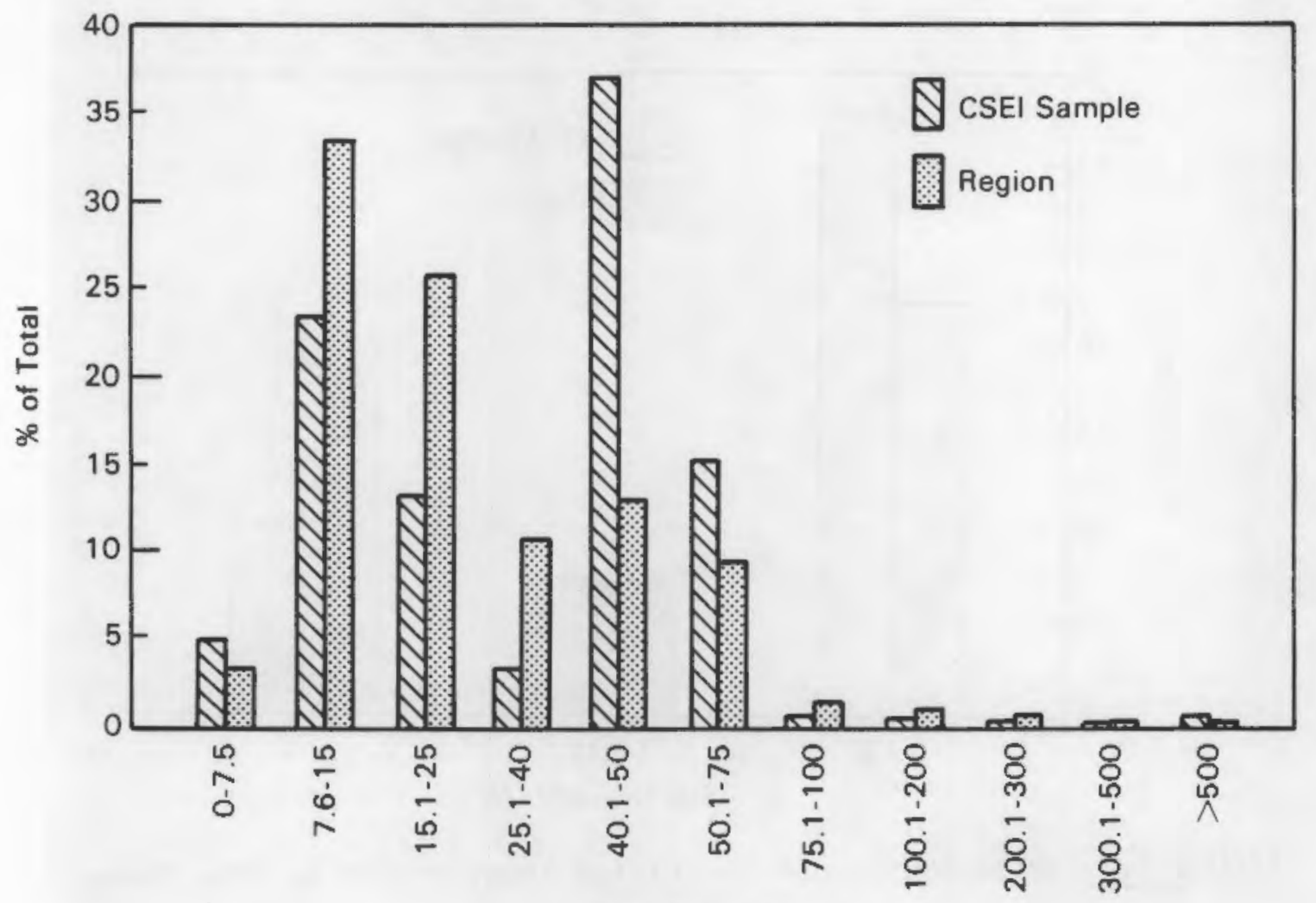

Size Group (kVA)

FIGURE 5.2. Distribution of Distribution Transformers by Size Category

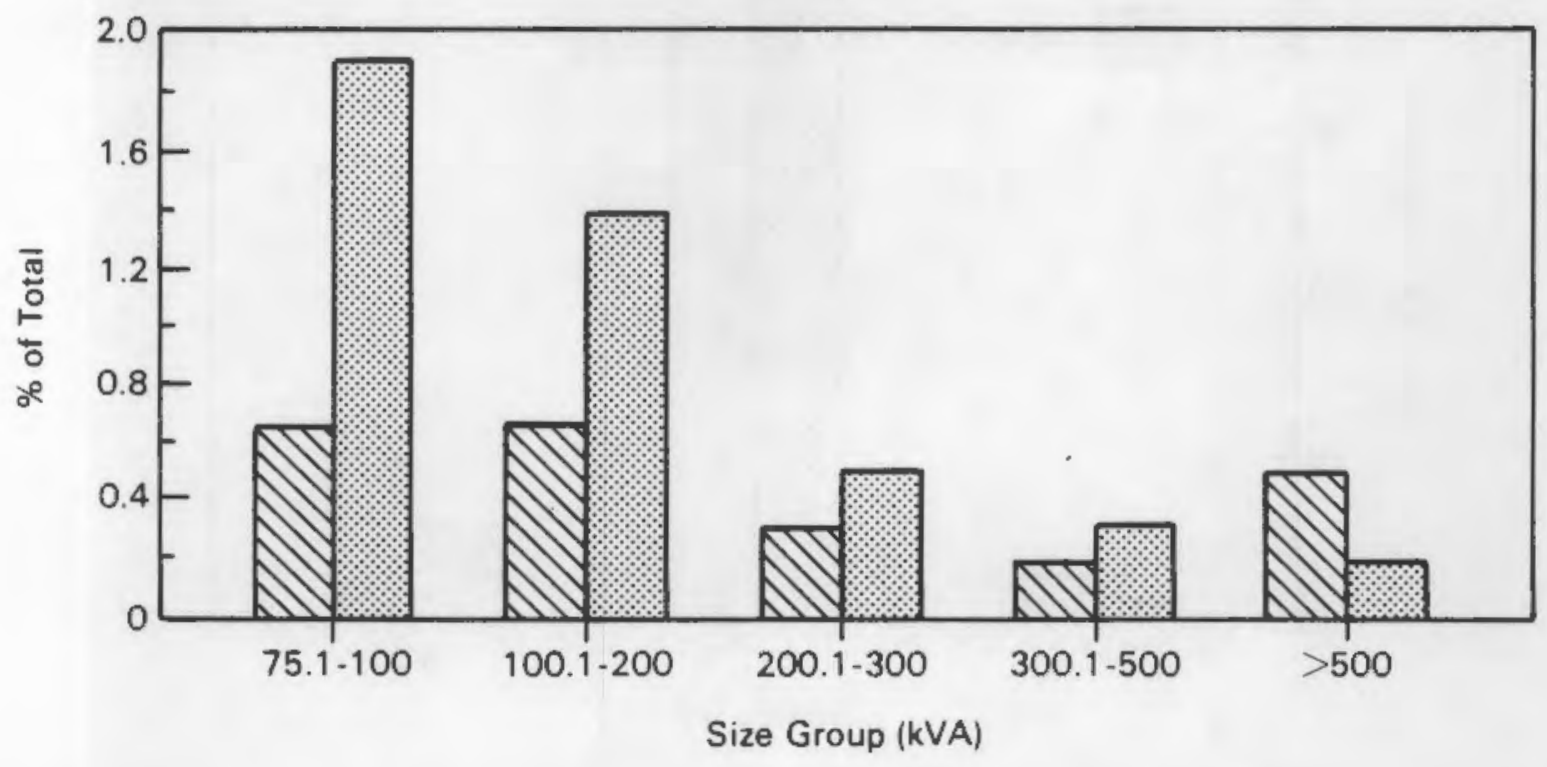

FIGURE 5.3. Detail from Figure 5.2 for Distribution Transformers Greater than $75 \mathrm{kVA}$ 


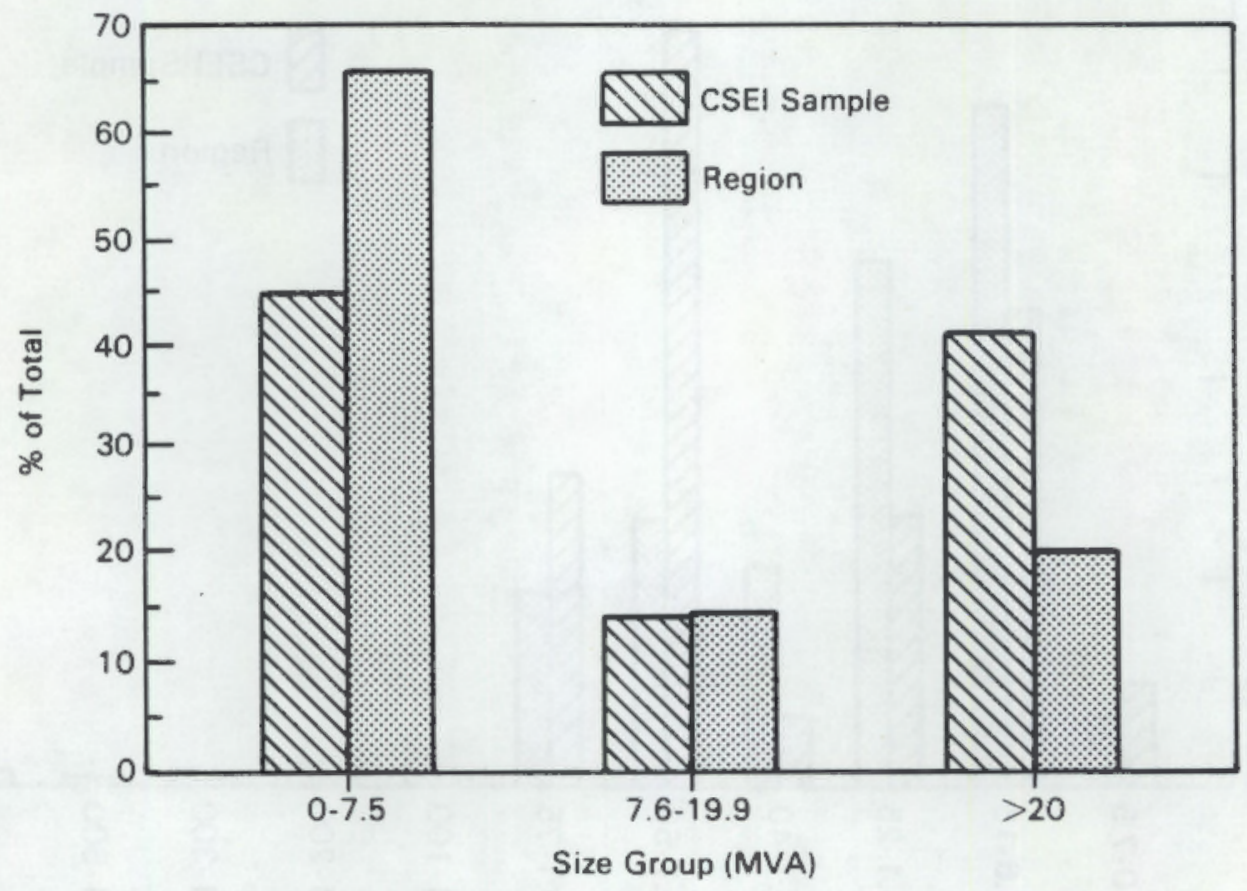

FIGURE 5.4. Distribution of Substation Transformers by Size Category

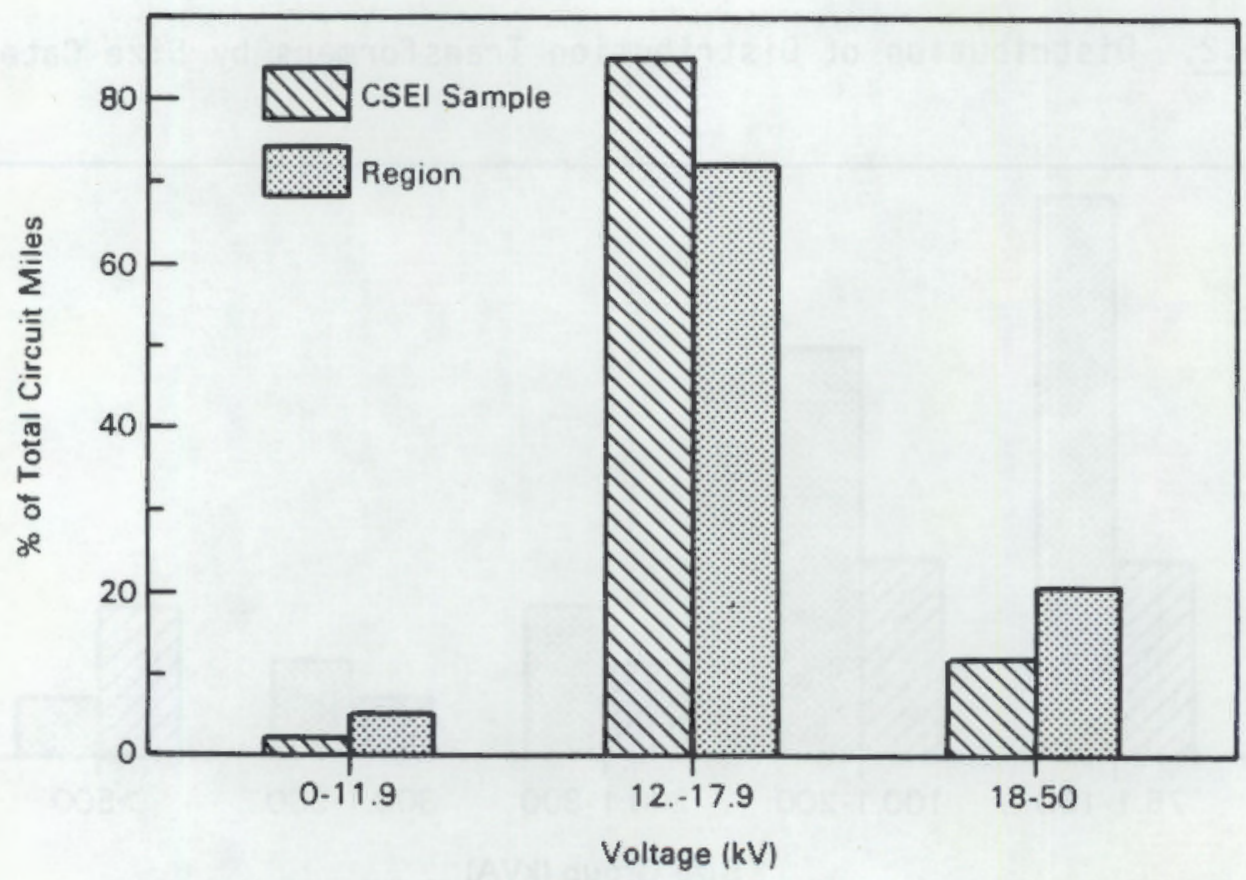

FIGURE 5.5. Distribution of Feeders by Size Category 


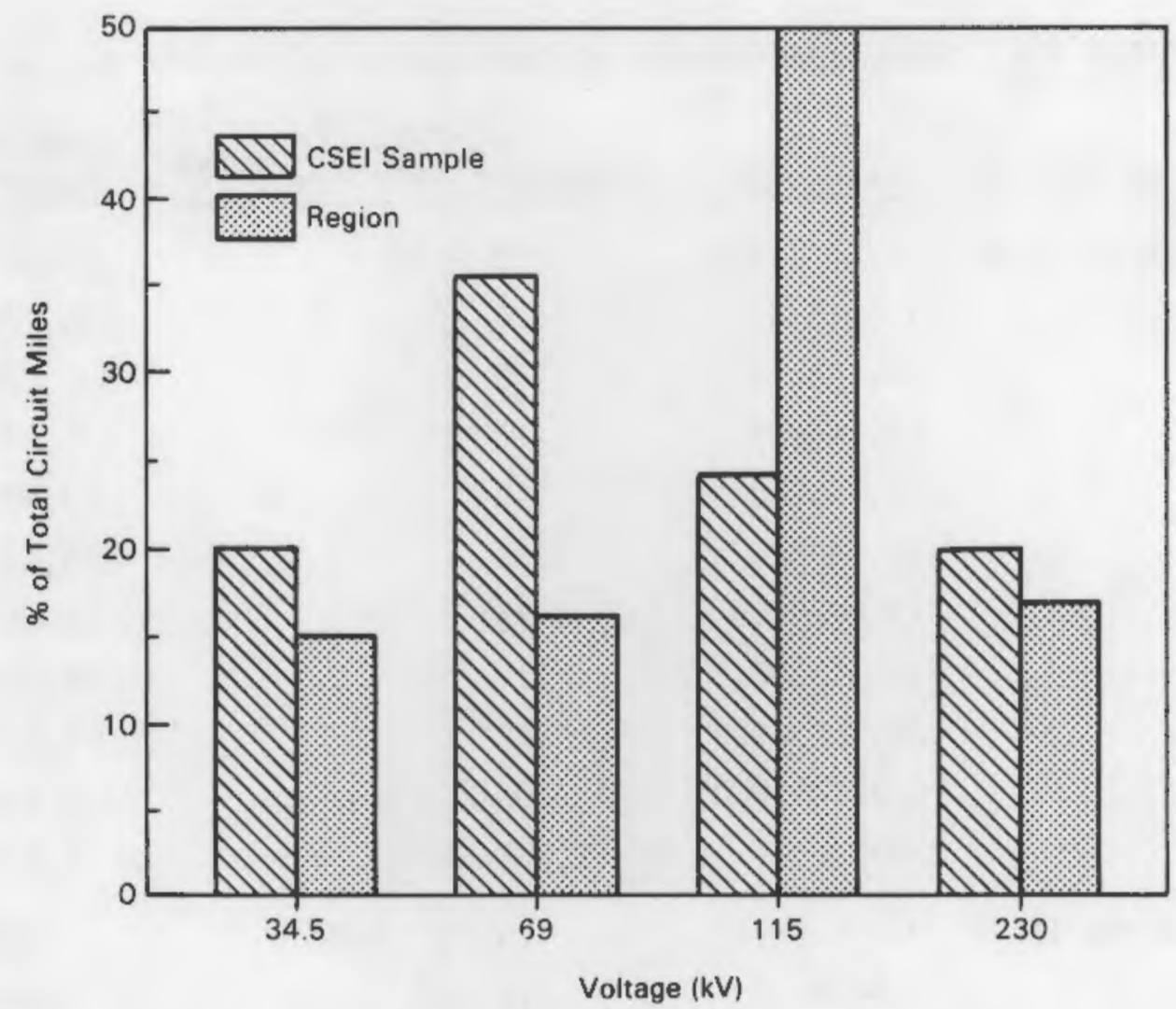

FIGURE 5.6. Distribution of Transmission Lines (Non-BPA Owned) by Size Category

ratio) for sample transformers. On the average, these transformers experience peaks that are below their installed capacities (i.e., less than 1.0). In contrast, national average peak loadings for most distribution transformer sizes (below $100 \mathrm{kVA}$ ) range from $115 \%$ to $155 \%$ (EPRI 1983). Comparable national averages for substation transformer peak loadings were not found, but the ratio of peak to installed capacity for these units based in the survey is even more startling. Small substation transformers (under 7.5. MVA), which comprise about $66 \%$ of the estimated regional stock of all substation transformers, appear to have peak loadings of only a little over $50 \%$ of their installed capacity.

Average annual loads in the region are also relatively low, compared to regional peaks. The bar charts shown in figures 5.9 through 5.12 present a facsimile of load factors by component size category. That is, they show average loads compared to annual peaks for the sample components. These figures indicate that peaks on all components are typically much higher than average 
TABLE 5.2. Estimated Number of Components in the BPA Region

\begin{tabular}{|c|c|c|c|}
\hline Component & $\begin{array}{c}\text { Size } \\
\text { Category } \\
\end{array}$ & $\begin{array}{l}\text { Size of Sample } \\
\text { Component (wtd. avg.) (a) }\end{array}$ & $\begin{array}{l}\text { Predicted } \\
\text { Quantity }\end{array}$ \\
\hline \multirow[t]{11}{*}{ Distribution $\mathrm{TX}$} & $0-7.5$ (kVA) & 5 (kVA) & $44,664^{(b)}$ \\
\hline & $7.6-15.0$ & 10 & 435,204 \\
\hline & $15.1-25.0$ & 15 & 331,274 \\
\hline & $25.1-40.0$ & 28 & 135,557 \\
\hline & $40.1-50.0$ & 48 & 173,401 \\
\hline & $50.1-75.0$ & 52 & 118,531 \\
\hline & $75.1-100.0$ & 75 & 24,656 \\
\hline & $100.1-200.0$ & 118 & 18,454 \\
\hline & $200.1-300.0$ & 232 & 6,384 \\
\hline & $300.1-500.0$ & 305 & 3,501 \\
\hline & $>500$ & 1,032 & 3,019 \\
\hline \multirow[t]{3}{*}{ Substation TX } & $0-7.5$ (MVA) & 5.727 (MVA) & $789^{(b)}$ \\
\hline & $7.6-20$ & 11.069 & 168 \\
\hline & $>20$ & 56.023 & 238 \\
\hline \multirow[t]{3}{*}{ Primary Feeders } & $0-11.9(k V)$ & $7.0(\mathrm{kV})$ & 3,508 (c) \\
\hline & $12.0-17.9$ & 12.6 & 43,219 \\
\hline & $18.0-50$ & 24.8 & 11,933 \\
\hline \multirow[t]{4}{*}{ Transmission } & $34.5(\mathrm{kV})$ & $34.5(\mathrm{kV})$ & $3,603^{(c)}$ \\
\hline & 69 & 6.9 & 4,254 \\
\hline & 115 & 11.5 & 12,080 \\
\hline & 230 & 23.0 & 4,161 \\
\hline
\end{tabular}

(a) In the loss calculations, a representative component size was. determined by computing a weighted average of the KVA, MVA or $k V$ of all the sample components in a given size category. For example, the weighted average kVA of sample transformers in the $0-7.5 \mathrm{kVA}$ category was $5 \mathrm{kVA}$; this value was used in the calculation of losses for that group. Characteristics such as load losses were scaled to these average sizes.

(b) Number of transformers in each size group.

(c) Conductor circuit miles. 


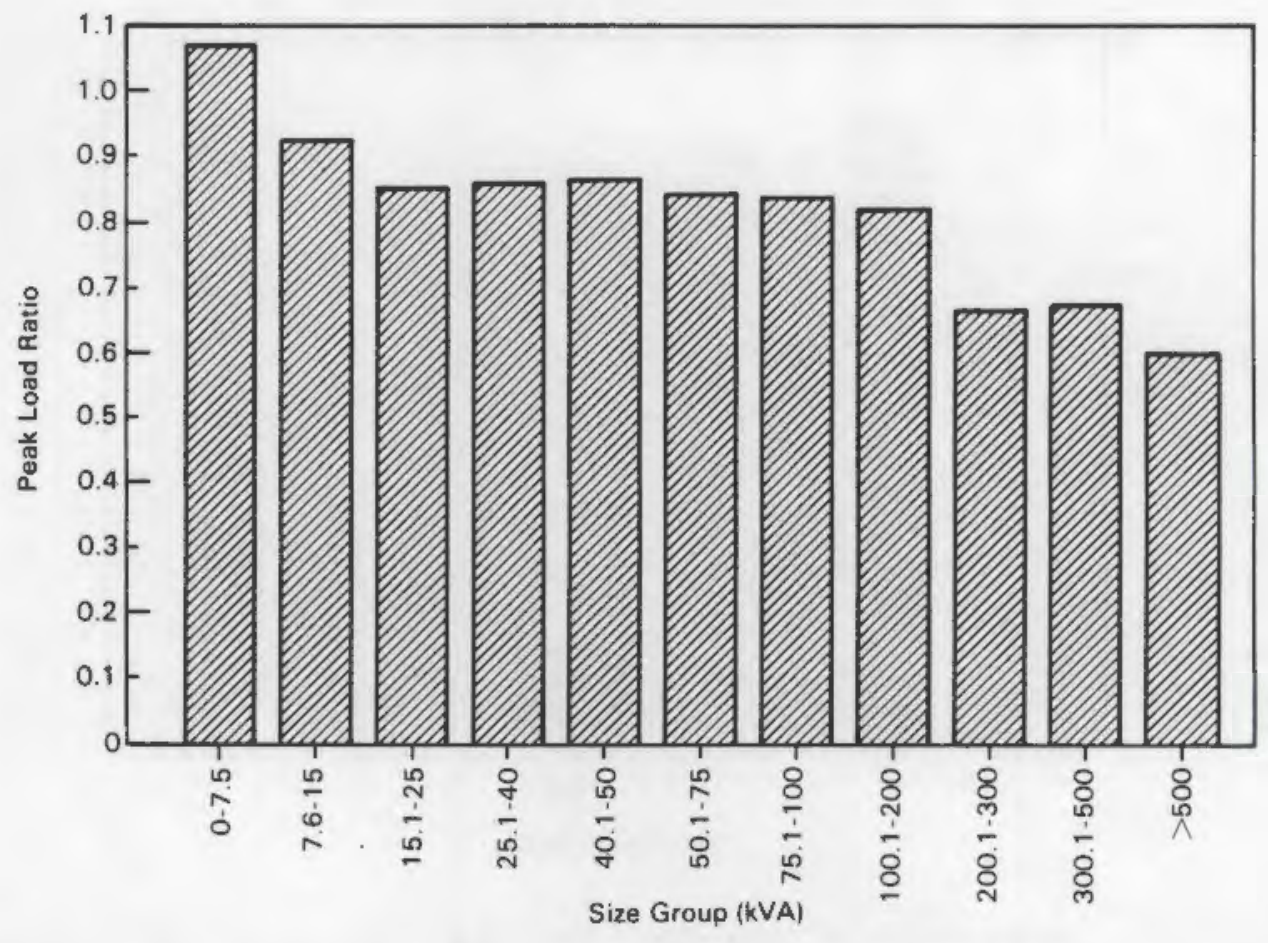

FIGURE 5.7. Peak Load Ratios of Distribution Transformers (Sample Data)

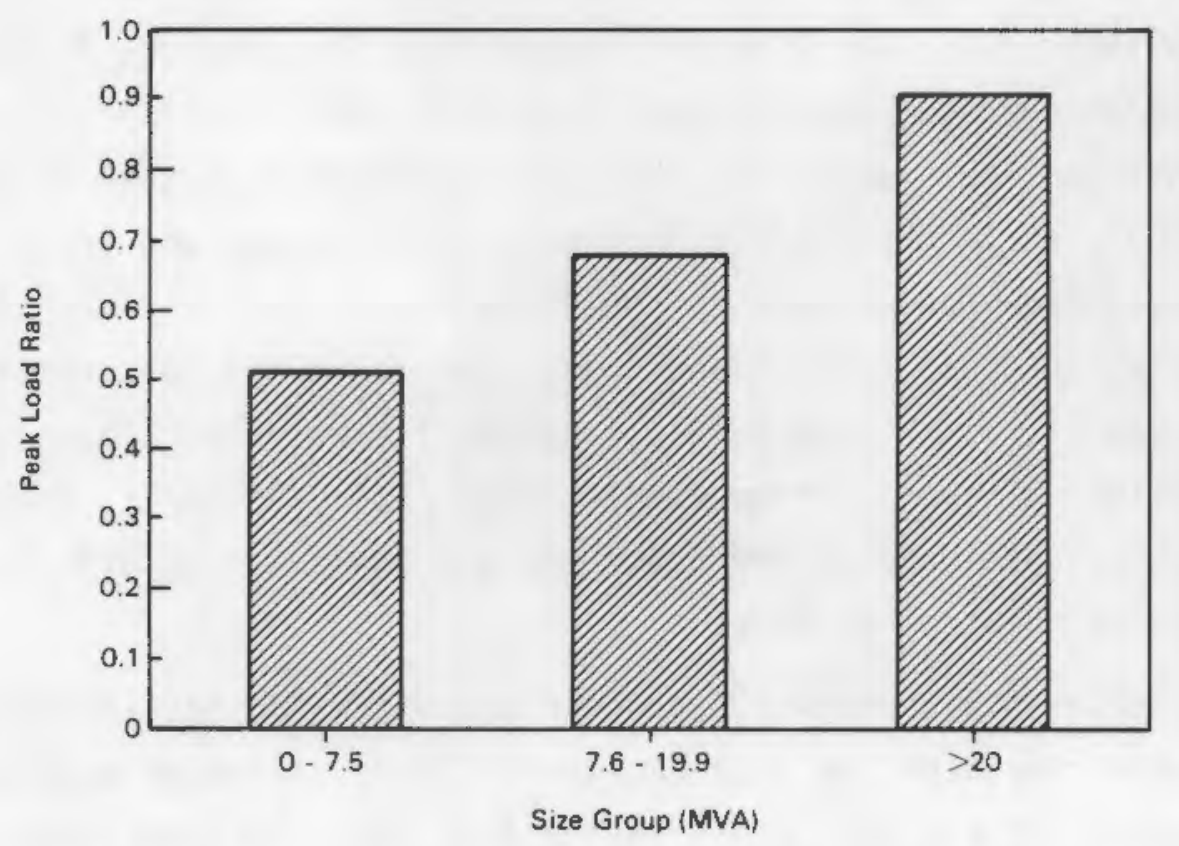

FIGURE 5.8. Peak Load Ratios of Substation Transformers (Sample Data) 


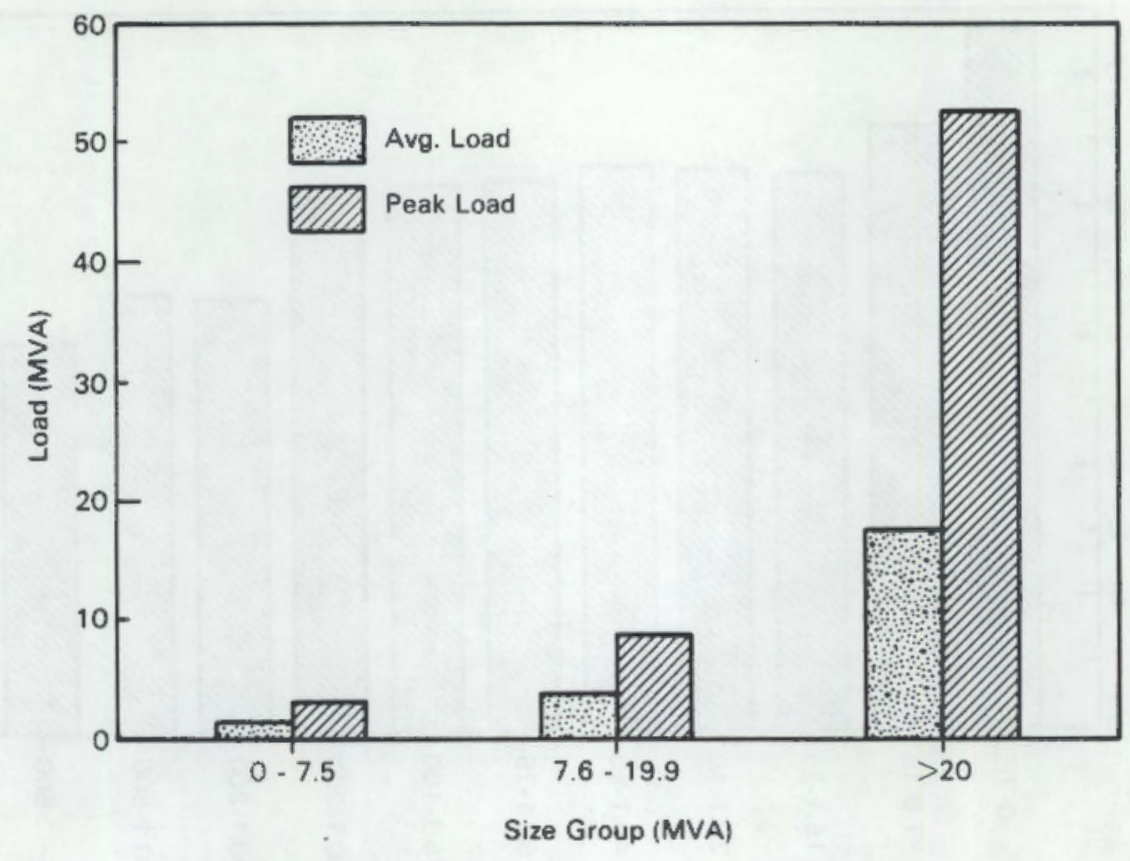

FIGURE 5.9. Comparison of Average Loads to Peak Loads for Substation Transformers, 1984 (Sample Data)

loads for most sizes. National data for distribution transformers indicate that for units under $100 \mathrm{kVA}$, it is not unusual for load factors to be quite low (0.266 with an average power factor level of 0.925) (EPRI 1983). However, the national average load factor for the full distribution system is about 0.635 (EPRI 1983), while the Pacific Northwest regional average (from the regional peak and requirement data in the INVTRY data base) appears to be below 0.4 for utilities in Clusters 1,3 and 4 and just above 0.4 for utilities in Cluster 2 (Figure 5.13). Figure 5.13 also shows the component load factors for each of the utility clusters, (from sample data). (In Cluster 1, there were insufficient acceptable data on the peaks and average loads of distribution transformers to calculate load factor.)

Finally, Tables 5.3 through 5.6 present the estimated loss-related characteristics of each component, by size category. These estimates were used to quantify the potential regional conservation from distribution-system efficiency improvements (loss reductions) that can be gained by replacing existing components either with more efficient units (in the case of transformers) or with larger conductors (feeders and transmission lines). 

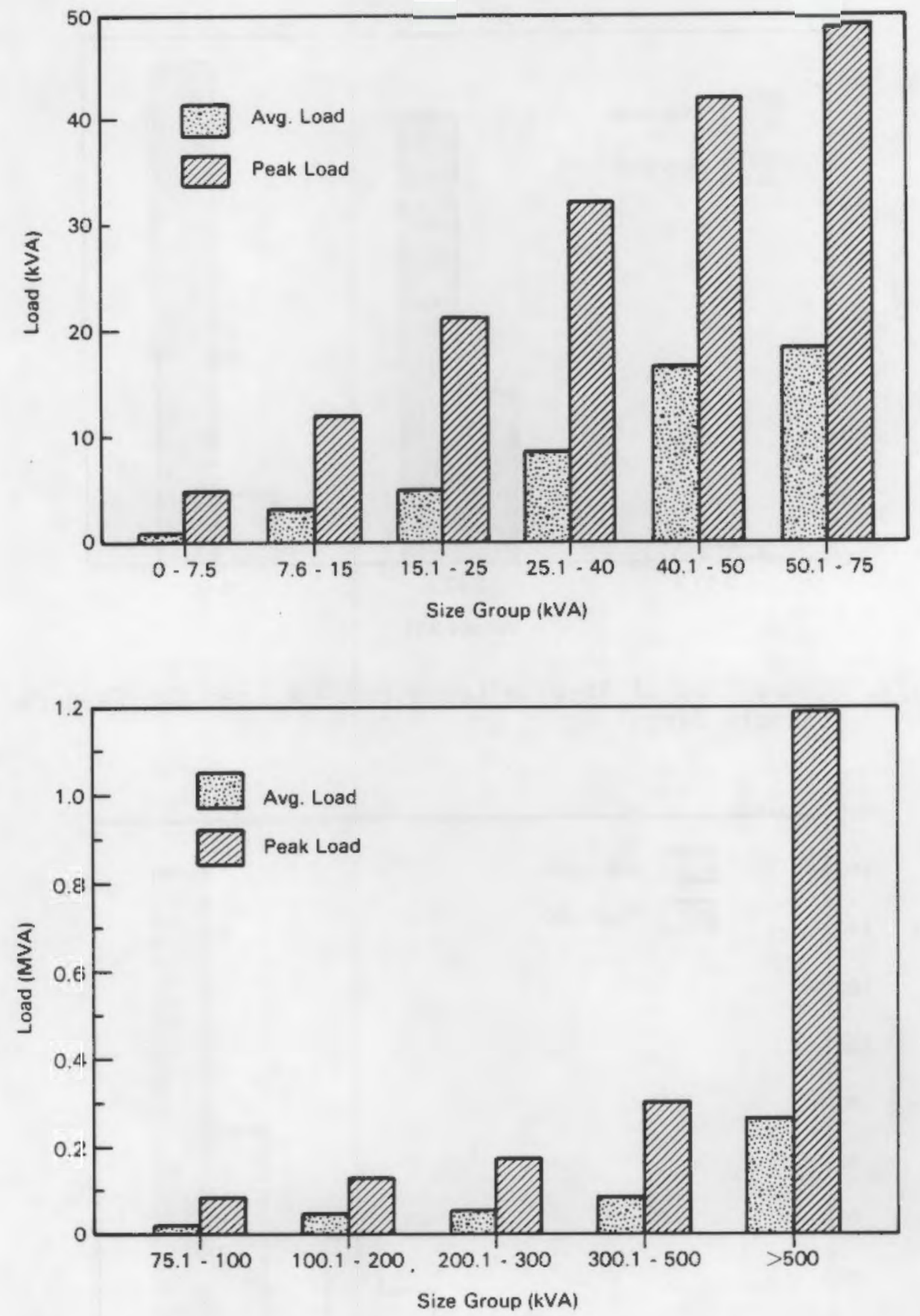

FIGURE 5.10. Comparison of Average Loads to Peak Loads for Distribution Transformers, 1984 (Sample Data) 


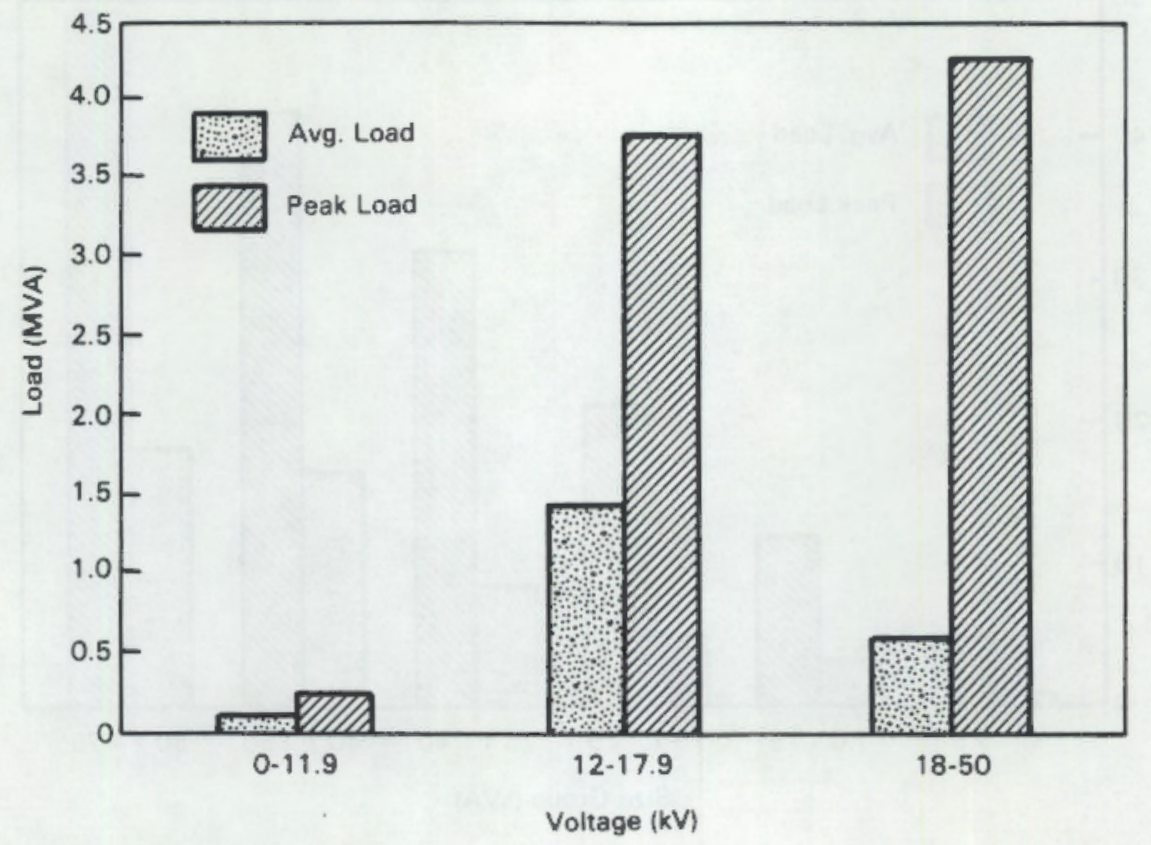

FIGURE 5.11. Comparison of Average Loads to Peak Load for Feeders, 1984 (Sample Data)

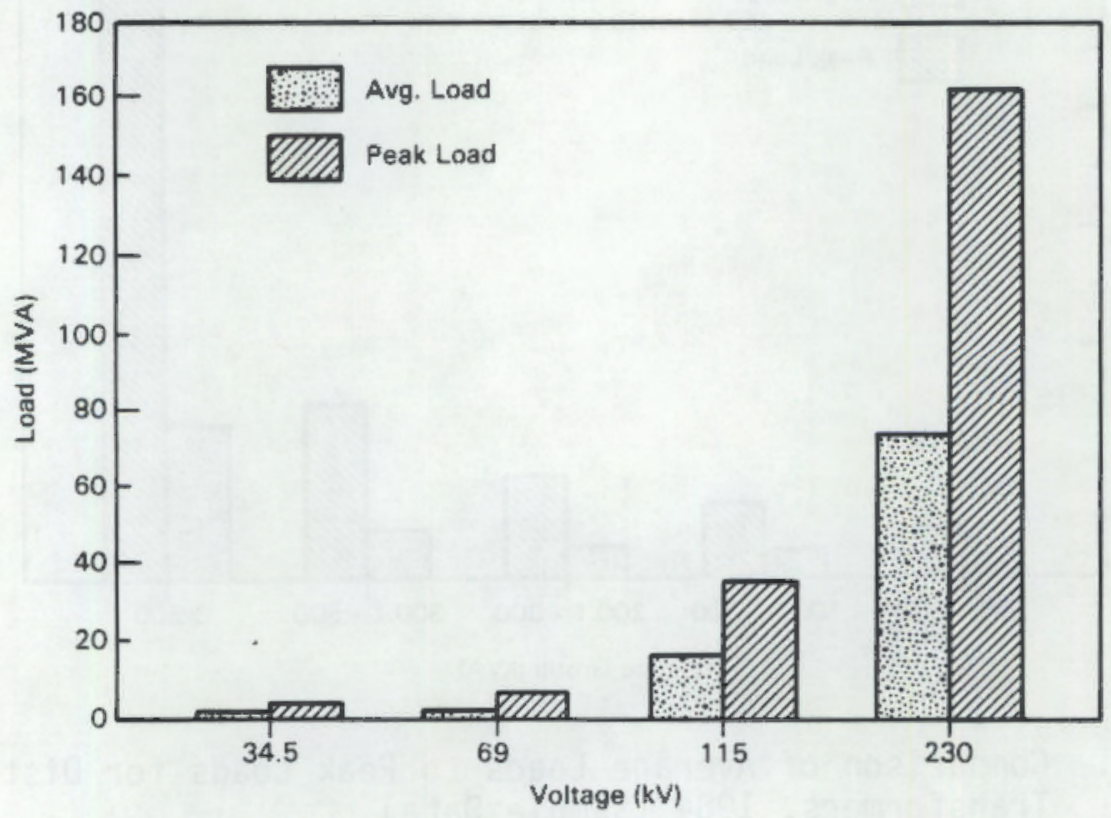

FIGURE 5.12. Comparison of Average Loads (in units of peak) and Peak Loads for Transmission Lines, 1984 (Sample Data) 


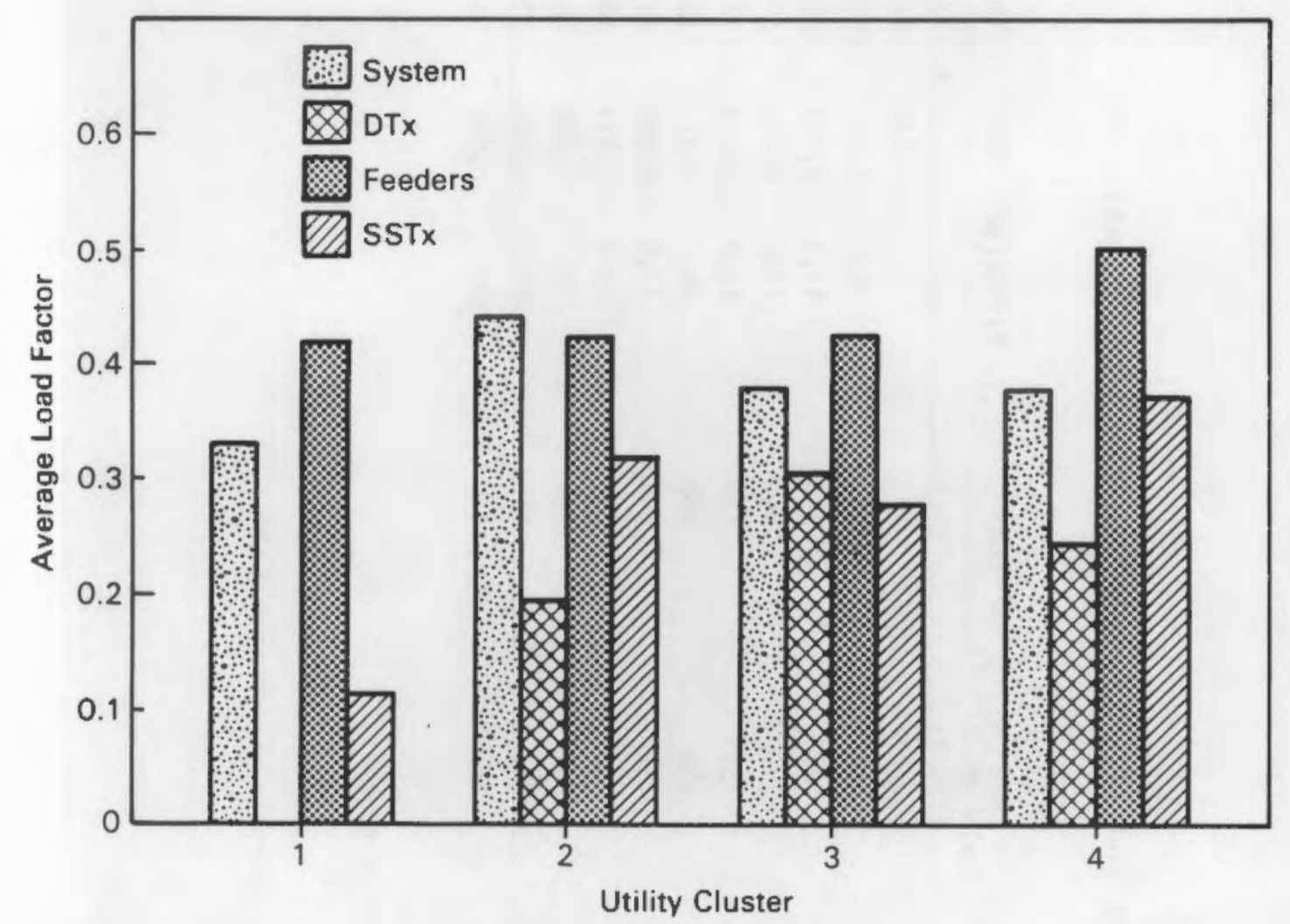

FIGURE 5.13. Comparison of System and Component Load Factors by Utility Cluster, 1984 (Sample Data) 
TABLE 5.3. Vistribution Transformers: Cateyories and Estimated Operating Characteristics of Regional Stock

\begin{tabular}{|c|c|c|c|c|c|c|c|c|c|}
\hline $\begin{array}{c}\text { Nominal } \\
\text { Category } \\
(\mathrm{kVA}) \\
\end{array}$ & $\begin{array}{c}\text { Average } \\
\text { Capacity (b) } \\
\text { (kvA) } \\
\end{array}$ & $\begin{array}{l}\log \\
\text { Average } \\
\text { Capacity } \\
\end{array}$ & $\begin{array}{l}\text { No Load } 48 s, 5) \\
\text { ExIsting } \\
\text { (watts) } \\
\end{array}$ & $\begin{array}{l}\text { Load Liss, } \\
\text { Existing } \\
\text { (yotts) } \\
\end{array}$ & $\begin{array}{r}\text { No Lood Loss ,d) } \\
\text { Replacement } \\
\quad(\text { watts) } \\
\end{array}$ & $\begin{array}{l}\text { Lood Los }\{c, d) \\
\text { Replacement } \\
\text { (yotts) }\end{array}$ & $\begin{array}{c}\text { Estimatiod } \\
\text { Peak } \\
(k \vee A) \\
\end{array}$ & $\begin{array}{l}\text { Peak } \\
\text { Load } \\
\text { Ratio } \\
\end{array}$ & $\begin{array}{l}\text { Estimated } \\
\text { Number } \rho^{f} \\
\text { Units }(\theta)^{-} \\
\end{array}$ \\
\hline 7 & 5 & 1.6 & 43 & 109 & 30. & 91 & 4.7 & 0.946 & 44664 \\
\hline 15 & 10 & 2.3 & 67 & 188 & 47 & 148 & 8.6 & 0.856 & 435204 \\
\hline 25 & 15 & 2.7 & 90 & 280 & 64 & 198 & 11.9 & 0.793 & 331274 \\
\hline 40 & 28 & 3.3 & 182 & 547 & 119 & 363 & 17.6 & 0.626 & 135557 \\
\hline 50 & 48 & 3.9 & 247 & 746 & 154 & 470 & 42.4 & 0.883 & 173401 \\
\hline 75 & 52 & 3.9 & 247 & 774 & 158 & 486 & 36.9 & 0.71 & 118531 \\
\hline 100 & 75 & 4.3 & 286 & 900 & 182 & 558 & 37.1 & 0.495 & 24656 \\
\hline 200 & 118 & 4.8 & 334 & 1062 & 213 & 547 & 60.5 & 0.513 & 18454 \\
\hline 300 & 232 & 5.5 & 406 & 1300 & 257 & 781 & 112 & 0.483 & 6384 \\
\hline 500 & 305 & 5.7 & 435 & 1394 & 275 & 836 & 150.1 & 0.492 & 3501 \\
\hline$>500^{(f)}$ & 1032 & 6.9 & 565 & 1821 & 354 & 1077 & 592 & 0.574 & 3019 \\
\hline
\end{tabular}

(a) See Table 5.2 for the ranges of each category.

(b) Averages weighted by number of transformers reported in each category.

(c) At peak load ratlo $=1.00$.

(d) Values derlved from CH2M-HILL (1981), pp. 45-46.

(e) From regression analysis.

(f) The $>500$ category Includes transformers that have Installed capacity exceeding $500 \mathrm{kVA}$. 
TABLE 5.4. Substation Transformers: Categories and Operating Characteristics

\begin{tabular}{|c|c|c|c|c|c|c|c|c|}
\hline $\begin{array}{c}\text { Category } \\
\text { (KYA) }\end{array}$ & $\begin{array}{c}\text { Average } \\
\text { Installed } \\
\text { Capactiy } \\
\text { (kva) } \\
\end{array}$ & $\begin{array}{l}\text { No } \\
\text { Lood Loss } \\
\text { Exist } \\
(k w) \\
\end{array}$ & $\begin{array}{l}\text { Load Loss } \\
\text { Existlygg } \\
\text { (kw) }\end{array}$ & $\begin{array}{l}\text { No } \\
\text { Load Loss } \\
\text { Rep lacement } \\
(k w)(c)\end{array}$ & $\begin{array}{l}\text { Load Loss } \\
\text { Replacement } \\
(\mathrm{kw})(\mathrm{c})^{-}\end{array}$ & $\begin{array}{l}\text { Average } \\
\text { Peak } \\
(k \vee A)(b) \\
\end{array}$ & $\begin{array}{l}\text { Peak } \\
\text { Load (d) } \\
\text { Ratio(d) }\end{array}$ & $\begin{array}{c}\text { Estimoted } \\
\text { Number } \\
\text { of Units }(\theta) \\
\end{array}$ \\
\hline$<7,500$ & 5,727 & 10.61 & 39.0 & 7.2 & 25.8 & 3,038 & 0.53 & 789 \\
\hline $\begin{array}{l}7,501- \\
20,000\end{array}$ & 11,069 & 15.4 & 50.4 & 9.5 & 31.6 & 7,084 & 0.64 & 168 \\
\hline$>20,000$ & 56,023 & 44.7 & 176.7 & 14.8 & 48.4 & 47,620 & 0.85 & 238 \\
\hline
\end{tabular}

(a) Welghted overage Installed capacity for each cotegory.

(b) Welahted averages for reported values In 5 ize category.

(c) Values for reference transformers (the most efflclent sample transformer in a glven size categoryl.

(d) Ratio of average peak load to (average) Installed capacity.

(e) From regression analysis. 
TABLE 5.5a. Primary Feeders: Operatiny Characteristics of Sample Data(a)

\begin{tabular}{|c|c|c|c|}
\hline 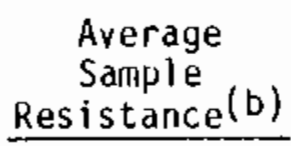 & $\begin{array}{c}\text { Lenyth } \\
\text { (Circuit Miles) } \\
\text { (c) }\end{array}$ & $\begin{array}{l}\text { Sum of Calculated } \\
\text { Losses (MWh) }(d)\end{array}$ & $\begin{array}{c}\text { KLOSS } \\
\text { (Constant) }\end{array}$ \\
\hline 2.57 & 112 & 2,172 & 7.55 \\
\hline 0.89 & $4,2 b 7$ & 283,481 & 74.82 \\
\hline 1.38 & 613 & 13,248 & 15.66 \\
\hline
\end{tabular}

TABLE 5.5b. Primary Feeders: Categories and Estimated Uperating Characteristics of Keyional Stock

\begin{tabular}{|c|c|c|c|c|c|}
\hline $\begin{array}{c}\text { Category } \\
(\mathrm{kV})\end{array}$ & $\begin{array}{c}\text { Estimated } \\
\text { Average } \\
\text { Operating } \\
\text { voltage (ky) (e) } \\
\end{array}$ & $\begin{array}{l}\text { Estimated } \\
\text { Conductor }\{1\} \text { द } \\
\text { (ExIstina) } \\
\end{array}$ & $\begin{array}{c}\text { Resistance } \\
\text { ExIsting } \\
\text { Conductor (b) } \\
\text { (ohms/m!le) } \\
\end{array}$ & $\begin{array}{l}\text { Res Istance of } \\
\text { Conductor } 3 \text { Sizes } \\
\text { Larger (ohms } / \mathrm{mi} \mid \theta \text { ) }(\mathrm{g})\end{array}$ & $\begin{array}{c}\text { Estimated } \\
\text { Length } \\
\text { (Circu }(\hbar) \\
\text { MIles) }\end{array}$ \\
\hline $0-11.9$ & 7.0 & 4 AWG & 2.57 & $1.38(1.0$ ANG $)$ & 3,508 \\
\hline $12.0-17.9$ & 12.6 & $2 / 0$ ANG & 0.89 & $0.55(266.8 \mathrm{Kcml})$ & 43,219 \\
\hline $18.0-50$ & 24.8 & 1 AWG & 1.38 & 0.72 (3/0 ANG) & 11,933 \\
\hline
\end{tabular}

(a) Table 5.5a data were used to compute a constant (KLOSS), which was then used in the actual loss calculations performed with data from Table 5.5b (see Tepel et al. i9a6).

(b) Real ACSR resistance (Standard Handbook for Electrical Enql neers, 1978) closest to welghted average of feeder resistances reported by utIlities.

(c) Sum of reported clrcult miles of all sample feeders in each category.

(d) Losses calculated for each feader/feeder segment.

(e) Wolghted average of sample data.

(f) The ACSR conductor slze ith aversge sample resistance (see footnote (b) above).

(g) Standard Handbook tor Electrical Enqlnoers, (1978); CRC Handbook (1981).

(h) Reglonal totals estimated by regression. 
TABLE 5.6a. Transinission Lines: Operating Characteristics of Sample Data(a)

\begin{tabular}{|c|c|c|c|c|c|}
\hline $\begin{array}{c}\text { Categorles } \\
\text { (Opernting kV) } \\
\end{array}$ & $\begin{array}{l}\text { Average Sample } \\
\text { Reslstance } \\
\text { (ohms/mile) (b) } \\
\end{array}$ & $\begin{array}{c}\text { Assumed } \\
\text { Conductor (c) } \\
\text { Size } \\
\end{array}$ & $\begin{array}{c}\text { Length } \\
\text { (circult miles) (d) }\end{array}$ & $\begin{array}{c}\text { Sum of } \\
\text { Calculated } \\
\text { Losses (Mwh) }(e) \\
\end{array}$ & $\begin{array}{c}\text { KLOSS } \\
\text { (constant) }\end{array}$ \\
\hline Low $(34.5)$ & 0.895 & $2 / 0$ ANG & 461.2 & 1,902 & 4.61 \\
\hline Med (69) & 0.895 & $2 / 0$ AWG & 806.8 & 12,836 & 17.78 \\
\hline $\mathrm{HI}(115)$ & 0.306 & $336.4 \mathrm{Kcmll}$ & 555.1 & 39,123 & 230.37 \\
\hline VHI (230) & 0.123 & $874.5 \mathrm{Kcml}$ & 456.8 & 65,624 & $1,167,46$ \\
\hline
\end{tabular}

TABLE 5.6b. Transmission Lines: Categories and Estimated Operating Characteristics of Regional Stock

\begin{tabular}{|c|c|c|}
\hline $\begin{array}{l}\text { Operatling }(f) \\
\text { oltage (kv) }\end{array}$ & $\begin{array}{c}\text { As sumed } \\
\text { Conductor } S \mid z e^{(c)}\end{array}$ & $\begin{array}{r}\text { Resistance } \\
\text { Existing(b) } \\
\text { Conductor } \\
\end{array}$ \\
\hline 34.5 & 2/0 AWG & 0.895 \\
\hline 69 & $2 / 0$ AnG & 0.895 \\
\hline 115 & $336.4 \mathrm{Kcmll}$ & 0.306 \\
\hline 230 & $874.5 \mathrm{kcmll}$ & 0.123 \\
\hline
\end{tabular}

\begin{tabular}{|c|c|c|}
\hline $\begin{array}{r}\mathrm{R} \\
\text { of } \\
\mathrm{S} 1 \\
\end{array}$ & $\begin{array}{l}\text { S Istance } \\
\text { Conductor } \\
\text { es Larger }(\mathrm{g})\end{array}$ & $\begin{array}{c}\text { Length } \\
\text { (clrcult ml les) }(h)\end{array}$ \\
\hline 0.385 & $(266.8 \mathrm{Kcml})$ & 4,603 \\
\hline 0.385 & $(266.8 \mathrm{Kcm} / \mathrm{l})$ & 4,254 \\
\hline 0.206 & $(500 \mathrm{kcmil})$ & 12,080 \\
\hline 0.104 & $(1033.5 \mathrm{Kcm} / 1)$ & 4,161 \\
\hline
\end{tabular}

(a) Table 5.6a data were used to compute a constant (KLOSS), which was then used in the actua loss calculations performed with data from Table 5.6b (5ee Tepel et al. 1986).

(b) Real ACSR resistance (Standard Handbook for Electrical Englneers 1978) closest to weighted average of transmission reslstances reported by utllities.

(c) ACSR conductor size ith overage sample resistance (see footnote b above).

(d) Sum of reported clrcult ml les of all sample transmission lines in each category.

(e) Losses calculated for transmission line segments.

(f) Standard transmission operating voltages.

(g) Standard Handbook for Electrlcal Enql neers (1978) CRC Handbook (1981).

(h) Electrlcal World (1983) 


\subsection{CONCLUSIONS}

This report has described the development of three data bases for the CSEI Assessment Project, and has provided details on the information contained in each of these data bases. In addition, a number of intermediate sumnary statistics about loss-related T\&D system characteristics have been presented to indicate some of the ways that this information can be used. At this level of analysis, a great deal of insight can be gained as to the strengths and weaknesses of the current regional network of T\&D facilities. A still higher level of analysis was used to determine the system's loss recovery potential, and to develop conservation supply curves (Tepel et a1. 1986).

These three data bases were essential for estimating the comparative costeffectiveness of various regional T\&D efficiency improvements. However, there are numerous nontechnical problems associated with implementing a regional program to improve distribution system efficiencies by equipment replacement or any other cost-effective strategy. Many of these problems are identified and discussed in the part of the CSEI study on institutional issues (Hendrickson and Darwin 1986). However, there is undoubtedly a potential for loss reduction, just as there is some evidence that system improvements are gradually taking place in the normal course of utility system maintenance and development. Ongoing analyses in the CSEI Assessment Project and other regional and individual utility efforts will no doubt provide more precise system information in the future, as well as a better understanding of how best to achieve efficiency improvements. This initial phase of the CSEI Assessment Project, including the data base development and supply curve analysis, does, however, provide a first step toward identifying and assessing the resource available through loss reductions.

The reliability of such research efforts depends on the accuracy and representativeness of the data upon which they are based. Variations in the quality and volume of data, the number of utilities supplying adequate informa-. tion, and the proportion of the estimated total regional stock that was represented in the CSEI systems data base make it likely that the loss calculations for transmission lines and substation transformers are more accurate than those 
for feeders and distribution transformers. Keeping good records on the first two components appears to be easier for utilities of all sizes, probably because there are fewer of these items in a utility system, because their operating parameters are more closely monitored, and because their replacement or repair may be a major cost to the utility. However, the representativeness of the average loss-related characteristics derived for the supply curve estimation is undoubtedly open to question. The response to the survey could well have been biased toward the utilities having the most interest in system efficiency improvement. Respondents could also have been primarily those utilities with the best records or most available engineering staff. Any of these factors could bias the sample data that were used in this phase of the study.

On the other hand, comparing a number of important T\&D characteristics estimated with these data with corresponding parameters from other loss studies indicates that the CSEI data are relatively reliable. The data do not show many outstanding or unreasonahle anomalies that run counter to expected characteristics of the region's T\&D stock. Sensitivity tests could be developed to bracket the parameters that were used in the supply curve calculations, and to determine the effects of modification of important inputs. However, the level of effort dictated for this phase of the CSEI Assessment Project did not warrant these procedures.

The data base created for the CSEI study is probably unmatched in its comprehensiveness and level of detail for a regional electrical distribution system consisting of a large number of utilities. Developing the data base demonstrated the difficulties associated with adequately characterizing T\&D systems at the component level for an entire region. Any future effort to do so with a more supportable sample design will be greatly enhanced as a result of this initial compilation. Using the CSEI data bases significantly improved the accuracy of supply curves that PNL estimated to described the conservation potential represented by T\&D system efficiency improvements. Furthermore, the characterization of regional T\&D component stocks and the estimations of losses developed in the CSEI assessment have the potential for much broader use in future assessments of T\&D system conservation options, plans, and policies. 
CH2M-Hill. 1981. Distribution System Efficiency Improvement Handbook. $D 0 \mathrm{E} / \mathrm{BP} / 171$, produced for the Bonnevithe Power Administration, Port Tand, Oregon.

CRC Handbook of Chemistry and Physics. 62nd Edition, Robert $C$. Weast and MeTín J. AstTe eds., CRC Press, Inc., Boca Raton, Florida.

Electrical World. 1983. Directory of Electric utilities. 92nd Edition, McGraw-Hill Book Company, New York, New York.

EPRI. 1983. Improved Methods for Distribution Loss Evaluation. EL-3261, Electric Power Research Institute, Palo Also, California.

Hendrickson, P. L. and R. F. Darwin. 1986. Decision Factors Affecting Transmission and Distribution Efficiency Improvements by Northwest ETectric Utilities. PNL-5735, Pacific Northwest Laboratory, Richland, Washington.

Standard Handbook for Electrical Engineers. 11th Edition, Donald G. Fink and H. Wayne Beaty eds., McGraw-Hill Book Company, New York, New York.

Tepel, R. C., J. W. Callaway, J. G. DeSteese, W. H. Doggett, A. D. Lee, and Z. T. Taylor. 1986. Customer System Efficiency Improvement Assessment: Supply Curves for Transmission and Distribution Conservation Options. PNL-6076, Pacific Northwest Laboratory, Richland, Washington. 
APPENDIX A

REQUEST FOR INFORMATION FORM SENT TO UTILITIES 
APPENDIX A

REQUEST FOR INFORMATION FORM SENT TO UTILITIES

The following questionnaire was sent to utilities in the Pacific Northwest region to request information on their distribution system components. Sixtysix utilities responded and provided information in various degrees of specificity. 
MIESTIONNAIRE ON SYSTEM CHARACTERISTICS

TRANSMISSION AND DISTRIBUTION EFFICIENCY IJPGRADES PROJECT

Customer name:

Contact Derson:

Titie:

Phone:

REPORTS:

When was your most recent loss study and/or work plan perfomed?

Year for loss study: Year for work plan:

If Dossible, woutd you please provide a coov of the loss study and/ar work olan?

'Nould you please enc'ose a coov of your annua? rooort?

RE: UTREME:YTS:

Annual Reouirements categorizod by source (Totat for January-Dacember):

Own generation:

Sudvilied from other

1093

¿982

utilities iplease narnel:

If you provide anv power to anv other utilities, please list names and amounts supolied for 1982 and 1983.

\section{SYSTEM CHARACTERISTICS:}

Power factor by delivery point:
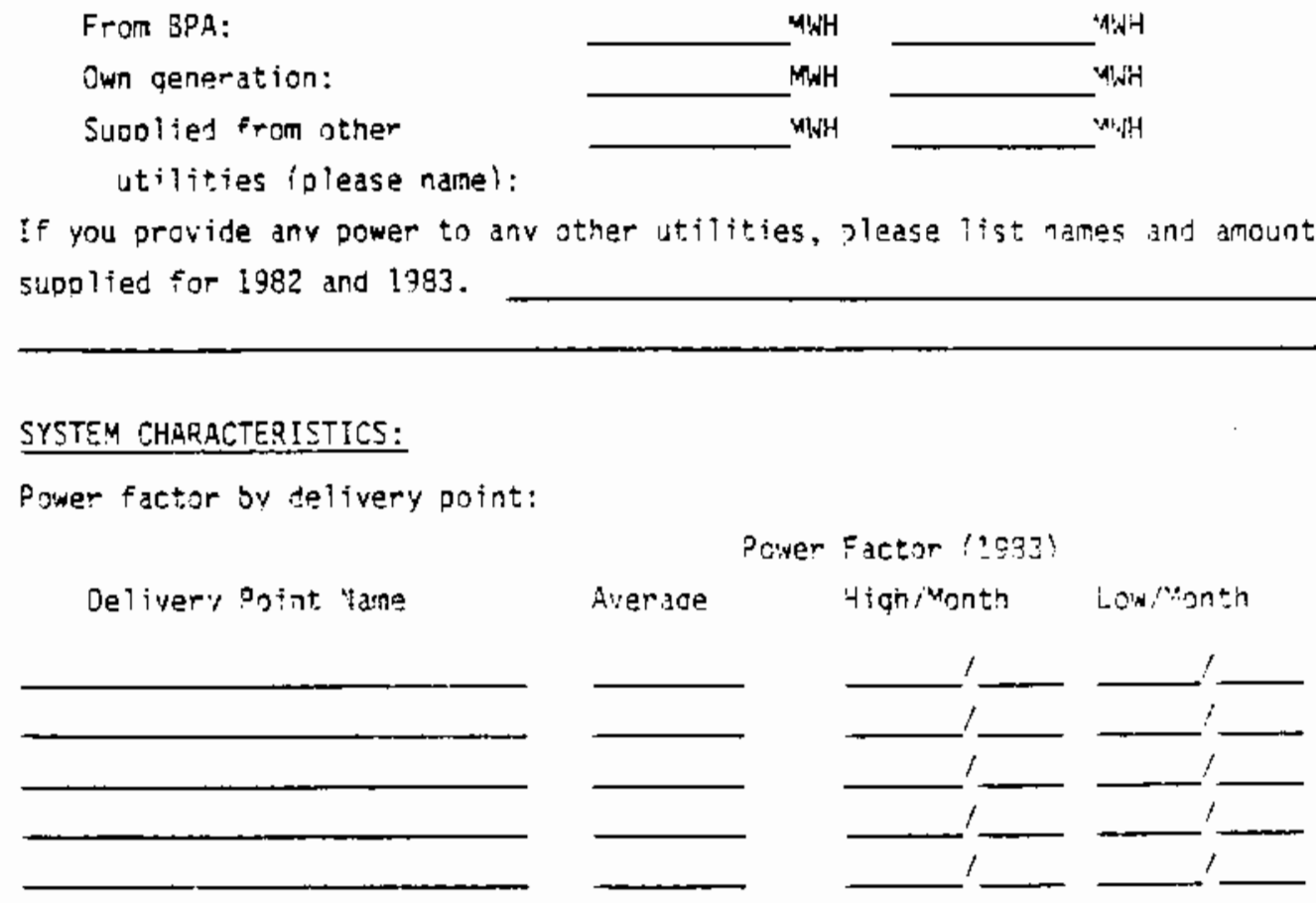

Please attach another pace, if noeded. 
LOSSES:

Estinates of losses (a) by source:

Feeders

Distribution transformers

Transmission/subtransmission lines

- Secondary system
How do you allocate these losses by scurce? (rules of thumb, measured?, a

Bulk power substations (if any)

study?, other?)

To what percentage of total sales could system losses be reduced if all loss componencs were replaced with higher efficiency components that were economically juscified? (estimate h) What percentage of losses would be experienced if all system loss components were replaced by the most efficient components currently available? (estimate $\%$ )

Are lass reduction measures being systematically installed as part of a regular system improvement plan?

If yes, what measures are deing

(a) applied in 1984, and (b) planned in 1985?

$-$

Have you experienced any trends (increases or decreases) in your percentage losses over the past 5 years? Can you attribute these to any actions on your part (system improvements, etc.) 
EOUIPMENT REPLACEMENT:

Could you provide typical (or estimated) information on equipment replacement and installation costs for major system components? The last column requests an estimate of the approximate number of these components replaced/jurchased per year.

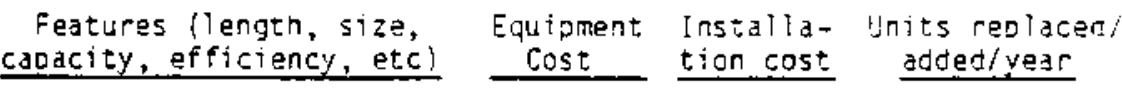

Substation

Transformer:

Distribution

Transformer:

Capacitor: 
PART 2: GENERAL INSTRUCTIONS

The information on the following pages is neeried ta characterize the varinus components of your transinission and diseribution sysien for BDats Custamer Systems Efficiency Improvement Study. Platse note that we are nor requesing information for any part of the transmission and distribution system falling outside of BPA's service area.

Is you will note, a separate page is provided for each different component included in this study. If additional room is neerted to list any single component, piease add additional pages. The first two components (transmission/subtransmission isnes and substation transformers) shouid be itemized individually on the information sheet. For the remaining components, it my be most efficient for you to group the components of a given type in your system, and provide average vaiues. When using average values, please include a brief description of how these values were derived (e.g., estimates, system inventories, studies, etc.l. We realize that some information will not be available. Dleasa make your best estimate and plit a notation to that effect.

We appreciate your efforts to characterize your T\&O systems as accurate?y as possible. This information wilt be valuable both for our effort :0 oozain a good estinate of the recoverable resource that losses represent, and as the basis for an effective and economically optimized loss reduction program by BPA. Please feel free to call Jenifer Callaway (509-376-474a) or Lisa Skumatz (509-376-4661) as questions arise.

Thank you for your help. 


\section{A. TRANSMISSION AND SIIBTRANSMISSION LINES}

Instructions: Please provide the following information on all transmission lines within your system (do not include lines owned and operated by BPA)

\begin{tabular}{|c|c|c|c|c|c|c|c|c|}
\hline $\begin{array}{l}\text { NAHE / } \\
\text { IOENT IF IER }\end{array}$ & $\begin{array}{l}\text { OPERATING } \\
\text { VOLTASE } \\
\left(X_{L} V_{-1}\right)\end{array}$ & $\begin{array}{c}\text { Type } \\
\text { (Sinqle/dout le } \\
\text { circuit) }\end{array}$ & $\begin{array}{c}\text { Capacity } \\
(\mathrm{kVa})\end{array}$ & $\begin{array}{l}\text { Resistance } \\
\text { (Ohens/Conductor } \\
\quad \text { mille) }\end{array}$ & $\begin{array}{l}\text { Length } \\
\text { (circult } \\
\text { miles) }\end{array}$ & $\begin{array}{l}\text { Annilal } \\
\text { Load } \\
\text { Mwll } \\
\end{array}$ & $\begin{array}{l}\text { Peak } \\
\text { Load } \\
\text { KVaㅡ } \\
\end{array}$ & $\begin{array}{l}\text { Power } \\
\text { Factor }\end{array}$ \\
\hline
\end{tabular}


Instructions: The following information is needed for the transformers in each non-BPA substation in your distribution systen. Please fill in the requested data on each type (by rated capacity) of transformer in each of your substations (see example).

\begin{tabular}{|c|c|c|c|c|c|c|c|}
\hline $\begin{array}{l}\text { bstation } \\
\text { Name }\end{array}$ & $\begin{array}{l}\text { Number of } \\
\text { transforiners } \\
\text { (each type) }\end{array}$ & $\begin{array}{l}\text { Capacity } \\
\text { (each trans- } \\
\text { former type) } \\
\text { (kva) }\end{array}$ & $\begin{array}{c}\text { Rated } \\
\text { Load Loss } \\
\text { (each Type) } \\
\text { (kW) }\end{array}$ & $\begin{array}{c}\text { Rated } \mathrm{Hn}^{\star} \\
\text { Load Loss } \\
\text { (each type) } \\
\text { (kW) }\end{array}$ & $\begin{array}{c}\text { Averaqe } \\
\text { age } \\
\text { each type }\end{array}$ & $\begin{array}{l}1983 \text { Peak Load } \\
\text { of Transformer } \\
\text { (kva) }\end{array}$ & $\begin{array}{l}1983 \text { Annua } \\
\left(10^{3} \text { kodh }\right)\end{array}$ \\
\hline
\end{tabular}

* If this information is not available, please inclurle the nane of the manufacturer, the data manifactured, and the serlal number of the unit. 


\section{c. DISTRIBIITION TRANSFORMERS}

Instructions: Please qroup your distribution transformers by type and rating, and provide the following inforination for each group.

\begin{tabular}{ccccc}
$\begin{array}{c}\text { Capacity } \\
(\mathrm{kVA})\end{array}$ & $\begin{array}{c}\text { Approximate } \\
\text { Number of Units }\end{array}$ & $\begin{array}{c}\text { Averaqe Peak } \\
\text { Lnad (kva) }\end{array}$ & $\begin{array}{c}\text { (standard, high, very high) } \\
\text { (qive percent of earh) }\end{array}$ & $\begin{array}{c}\text { Averaqugal Load } \\
(10\end{array}$ \\
\hline
\end{tabular}

RESIDENTIAL

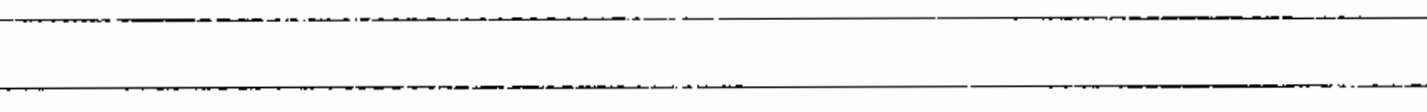

CONHERCIAL

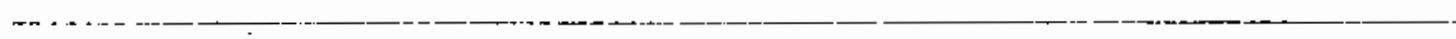

INDIJSTR I AL

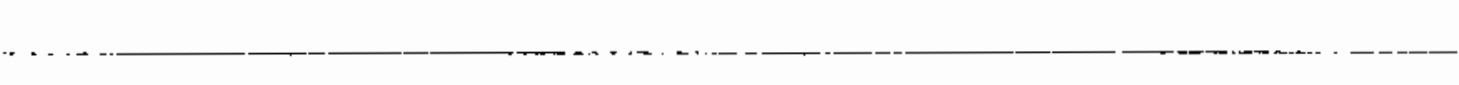

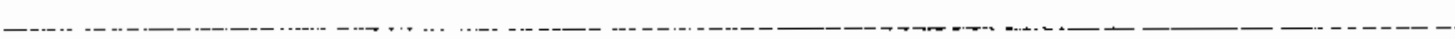

AGR ICIUL TIURAI. 
Instructions: Please provide the following information on the primary feeders in your system. Please 1 ist the primary lilles individually, where possible.*

\begin{tabular}{|c|c|c|c|c|c|c|c|c|}
\hline IDENT IF ICATION & & $\begin{array}{l}\text { Tyре: } \\
1=36 y \\
2=16 Y \\
3=290\end{array}$ & $\begin{array}{l}\text { Material } \\
1=A C S R \\
2=\text { CODPer } \\
3=\text { AAAC }\end{array}$ & & Annual & & & $\begin{array}{l}\text { (Opt jonal info.- } \\
\text { see note below:) }\end{array}$ \\
\hline $\begin{array}{l}\text { (Substation \& No. } \\
\text { If Iisted as } \\
\text { Individual Lincs) }\end{array}$ & $\begin{array}{l}\text { OPERATIHG } \\
\text { VOLTAFE } \\
\left(\mathrm{kV} V_{\mathrm{L}-\mathrm{L}}\right) \\
\end{array}$ & $\begin{array}{l}4=? 0 y \\
5=0 \text { ther } \\
\text { Specify }\end{array}$ & $\begin{array}{l}4=\mathrm{cw} / \mathrm{copper} \\
5=0 \text { ther } \\
\text { Soecify }\end{array}$ & $\begin{array}{l}\text { Conductor } \\
\text { Size }\end{array}$ & $\begin{array}{l}\text { Logुd } \\
\left(10^{3}\right. \\
\mathrm{kWh}) \\
\end{array}$ & $\begin{array}{l}\text { Annual } \\
\text { Peak Load(kva) }\end{array}$ & $\begin{array}{l}\text { Circuit } \\
\text { Miles }\end{array}$ & $\begin{array}{l}\text { Average }{ }^{*} \text { Number* } \\
\text { Lenqth of Primaries }\end{array}$ \\
\hline
\end{tabular}

* Larqe utilities with very extensive nrinary systens may wish to group primary feeders according to voltage. In this case, please provide the hest tyeical values available, hut inclurle the total number of circuit miles and the average lenqth and number of fines in each voltage category. If typical values are used, please so indicate. 
Instructions: Please group your overhear laterals by voltaqe and provide the following information, in typical values.

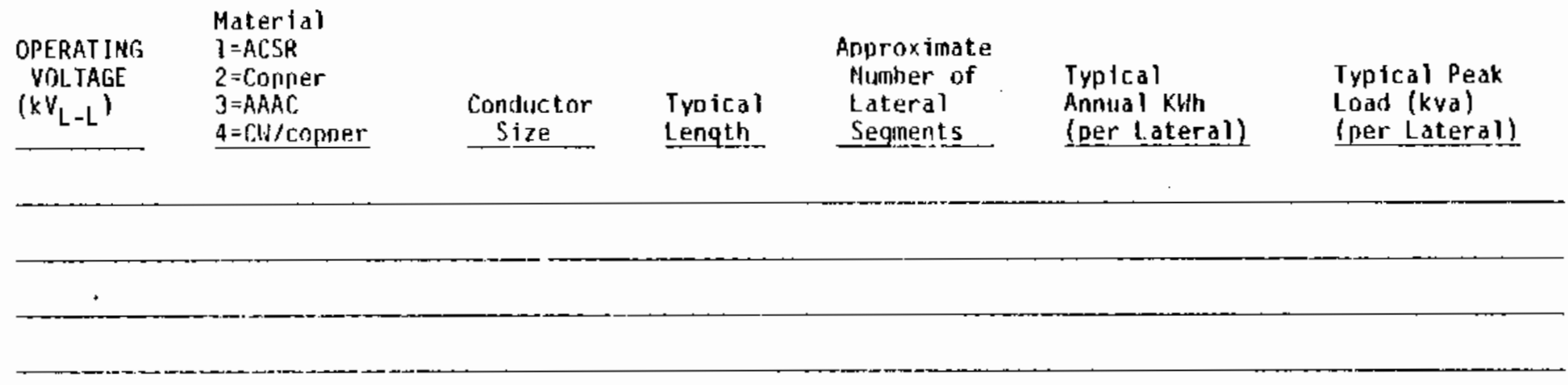




\section{F. IJNDERGROUND DISTRIBITTION LINES}

Instructinos: Please qroup your unferqround distrthution lines by voltage and provide the following information as accurately as possible.

OPERATING

VOLTAGE

$\left(k V_{L-L}\right)$

Typical Approximate

Sequilent Number of

Typical

Annual kWh

Typical Peak

Type Matertal Conductor

Length

Number of
Senments.

(per seqment)

Load (kva)

(per segment)

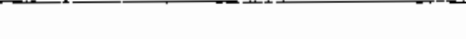


APPENDIX $\mathrm{B}$

BPA REGION UTILITIES BY CLUSTER 
BPA REGION UTILITIES BY CLUSTER

\begin{tabular}{|c|c|c|c|c|}
\hline mint & CODE & TTHE & 'statt & CLUSTEI \\
\hline 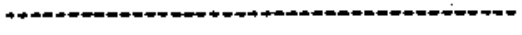 & & & & - - \\
\hline LLDEX MUTUAL LIGHT CONLLAT & vith & 3 & $\mathbf{s h}$ & 1 \\
\hline 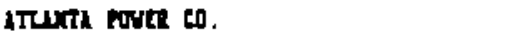 & LL & 5 & t] & 1 \\
\hline oulat eIT ticr & set & 1 & wh & $\mathfrak{t}$ \\
\hline avtert maxteres otsntaviok 5T5Th & suts & 1 & to & 1 \\
\hline Cugt Etectile sokis & CAEB & 1 & OR & a \\
\hline 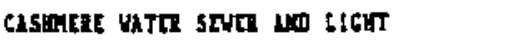 & crst & 1 & vk & 1 \\
\hline CETLLLA RUNICIFAL FYORO & $\cot$ & 1 & Wh & 1 \\
\hline eitr or L5tatuon & CASt & 1 & OR & 1 \\
\hline Cits of Cascade tocks & ccas & 1 & 02 & 1 \\
\hline CITt of Chinti & coct & -1 & $\mathbf{n}$ & 1 \\
\hline CITT OE CHIVTEY & COCE & 1 & w & 1 \\
\hline citT of coutes our & coco & 1 & ith & 1 \\
\hline cith of aecteo & CDED & 1 & 10 & i \\
\hline CiTh of DQALK & $\cosh$ & 1 & OR & $!$ \\
\hline CITY OF ELLESEVURG & $\cos$ & 1 & in & 1 \\
\hline cith or itreast & cor & 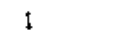 & $i h$ & 1 \\
\hline CITT OE FAREST CROVE & crod & 1 & Oก & 1 \\
\hline CITt oE nisidore & MIM: & 1 & ID & 1 \\
\hline ctits of nomorit & CKDN & 1 & OR & I \\
\hline CIT of PLUnofa & pown & t & 10 & 1 \\
\hline NAKE & $\cos 5$ & ITPPE & STATE & cioster \\
\hline ........................ & $\cdots$ & & $\cdots$ & $\cdots$ \\
\hline CiTt of sonk sprincs & SoOk & I & 10 & l \\
\hline cIT of sonhs & $\operatorname{csin}$ & $\mathbf{i}$ & Vh & 1 \\
\hline CITY Of YEISER & HESA & 1 & ID & 1 \\
\hline C:Tt OE MOALEY & WORL & $\mathbf{i}$ & $\overline{i j}$ & $i$ \\
\hline QtJPoki & DUPT & 1 & in & 1 \\
\hline EKTEHYILLE POYEA RKD LIGKT & EPL & : & $\forall$ & 1 \\
\hline ELAURST MTULL POGLR LHO LIGR & EMPL & J & wh & 1 \\
\hline 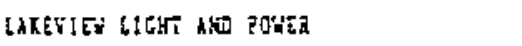 & LLE? & 3 & $\mathbf{u}$ & 1 \\
\hline MCELAAM LICHT ANO gOWER & ret? & 1 & $\omega$ & 1 \\
\hline 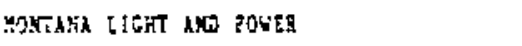 & MLiP & 5 & $\mathrm{nt}$ & i \\
\hline OACAS POWEZ AND LICKT COKPAKT & OPt5 & 3 & Wh & $i$ \\
\hline 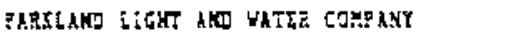 & ?LW6 & 3 & vi & 1 \\
\hline PEWKINSWLA GICT: COKPAM? & PEAt & 3 & wh & $\mathfrak{l}$ \\
\hline RUSTOH :Lsctalc iTILITI & stit & 1 & $v_{\lambda}$ & 1 \\
\hline SAIEM EEECTIS & SE & 3 & GR & l \\
\hline TALOER ELECTRIC & Thrs & $\mathbf{3}$ & Yh & 1 \\
\hline TOW af KILTJN & TOH & 1 & $b i$ & l \\
\hline Tovx of SiEiLdcogr & Tost & โ & in & 1 \\
\hline TONB of HATERTLIE & THAT & I & wh & 1 \\
\hline 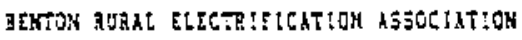 & $\sin 2 \lambda$ & J & पk & 2 \\
\hline بłkE & $\cos 2$ & WTte & STAIE & CLvisin \\
\hline 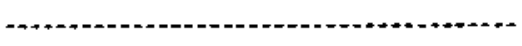 & $\cdots$ & - -... & 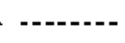 & ---- \\
\hline $316 \quad 3 E x D R \leq A$ & BigR & 3 & ih & $i$ \\
\hline 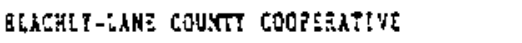 & atce & ; & งa & $?$ \\
\hline PETTRAL ELECThIC COOPSARTIVE & CENC & 3 & OR & $?$ \\
\hline CIT OE RLBION & CAL3 & 1 & IV & I \\
\hline C:TY of Bגkeok & GBUN & 1 & GE & : \\
\hline cttt of Jowkens EER?Y & CBIY & 1 & 10 & I \\
\hline
\end{tabular}




\begin{tabular}{|c|c|c|c|c|}
\hline CITY OT MEYEURK & GEY & 1 & 10 & 1 \\
\hline CLEARVATER POUER COMPANY & CPC & j & [ ] & 1 \\
\hline COLUMEIA AnSIN EteCTRIC COOPERATIVE & eget & 3 & on & : \\
\hline 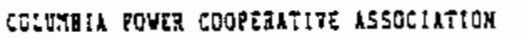 & $\operatorname{cpth}$ & 3 & 吗 & $?$ \\
\hline COCUNSIA RER & COLR & 3 & Wh & 2 \\
\hline 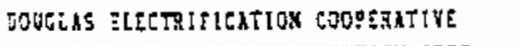 & DEC & 3 & 09 & 3 \\
\hline EAST THO MUTUA ITECTEITICATION COOP & EMEt & i & 10 & $\hat{\imath}$ \\
\hline 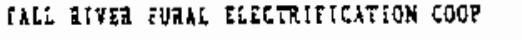 & ONE & 3 & [ง & 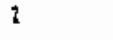 \\
\hline THMES ELECTIC COHLT & otrc & $\mathbf{3}$ & ID & 2 \\
\hline fLATELA Etectilc coap & Fite & ] & int & 1 \\
\hline culth Electric cadp & GeC & 3 & IIT & 2 \\
\hline 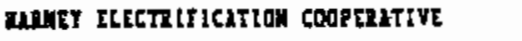 & atc & 3 & al & $?$ \\
\hline HOOD IIVI ELECTIFICATIOS COOPERATIVE & hate & 3 & ar & $i$ \\
\hline 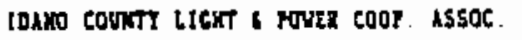 & tets & j & 10 & $\mathbf{I}$ \\
\hline MLME & $\cot$ & VTtRE & $\sin$ & ELISTER \\
\hline - & $\cdots$ & & & \\
\hline KOOTDUI ELECTIFICATION COOPEAT:YE & tet & 3 & 10 & 3 \\
\hline CWE GECTIIC COOEERTITE & the & 了 & or & 1 \\
\hline LIXCOLA II ECTIL COOHERATIVE (IT) & sech & 3 & $\mathrm{nt}$ & $\mathbf{2}$ \\
\hline LIGCOSA GLETTIC COOPERTIVE (VRSH.) & tact & 3 & $\mathbf{W h}$ & 2 \\
\hline LOST REVER GECTIFICATIOK COOPERATIVE & LOST & 3 & 10 & ? \\
\hline MIDSTATE ELECTIIICATIOK COOPERATIVE & net & 3 & od & 2 \\
\hline MITTOK-EREEUTER LIGKT AND MOVER & MrLF & 1 & OR & 1 \\
\hline nISSOULA tLETRIC COOP & niss & 3 & $n \pi$ & 2 \\
\hline YODEAM IESCTR IC WhTE COHPAKY & प्रES & J & Yz & 3 \\
\hline MESPELEM VACLE ELECTRTC COOPEATIVE & NHEC & j & Yh & ? \\
\hline NORTKERK LIGXTS INE. & $\mathrm{BLi}$ & 3 & 10 & 2 \\
\hline 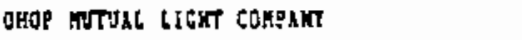 & OHOP & 3 & $\mathbf{Y A}_{\mathbf{A}}$ & 2 \\
\hline OKANOEAN COUXT ELECTIE COQPERATIVE & OCEC & 1 & $w_{h}$ & \pm \\
\hline PGAIRIE FOWER COOPERATIVE & eq5 & 3 & ib & 1 \\
\hline 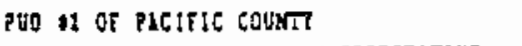 & PACP & $i$ & Wh & $t$ \\
\hline RATT RIVTR GUAL HELTRIC CDOPERATIVE & RAE & I & 19 & : \\
\hline RAYALL ColxTt ELECTht: COo? & RCES & 3 & $\mathbf{k}$ & 1 \\
\hline RIVETSIOE EEICTIC COWFAKY & aEt & 3 & 10 & 3 \\
\hline ZUPERT & RIST & $t$ & [D & 1 \\
\hline IISAL IIECTRIC COHEAYY & RUIE & : & 10 & $?$ \\
\hline NAXE & Cuñ & JT?E & STAI: & Citstet \\
\hline - & & anc..... & $\cdots$ & \\
\hline SALYON RIVER ELECTALC COOSEATIYE & $\mathrm{SEE}$ & 1 & 10 & 3 \\
\hline SIERR ?ACIFIC ?OHE & $5 P:$ & $\vdots$ & 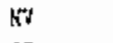 & 1 \\
\hline SOUTN SIDE ELECTRIC LINE & SE:L & $?$ & I5 & 1 \\
\hline 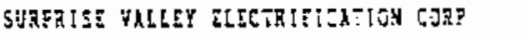 & $3+5$ & 1 & $\mathrm{GH}$ & 1 \\
\hline WIT GICHT AND ROSEA COMPAST & y:?6: & 1 & 10 & 2 \\
\hline VEAR IRQITATIOA DISTRICT & $7 i 0$ & 1 & vil & 1 \\
\hline VIGILARTE ELER COOP & $\ddot{B E}$ & 1 & nt & $i$ \\
\hline 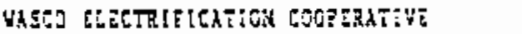 & di & 1 & $\alpha z$ & 1 \\
\hline WELL RUPAL ELEtTaIC COOP & vet: & $i$ & NV & 3 \\
\hline 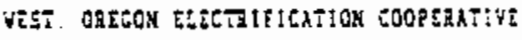 & voze & j & or & 1 \\
\hline CHELAR COUNTY PUD & corta & $?$ & $4 k$ & 1 \\
\hline CIn of kexLewtis: & CMCx & i & OR & 1 \\
\hline CLALAY COUTT PUD & Gist? & : & ith & j \\
\hline CAKS MMEAS POHEA, iNC. & Gak? & 3 & Gâ & i \\
\hline 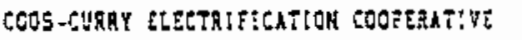 & $\cos$ & $\vdots$ & $\alpha$ a & 3 \\
\hline 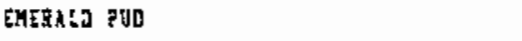 & EME? & $\mathbf{i}$ & 吆 & $\dot{3}$ \\
\hline rERAY COUNT PUD & ica? & : & $i_{k}$ & 3 \\
\hline 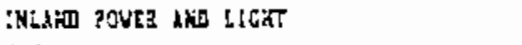 & INR: & 3 & wh & 1 \\
\hline KITITAS COEkTY ?UD & $\operatorname{kIT}$ & 2 & in & 3 \\
\hline KLICXIThI COUXTh eto & KEl? & $?$ & $6 h$ & 3 \\
\hline NAHE & $\cos z$ & GTES & STATE & citstis \\
\hline
\end{tabular}




\begin{tabular}{|c|c|c|c|c|}
\hline \multicolumn{5}{|c|}{$\varepsilon^{*} \bar{g}$} \\
\hline$-9-$ & כד & + & IIYע & YHOJY1--XзSIYY \\
\hline$-8-$ & หว & 9 & DIYY & 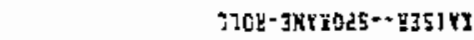 \\
\hline$-p$ & v & $?$ & $\sin y$ & OZY-IKYYOAS--1351YY \\
\hline$-0-$ & 80 & s & YII! & 0.गTEL: \\
\hline-0 & уо & 9 & KE:Hh & 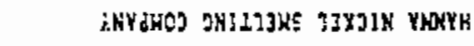 \\
\hline$-n-$ & Y & , & 59 & J3zis 3yoxiา \\
\hline$-8-$ & ED & 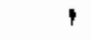 & $32:$ & 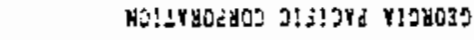 \\
\hline$-8-$ & YA & , & EJYi & 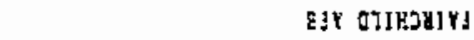 \\
\hline+0 & Yh & $b$ & 300 & OבOANYH 300 \\
\hline$-8-$ & $Y$ & 5 & BKसS & 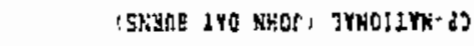 \\
\hline$-n-$ & צץ & $\xi$ & kiz) & J \\
\hline$=0$ & yo & 4 & dyog & SEI3KIOKE 30 C\&OJ \\
\hline-0 & $V_{h}$ & 9 & BHY & LWYUNOS LIONתBOEEY \\
\hline$-8-$ & in & 1 & $\mathrm{HE}$ & KoIIWLYTZZE 20 nY3ine \\
\hline$-\theta$ & 时 & r & HS & 53Nik 10 af 3 tha \\
\hline$-0-$ & ix & 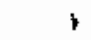 & ANIB & OLYAYA ZIY NYIOH do UnE \\
\hline-0. & H & , & INJa siod & 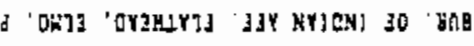 \\
\hline$+\theta$ & so & i & ozrr & iNY \\
\hline$-6-$ & ห⿻ & 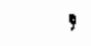 & צ'כו & 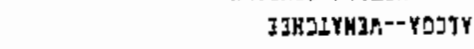 \\
\hline ะ315ดIว & $32 \times 15$ & $32 \lambda L A$ & 3003 & $3 \mathrm{kn}$ \\
\hline$-\theta^{*}$ & YA & , & : & YAACJKYA--YOJTY \\
\hline$-0-$ & YA & 4 & 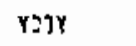 & ACJt--rojtr \\
\hline 4 & Yค & $\xi$ & JAMA & 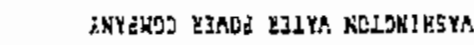 \\
\hline b & In & $\xi$ & $293 \pi$ & \\
\hline$\dagger$ & to & 1 & anies & 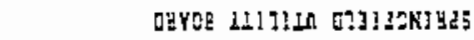 \\
\hline$r$ & 捔 & $t$ & dDK5 & and HSINDHOKS \\
\hline 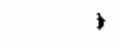 & $Y_{\AA}$ & I & 395 & 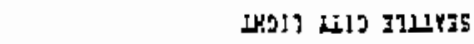 \\
\hline$b$ & Yh & $\xi$ & IZS: & 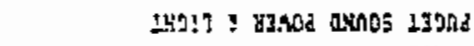 \\
\hline 1 & 180 & $s$ & 3 & 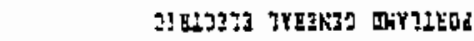 \\
\hline b & al & 5 & 57dd & 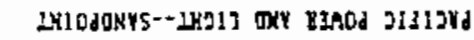 \\
\hline 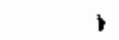 & yo & 5 & 07dd & 3!-A-0--Iysil ory unod JIIIJYd \\
\hline b & 40 & ; & Wda & 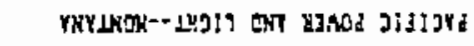 \\
\hline $\mathbf{r}$ & is & $i$ & Kryo & and Luna nrsokrso \\
\hline 十 & ix & 5 & उद्य & 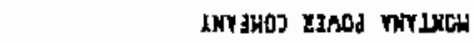 \\
\hline+ & YA & $i$ & tdrh & if and Lunos kOSTR \\
\hline b & 01 & 5 & 2d & 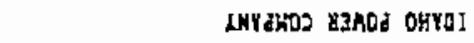 \\
\hline 1 & ס & 1 & 3101 & נדצ' \\
\hline i & YA & $i$ & dIX & 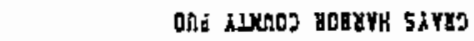 \\
\hline 1 & $\mathrm{Yh}$ & 2 & LEJ & aOd WUNDS LNRE \\
\hline , & in & $\imath$ & dYuJ & OAd WOOD XIJ3NTB3 \\
\hline Bz1SnT2 & 32715 & 3dس & 3000 & $\operatorname{Inx} x$ \\
\hline 1 & Ho & $t$ & 81M & 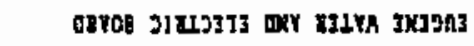 \\
\hline b & หล & I & topo & and Wrnos STI3000 \\
\hline 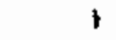 & Y & ? & ans? & 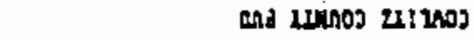 \\
\hline+ & 80 & 2 & แ23 & and IIKYISLII \\
\hline$\vdash$ & YA & 2 & dצב & 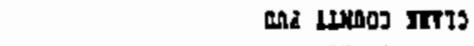 \\
\hline r & $m$ & I & נעוכ3 & 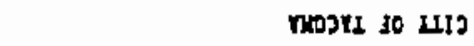 \\
\hline เ & YA & 1 & Idos & 51133x/ $210230 \mathrm{LI}$ \\
\hline$\vdash$ & aI & 3 & IIIJ & ס \\
\hline $\boldsymbol{1}$ & עo & $\tau$ & dחI2 & 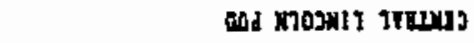 \\
\hline 3 & In & $t$ & axi & an whos wougs \\
\hline $\mathbf{t}$ & th & $\imath$ & dith & atd waes masivth \\
\hline ! & ED & E & voln & 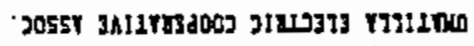 \\
\hline t & aO & 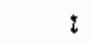 & 211 & and xoour?112 \\
\hline$\varepsilon$ & in: & : & iYx5 & 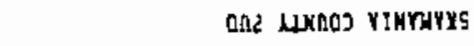 \\
\hline £ & $\psi_{f_{t}}$ & 1 & 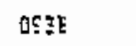 & 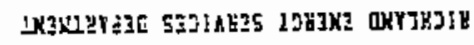 \\
\hline$\varepsilon$ & พs & $\mathfrak{t}$ & 2206 & ane luncs ingizuc axid \\
\hline$r$ & Eto & t & d & and Wenos osske Nitylagh \\
\hline$\xi$ & YP & $t$ & idrk & It and LLRnCJ nosw \\
\hline E & LA & [ & $1 E A T$ & 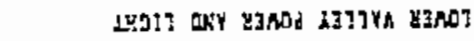 \\
\hline t & Y⿻ & $i$ & $2 \times 37$ & 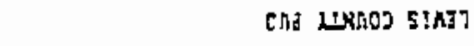 \\
\hline
\end{tabular}




\begin{tabular}{|c|c|c|c|c|}
\hline 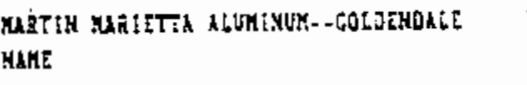 & $\begin{array}{l}\text { Muc } \\
\text { CODE }\end{array}$ & inteE & $\begin{array}{l}\text { Jik } \\
\operatorname{sintE}\end{array}$ & $\begin{array}{l}\text {-7- } \\
\text { CLUST:B }\end{array}$ \\
\hline--- & $\cdots$ & - & -- & - \\
\hline MART:N MRIETL--THE JALLES & [T:AD & 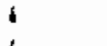 & on & $-8-$ \\
\hline QAECON NETALURGICAL COAPORATION & OHC & 1 & 0ล & $-9-$ \\
\hline 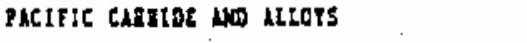 & $\mathbf{r e d}$ & 6 & OR & $-4-$ \\
\hline 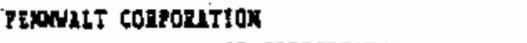 & PC & 6 & OQ & $-8-$ \\
\hline PORT TONSED Rape CORPORTATIOK & 67 & 6 & or & $-4-$ \\
\hline 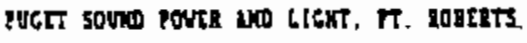 & Psta & s & Wh & -4 \\
\hline REYWOLDS ATTALS EOKRAKT--LONGVICN & RHCL & 1 & ix & $-8-$ \\
\hline 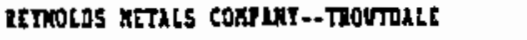 & Exct & 6 & on & $-9-$ \\
\hline U5X, ISX SHLTMED, "SSX COKFLEI USA RADLO & U5N & 1 & Wh & $-0-$ \\
\hline viteon count gro & Mhe & 2 & $V_{\lambda}$ & $-9-$ \\
\hline
\end{tabular}

(a) Type of utility: 1 = municipal; 2 = public utility district; $3=$ cooperative or other public; 4 = federal; $5=$ privately owned; 6 = direct service industry.

(b) "State" refers to the state in which the greatest portion of a utility's service area lies, and/or the state in which its corporate headquarters are located.

(c) See Appendix D for explanation of cluster. A " 0 " indicates that the customer was not included in the 4-category clustering used for estimation of the regional stock of distribution system components. 
APPENDIX C

NAMES OF VARIABLES OR ATTR IBUTES USED IN DATA BASES 
I. INVTRY DATA BASE

ADDRESS1, ADDRESS2 Utility mailing address

ALLID

Comprehensive utility identification information

ANNGEN

Annual requirements file for NW Power Pool (generating) customers, MW, 1978 to 1983

averiwent

Average annual megawatts, required power

calweeks

Number of weeks in requirement reporting period

CITY

Location of utility headquarters

CODE

Four letter code used for utility identification

COMCUST

Number of commercial users served annually by utility

COMMERC

Annual sales to commercial users by atility

CONTACT

Name of utility or organization representative contacted by CSEI staff

CUSTNO.1

Customer (utility) number assigned to BPA in annual sales files

CUSTNO.2

Customer number assigned by BPA in monthly sales files

CUSTNO.3

Customer number assigned by BPA to utilities in FILE3

(annual requirements, fult service customers)

CUSTN0.4

Customer number assigned by BPA to utilities in FILE4

(energy requirements of generating utilities)

OATATYPE

Boolean value $(1,2)$ used to identify a row of data as number of consumers or sales (by sector)

DELPT

BPA power delivery point

DOMCUST

Number of domestic users served annually by utility 


\begin{tabular}{|c|c|}
\hline DSIREQS & $\begin{array}{l}\text { Annual requirements for direct service industries, MWh, } \\
1978-1984\end{array}$ \\
\hline DOMESTIC & Annual sales to domestic users by a utility \\
\hline FEDS\&R & $\begin{array}{l}\text { Annual deliveries to federal customers by delivery } \\
\text { points }\end{array}$ \\
\hline FERC & Federal Energy Regulatory Comission utility category \\
\hline FILEl & $\begin{array}{l}\text { Corrected annual sales file for BPA customers, MWh, } \\
1978-1983\end{array}$ \\
\hline FILE3 & $\begin{array}{l}\text { Corrected annual requirements file for BPA preference } \\
\text { customers, MWh, } 1978 \text { to } 1983\end{array}$ \\
\hline FILE4 & $\begin{array}{l}\text { Corrected annual requirements file for NW Power Pool } \\
\text { Customers, MWh, } 1978 \text { to } 1983\end{array}$ \\
\hline GROUP & East or West group, BPA \\
\hline hour & Hour at which peak daily demand occurred \\
\hline INDCUST & Number of industrial users served annually by a utility \\
\hline INDUSTRY & Annual sales to industrial users by a utility \\
\hline I0U83 & Nw Power Pool customers requirements data file, 1983 \\
\hline IOUS\&R & $\begin{array}{l}\text { Combined sales and requirements file for NW Power Pool } \\
\text { customers, by consumer sector, } 1978 \text { to } 1983\end{array}$ \\
\hline IRRCUST & Number of irrigation users served annually by a utility \\
\hline IRRIG & Annual sales by MWh to irrigation customers \\
\hline month & Month in which requirement was measured (integer 1-12) \\
\hline NAME & Utility name \\
\hline NAMENUMS & Utility names with BPA sales and requirements ID numbers \\
\hline NUMBER & Tabulation of utility codes by cluster number \\
\hline OFFICE & BPA area office to which a utility is assigned \\
\hline OTHCUST & $\begin{array}{l}\text { Number of unclassified users served annually by a } \\
\text { utility }\end{array}$ \\
\hline OTHER & Annual sales to unclassified users by a utility \\
\hline
\end{tabular}


peakmo

peakmw

peakreq

PHONE

PREQ83

PUBS\&R

PU8S\&R83

region

REQMWH

REQPEAK

rpday, rpmonth

SALESMWH

SALES83

SECS\&R

STATE

SUBJECT

TITLE

TOTCUST

UTYPE
Month in which highest peak requirement by a direct service industry (DSI) customer occurred

Peak requirement, in megawatts

Peak requirement of a DSI customer in a given year, in megawatt hours

Utitity phone number

Preference customers requirements data file, 1983

Combined sales and requirements file for preference customers by consumer sector, 1978 to 1983

Same as PUBS\&R except for 1983 on ty

Boolean value for utility requirements data to indicate purchases for services areas within or outside BPA regions

Total annual requirement of a utility, in megawatt hours Peak requirement in megawatt hours, generating utilities Day and month in which peak requirement (megawatts) was received for generating utilities

Total annual sales of a utility, in megawatt hours 1983 sales by consumer sector, all 8PA customers

Annual sales and requirements by consumer sector for secondary customers (nongenerating utilities that purchase power from other P8A customers), 1978 to 1983

Two letter code to identify state in which utility operates

Text field describing purpose of utility or organizations contact by CSEI staff

Organizational title of person contacted by CSEI staff Total number of users (all sectors) served annually by a utility

Type of utility: 1 = municipal; 2 = cooperative; $3=$ public utility district; 4 = federal, $5=$ investorowned utility; 6 = direct service industry 


\begin{tabular}{|c|c|}
\hline YEAR & $\begin{array}{l}\text { Year for which data in row are recorded }(76=1976 \text {, } \\
77=1977 \text {, etc.) }\end{array}$ \\
\hline ZIPCODE & Zipcode of utility headquarters \\
\hline I I. QUUEST DATA BASE & \\
\hline LOSTPCT & Total system loss as estimated by utility \\
\hline QALLOCBY & $\begin{array}{l}\text { Basis of utility estimate of loss allocation by system } \\
\text { component }\end{array}$ \\
\hline QCONTENT & Talley of responses by portion of the survey \\
\hline QCOUNT & Tally of utilities that responded to the survey \\
\hline QEQREPL & Utility equipment replacement information from survey \\
\hline QLOSSBP\% & $\begin{array}{l}\text { Percent of estimated losses attributed to bulk power } \\
\text { system }\end{array}$ \\
\hline QLOSSOTS & $\begin{array}{l}\text { Percent of estimated losses attributed to distribution } \\
\text { transformers }\end{array}$ \\
\hline QLOSSES & $\begin{array}{l}\text { Utility's estimate of the allocation of system losses by } \\
\text { component }\end{array}$ \\
\hline QLOSSEST & $\begin{array}{l}\text { Subset of QLOSSES with annual sales and requirements } \\
\text { from CSEI sales and requirements files }\end{array}$ \\
\hline QLOSSF $\%$ & $\begin{array}{l}\text { Percent of estimated losses attributed to primary } \\
\text { feeders }\end{array}$ \\
\hline QLOSSSS\% & $\begin{array}{l}\text { Percent of estimated losses attributed to secondary } \\
\text { feeders }\end{array}$ \\
\hline QLOSSUN\% & Percent of estimated losses attributed to unknown source \\
\hline QLOST/S\% & $\begin{array}{l}\text { Percent of estimated losses attributed to substation } \\
\text { transformers }\end{array}$ \\
\hline QLRCOM & $\begin{array}{l}\text { Comment by utility on recently installed or planned loss } \\
\text { reduction measures (text) }\end{array}$ \\
\hline QPODPF & $\begin{array}{l}\text { Utility's estimate of average power factor at point of } \\
\text { delivery (POD) }\end{array}$ \\
\hline QTRNDCOM & Comment by utility on expected system loss trends (text) \\
\hline
\end{tabular}


The following attributes contain boolean values to indicate the receipt of information on a given portion of the survey questionnaire. The attributes also represent categories of subattributes, not listed here, that hold coded or verbatim information from portion of the questionnaire indicated by the attribute name.

QEQPREPL

QLOSS

QPARTB

QREPORTS

QREQS

QSYSCHR
Equipment replacement practices and/or plans

Estimates of system loss by component

Component characterization information on Part $B$ of questionnaire

Annual business reports

Utility-reported annual requirements in $\mathrm{MWH}$ and source 1982 and 1983

Power factor information

III. SYSTEMS DATA BASE

Annuat Load

Capacity

Code

Cluster Number

DT-AVG

DTCORR

DTRAN

Efficiency

ID Name

KV
Annual energy handled by a component, usually megawatt hours

Either the nameplate rating, or the generally assumed safe, maximum continuous power handling ability of a device, usually kilovolt-amperes

Four letter code for utility (text)

Integer between 1 and 4 that indicates the utility cluster of each customer (see Appendix C)

File of transformers classified by size category, average operating characteristics, and efficiencies (LoTUS file)

Lotus file of QDTRAN, with apparent errors corrected (L.OTUS file)

Original unedited file of distribution transformer data from survey (LOTUS file)

The ratio of the power output of a component to the power input

Utility-assigned name to a distribution system component Operating voltage, kilovolts 
Length

Load Factor

Losses

Loss Factor

Load Loss

Material

No Load Loss

Number of Units

Peak

Power Factor

Q Number

QDTRANI

QISQR (Loss Scale)

QLATERAL

QOVERH4

QOVERH4A

QSTRAN2

QTLINE

Recovery

Resistance
Conductor length, circuit miles

The average loading of a component in per units of peak loading

The energy dissipated by a distribution system component, usually expressed in kilowatt-hours

The average loss of a component in per units of peak loss

The copper or winding losses in a transformer, watts or ki lowatts

Conductor materia 1

The iron or core losses in a transformer, watts or kilowatts

Item count

Peak loading, usually kilovolt-amperes

Ratio of apparent power to active power

Integer for utility identification in SYSTEMS

Edited file of distribution transformer information (RBASE relation)

A relative loss measure used in analysis, unitless

Secondary feeder information from the survey (RBASE relation)

Edited file or primary feeder information (RBASE relation)

Lotus file of RBase file of same name (LOTUS file)

Edited file of substation transformer information (RBASE relation)

Transmission line information frorn the technical portion of the survey (RBASE relation)

The estimated energy that would be saved by a given action, usually in average annual megawatts

Ratio of voltage to current, ohms/rite 
ST-CORR

STCS83

ST -EFF

ST-LOSS

STR4L

STR $4 M$

STR4S

TLCLOSS

TLCORR
Lotus file of QSTRAN2 with apparent errors corrected (LOTUS file)

ST-CORR file combined with 1983 customer sales

information (LOTUS file)

Same as ST-CORR with estimated transformer efficiencies (LOTUS file)

File with estimated losses for each reported substation transformer

Subset of ST-EFF, large size transformers (LOTUS file)

Subset of ST-EFF, medium size transformers (LOTUS file)

Subset of ST-EFF (category labeled "small") (LOTUS file)

Estimated loss per circuit mi le of sample transmission lines (LOTUS file)

Transmission line operating characteristics, standardized (LOTUS file) 
APPENDIX D

CLUSTER ANALYSIS 
APPENDIX D

CLUSTER ANALYSIS

INTRODUCTIDN

There are 170 customers within the BPA service area covering all or part of seven states. Most of these customers are utilities that purchase power from BPA. The utilities range in size from large investor owned companies with over 1 million residential customers to very small municipal and cooperative systems serving less than 500 customers. In order to reduce the variation in distribution system characteristics that results from this diversity, similar utilities were grouped into clusters. Dne hundred and forty seven BPA customers $(a)$ were grouped into strata based on cluster analysis of the customer sector (domestic, irrigation, commercial, industrial and other) sales data, utility type (municipal, PUD, cooperative, IOU, and federal), and magnitude of total sales. The clustering program used, called CLUSTER, was developed by Marshall and Romesburg at Utah State University. The basic data for each utility were the MWh sold in each of the five consumer sectors: domestic, irrigation, commercial, industrial, and other. Thus, each utility was represented by a vector of five observations, and the measure of dissimilarity between utilities was the Euclidean distance in the 5-dimensional space. The clustering algorithm used was an unweighted pair group method based on average distance between current clusters (referred to as UPGMA in the literature).

Preliminary analysis of the data revealed that the observations for each customer sector were highly skewed, with half of the observations being less than $1 \%$ of the maximum for each customer sector. In order to avoid standardizing (levelizing) with arithmetic averages that did not represent the centers of the distributions, the data were transformed by taking their natural (base e) logarithm, which produced a more normal (Gaussian) distribution. A standard

(a) Individual sales records were not available for the remaining 23 customers, which are federal agencies and small utilities that purchase power from other BPA customers. 
normal distribution was then developed from the "In" transformed data by subtracting the mean and dividing by the standard deviation, which produced data for clustering that were on about the same scale as standard normal deviates.

The clustering algorithm defined $g$ clusters with 5 to 59 members (utilities) each. These 9 clusters were reorganized to account for utility types (municipal, PUD, cooperative, IOU, and federal). The original clusters reflected the size (total MWh sales for 1982) of the utilities, and this was maintained in the reorganization into strata.

Figure D.1 provides an indication of the face validity of the defined strata. These "boxplots" summarize the distribution of the total MWh for the utilities included in each stratum. The "box" contains $50 \%$ of the observations, with a plus sign marking the median. The "whiskers" reach out to include "close" observations. An observation moderately separated from the "whiskers" is marked with an asterisk and is called "out" and a more separated observation is called "far out" and marked with an " 0 ". These terms have precise definitions in terms of the spread, or the distance between the upper and lower quartiles (called "hinges"). The upper whisker extends to the last observation falling within the upper hinge +1.5 (spread), an observation between the upper hinge +1.5 (spread) and upper hinge +3.0 (spread) is "out," and a point beyond this is "far out." Similar definitions hold at the lower end of the boxplot.

The Unclassified Stratum is a catch-all stratum that includes the two smallest utilities (Atlanta and Minidoka) and one of the largest (Seattle). It is composed of the late-joiners in the clustering and so includes the "unusual" utilities. The boxplot in Figure D.1 reflects this diversity. The other strata group utilities hased on the cluster analysis and the logical analysis of the utility types. Three of the strata $(5,6$ and 9,) have mixed utility types. There is some overlap in the boxplots, but they do add to the face validity of the stratification, and to the names assigned to the strata. The strata appear to strike a good balance between the customer sectors served, the type of utility ownership, and the overall size of the utility. 


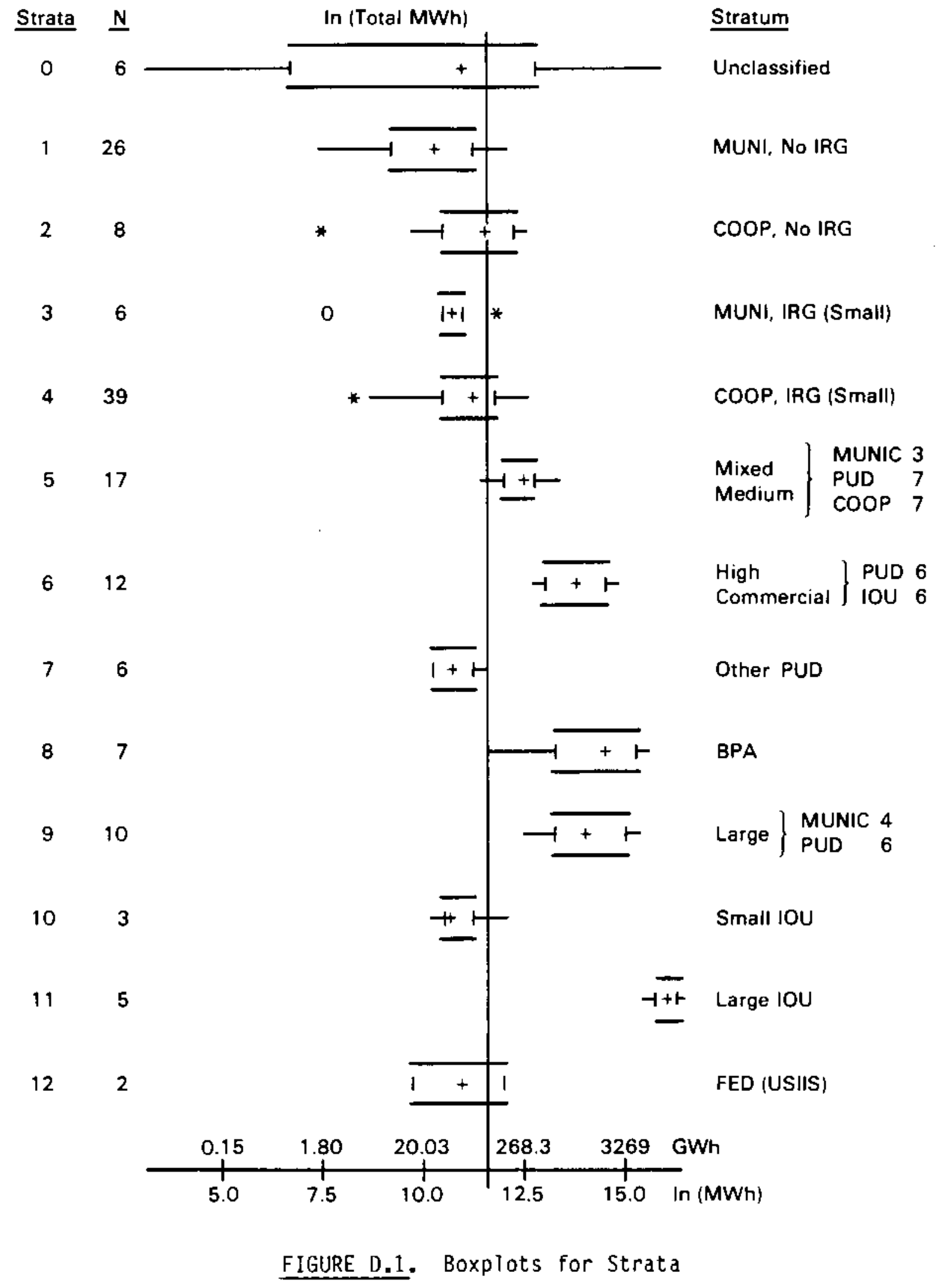


Table D.1 organizes the strata by percentage of total MWh sold. Since Seattle accounts for most $(92.7 \%)$ of the total MWh for Stratum 0 , it is separated out, ranking tenth among all groups. The 3D utilities (20.4\%) of the first six rank groups account for only $2.4 \%$ of the total MWh. By itseif, Seattle sells almost as much electricity as the 95 utilities in the first eight rank groups. The six High Commercial Utilities (Stratum 6 and rank group 11) have total sales twice as large as Seattle's. BPA's direct service customers used about the same amount of electricity as the 10 Large Municipal and PUD utilities. Finally, the five Large IOUs account for more than one-third (38\%) of the total, equivalent to the total usage of the 139 utilities excluding BPA and Seattle.

IABLE D.1. Strata Ordered by Total GWh Sold

\begin{tabular}{|c|c|c|c|c|c|c|c|c|c|}
\hline Rank & Tota i G!H & Stratum & 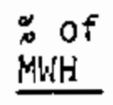 & $\begin{array}{c}\stackrel{c}{o} \text { of } \\
\text { Utilities }\end{array}$ & $N$ & Stratum & $\begin{array}{l}\text { CUM } \\
\text { il } \\
\end{array}$ & $\begin{array}{l}\text { CUM } \\
\text { iniH s }\end{array}$ & $\begin{array}{r}\text { Cu. } \\
\approx \\
\approx\end{array}$ \\
\hline I & 239 & 12 & 0.2 & 1.4 & 2 & USIIS & 2 & 0.2 & $\therefore .4$ \\
\hline 2 & 254 & 10 & 0.2 & 2.0 & 3 & Small IOU & 5 & 0.4 & 3.4 \\
\hline 3 & 392 & 3 & 0.3 & 4.1 & 6 & MUNI, IRG & 11 & 0.7 & 7.5 \\
\hline 4 & 398 & 7 & 0.3 & 4.1 & 6 & Other PUL & i7 & 1.0 & $\because \therefore \varepsilon$ \\
\hline 5 & 627 & $\begin{array}{c}0 \\
\text { Other }\end{array}$ & 0.5 & 3.4 & 5 & Unclassitied & 22 & 1.5 & 15.0 \\
\hline 6 & 1,144 & 2 & 0.9 & 5.4 & 8 & COCP, NO IRG & 30 & 2.4 & 20.4 \\
\hline 7 & 1,308 & 1 & 1.0 & 17.7 & 26 & MUNI, No. IRG & 56 & 3.4 & .38 .1 \\
\hline 8 & 4,056 & 4 & 3.1 & 26.5 & 39 & COOP, IRG & 95 & 0.5 & 64.6 \\
\hline 9 & 5,696 & 5 & 4.3 & 11.6 & 17 & Mixed, Med. & 112 & 10.8 & 75.2 \\
\hline 10 & 7,918 & $\begin{array}{c}0 \\
\text { Seattle }\end{array}$ & 6.0 & 0.7 & 1 & Seattle & 123 & 16.8 & 75 \\
\hline 11 & 16,060 & 6 & 12.1 & 8.2 & 12 & High Commercial & 125 & 28.9 & $8 E .1$ \\
\hline 12 & 21,401 & 9 & 16.2 & 6.8 & 10 & Lârge MilUNI + Pl!C & 135 & 45.1 & $9 i .9$ \\
\hline 13 & 21,871 & 8 & 16.5 & 4.8 & 7 & $B P A$ & 142 & 61.6 & $\varrho_{\hat{C}} \hat{\mathrm{T}} . \overline{\mathrm{T}}$ \\
\hline 14 & 51,016 & 11 & 38.5 & 3.4 & 5 & Large IOU & 147 & $100.1^{\mathrm{a}}$ & $100.1^{\mathrm{a}}$ \\
\hline
\end{tabular}

(a) Column totals do not add exactiy to $100 \%$ due to rounding. 
The stratification provides a logical organization of the utilities into groups for characterizing "similar" utilities. The method of stratification was based on sales to customer sectors and utility ownership, so that "similarity" is defined in terms of these characteristics, which have some face validity as indicators of similar energy loss patterns. But energy loss is a function of the hardware (i.e., lines and transformers) in each utility's distribution system. A major goal of the stratification is to reduce the scope of the data collection effort by reducing the number of utilities for which detailed hardware inventory data are collected. Under the reasonable assumption that energy losses are roughiy proportional to sales, the larger utilities will have the largest losses.

The cluster analysis was based on an order-preserving transformation of the MWh sales to customer sectors. This transformation preserved the size of the utility as an important factor, and the consideration of type of utility ownership in the definition of the final stratification brought in another factor that could influence loss control policy (if not actual losses). This is not the only approach that could have been used. It was chosen because this approach appeared to provide the best hope for defining strata that would be least sensitive to errors in the data and most accurate for MWh loss estimation, given the data available. Other variables considered were: $k$ wh divided by number of customers, number of customers, and percentage of total sales in each sector. The cluster analysis was done for the percentage of total sales in each sector data resulting in (again) 9 clusters with 2 to 46 utilities per cluster. Since percentages of a tota) are interdependent (e.g., if the domestic sector accounts for $75 \%$ of the total MWh, no other sector can account for more than 25\%), these clusters did discriminate more exactly in terms of customer sector mix than the transformed MWh data. Both clusterings had BPA direct service customers and the two U.S. Interior Indian Services customers (USIIS) well separated from the other utilities, and utilities with no, or very low, sales in a particular sector grouped together. An example of a major difference was that the five Targe IOUs constituted a distinct cluster in the Mwh clustering but were buried among the cluster with 46 utilities in the percentage based approach. 
Valid loss data for the regression analysis were avajlable for 117 of the 147 utilities used in the cluster analysis. Four strata from Figure 0.1 were not included in the regression analysis. The seven BPA groups, Stratum 8, of direct service industries are planned for special handling as separate stratum, along with Whatcom PUD (Utility Code 482), from the Unclassified Stratum 0. The three Small IOUs, Stratum 10, and the two USIIS, Stratum 12, have no loss data. The Unclassified Stratum, 0, had two utilities with no loss data; Seattle and Idaho Falls were moved to Stratum 11 to join the large IOUs; and Minidoka, a small utility with a large (16.7\%) loss, was removed from the analysis. The remaining 16 utilities with no loss data were distributed among the original strata. These revised strata, including only the 116 utilities with loss data, did not have enough utilities for stratum-by-stratum regression analysis so they were aggregated into four groups, as defined in Figure 0.2. Figure 0.3 shows the boxplots of In (MWh Total) for the four groups which were used in the supply curve analysis.

The variable

$$
\text { TINDEX }=\text { M2 = (Circuit Miles } / N \text { Customers) (\% Self-Generation) }
$$

was also used in developing the estimation equations. Two other indicators of extent of transmission involvement were also used:

$$
M 1=\ln (\text { Circuit Miles) }
$$

and

$$
M 3=\ln [(\text { Circuit Miles } \times \% \text { Self-Generation }) / 100]
$$

The full statistical model fitted to these data was

$$
\begin{aligned}
\ln (L)= & a+b_{1} M 3+b_{2} L D O M+b_{3} L I R G+b_{4} L C O M \\
& +b_{5} L I N D+b_{6} L O T R E+e
\end{aligned}
$$




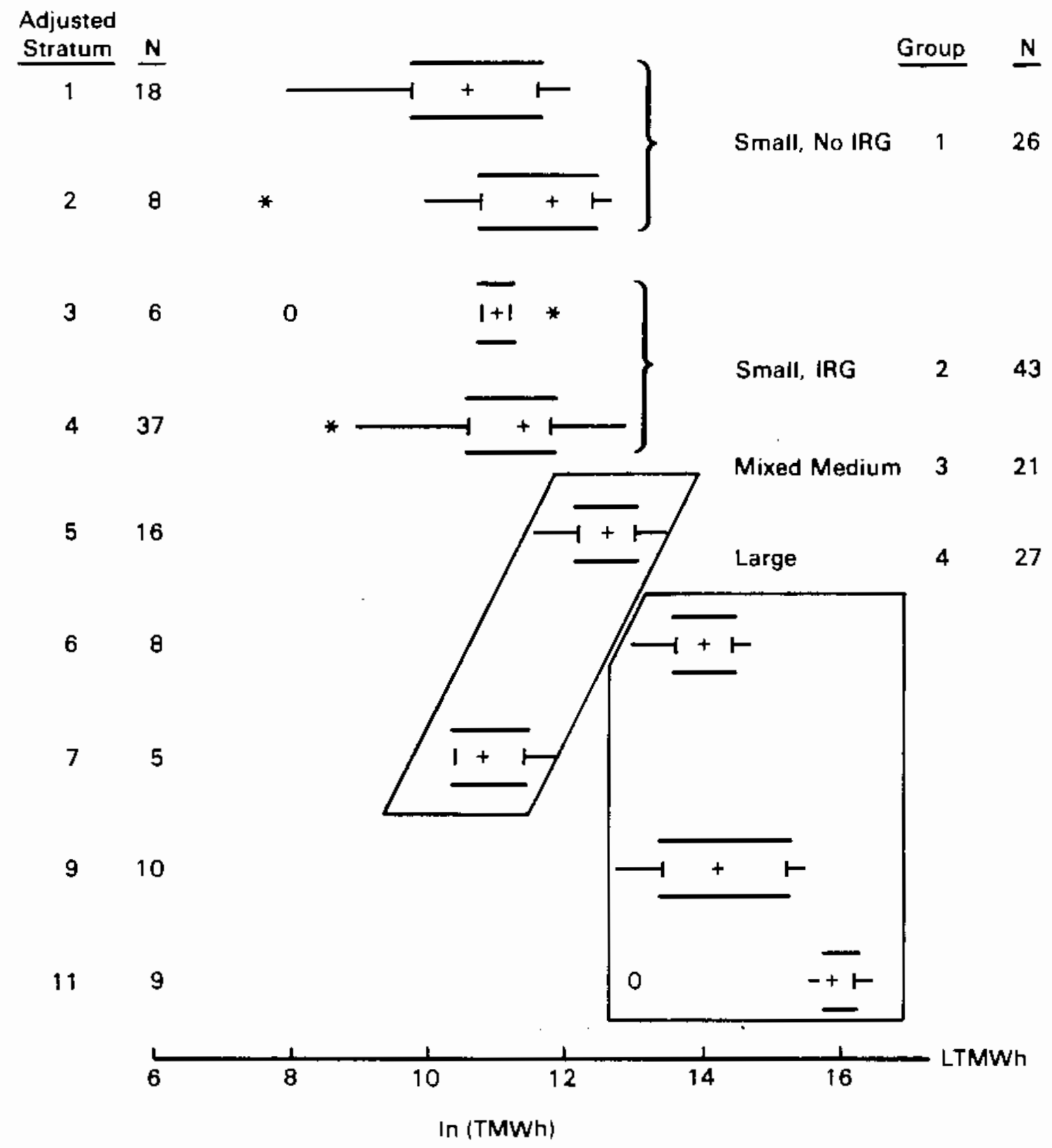

FIGURE D.2. Boxplots for the 117 Utilities with Loss Data, by Adjusted Strata 


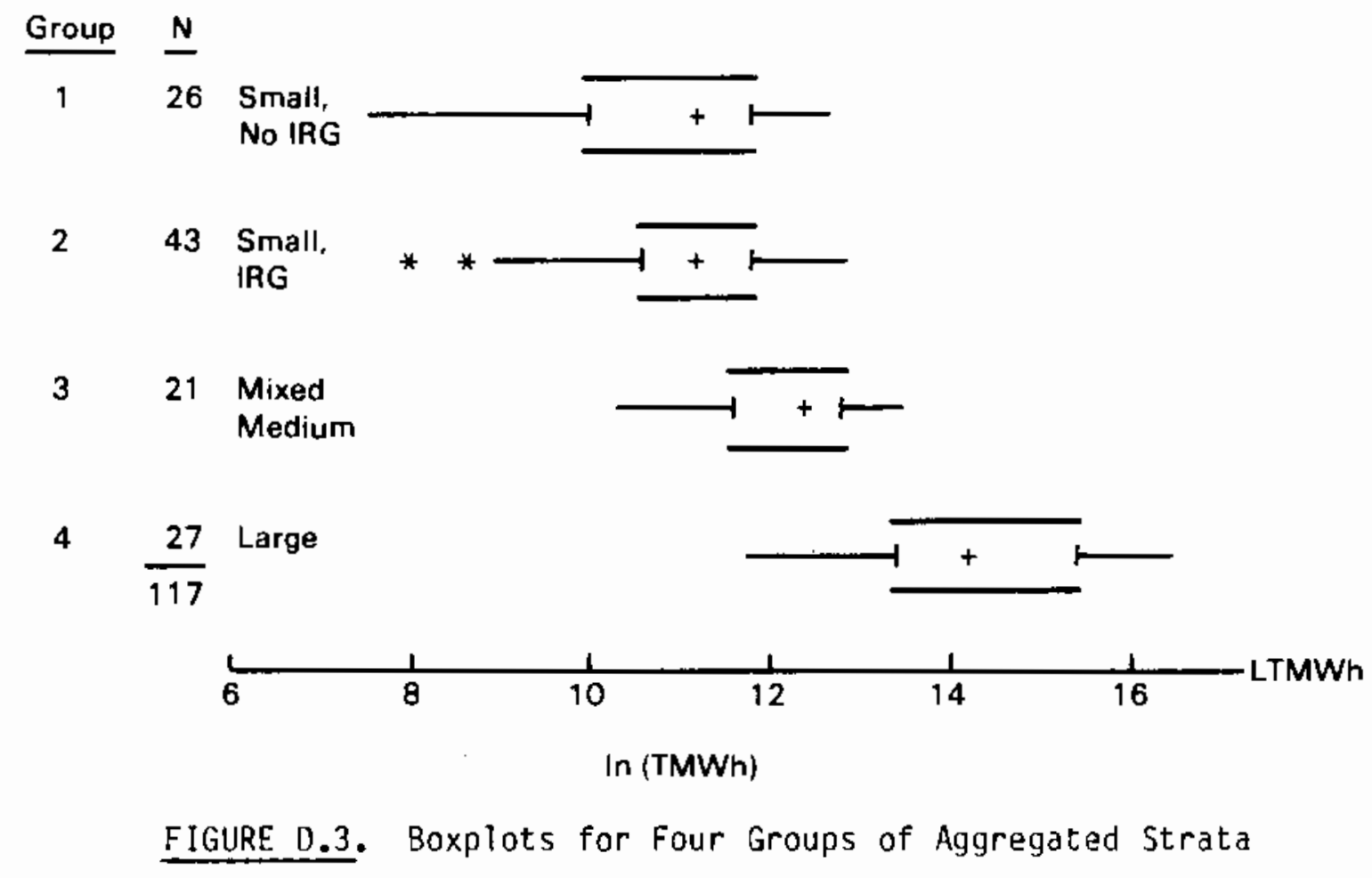

where $M 3$ is the third transmission index defined above (when a utility had no data on self-generation, M3 was set to zero), LDOM, ..., LTOR are the natural logarithms of the MWh sales to the five customer sectors

$a, b_{1}, \ldots, b_{6}$ are the regression coefficients to be estimated by mini mizing the sum of squares of $e$, the residual from the fit $\ln (L)$ is the natural logarithm of the utility's loss

The system loss, L, was calculated as the difference between the GWh required from the BPA grid (plus self-generation) and the total GWh sold (or for the utility's own use) by the utility as reported by the utility.

This model (Equation D.1) was fitted to all of the 117 utilities with loss data and to each of the four groups separately. All of the 16 utilities with self-generation data were in Group 4. The results are given in Table 0.2.

The procedure used was to fit the full model, determine which coefficients were statistically different from zero, remove their carrier (independent) 
TABLE D.2. Suminary of Fits of $\ln$ (Loss, GWh) to $\ln$ (Sector Sales) and $M 3$

\begin{tabular}{|c|c|c|c|c|c|c|c|c|c|c|c|c|c|}
\hline \multirow[b]{2}{*}{ Grouta } & \multirow[b]{2}{*}{$\underline{N}$} & & \multicolumn{8}{|c|}{ Estinated Coefficients } & \multirow{2}{*}{$\begin{array}{l}\text { Adj. } \\
\mathrm{R}^{2} \\
\end{array}$} & \multirow[b]{2}{*}{ sd(Pesid) } & \multirow[b]{2}{*}{ 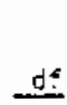 } \\
\hline & & & a & M3 & 100:4 & LIRC & LCLOY & LIIHE & LOTR & LSOL & & & \\
\hline ALL & 117 & Coeff. & $\begin{array}{l}-6.656 \\
-8.66\end{array}$ & $\begin{array}{l}0.12206 \\
3.96\end{array}$ & $\begin{array}{l}0.70898 \\
0.18\end{array}$ & $\begin{array}{l}0.07030 \\
5.92\end{array}$ & $\begin{array}{l}0.10465 \\
1.32\end{array}$ & $\begin{array}{l}0.03389 \\
2.48\end{array}$ & - & & $\begin{array}{l}91.5 \\
91.5\end{array}$ & $\begin{array}{l}0.5277 \\
0.5325\end{array}$ & $\begin{array}{l}111 \\
110\end{array}$ \\
\hline 1.1 & 26 & $\begin{array}{l}\text { Coeff. } \\
t\end{array}$ & $\begin{array}{l}-7.972 \\
-8.56\end{array}$ & $\star$ & $\begin{array}{l}0.37031 \\
9.67\end{array}$ & * & $(0.65)$ & $(0.21)$ & $(0.71)$ & & 78.7 & $\begin{array}{l}0.6625 \\
0.6329\end{array}$ & $\begin{array}{l}2 \div \\
2 i\end{array}$ \\
\hline 1.2 & 26 & Coeff. & $\begin{array}{l}-2.575 \\
-7.37\end{array}$ & $\star$ & & $*$ & & & & $\begin{array}{l}0.00549 \\
10.05\end{array}$ & 81.3 & $0 . \equiv 527$ & 24 \\
\hline 2 & 43 & $\begin{array}{l}\text { Coeff. } \\
t\end{array}$ & $\begin{array}{l}-6.540 \\
-9.56\end{array}$ & * & $\begin{array}{l}0.63923 \\
0.90\end{array}$ & $\begin{array}{l}0.14408 \\
5.67\end{array}$ & $\langle 0.65)$ & $\begin{array}{l}0.6652 \\
3.93\end{array}$ & $(1.10)$ & & $\begin{array}{l}86.9 \\
87.0\end{array}$ & $\begin{array}{l}0.3579 \\
0.3569\end{array}$ & $\begin{array}{l}39 \\
37\end{array}$ \\
\hline 3 & 21 & $\begin{array}{l}\text { Cooff. } \\
t\end{array}$ & $\begin{array}{l}-8.662 \\
-5.17\end{array}$ & * & $\begin{array}{l}0.9435 \\
5.43\end{array}$ & $\begin{array}{l}0.13801 \\
3.82\end{array}$ & $(1.46)$ & $(-0.52)$ & $\begin{array}{l}-0.11594 \\
-2.03\end{array}$ & & $\begin{array}{l}79.0 \\
79.2\end{array}$ & $\begin{array}{l}0.4173 \\
0.4751\end{array}$ & $\begin{array}{l}17 \\
15\end{array}$ \\
\hline 4 & 27 & $\begin{array}{l}\text { Coeff. } \\
t\end{array}$ & $\begin{array}{l}-5.416 \\
-3.83\end{array}$ & $\begin{array}{l}0.18208 \\
4.41\end{array}$ & $\begin{array}{l}0.7219 \\
6.53\end{array}$ & $\{1.24\}$ & $\overline{(-1.47)}$ & $(0.11)$ & $(-0.24)$ & & $\begin{array}{l}85.4 \\
85.1\end{array}$ & $\begin{array}{l}0.6035 \\
0.5939\end{array}$ & $\begin{array}{l}24 \\
20\end{array}$ \\
\hline
\end{tabular}

\footnotetext{
Notes

- means ail data mere zero for this variable in this group

- means the variable was not statistically significant in the fit to tre full model

$t$ the values in the $t$ row ars the Stucent's t statistic for the coefficient above it. li there is a dash above it, then it is parenthesized to indicate that is the t-value from the full model. A coefficient was judged "non-significant" if its t-vaiue was in the interval.$+ i .5$, which includes about $85 \%$ of the expected valuss of $t$ when the true coefficient is zero. The $\bar{R}^{6}$ and sd(Resid) in the trow are the for the full model.
}

variable and rerun the regression. (The MINITAB statistical software package was used to do the analyses.) As noted at the bottom of Table 0.2, the critical t-value used for judging significance was \pm 1.5 , which is about the 85 th, two-sided percentile of the t-distribution.

Only the LOTR carrier in the fit of the full model to all 117 utilities was judged to produce a nonsignificant contribution to the fit (t-value of -0.81 ). Its removal had no effect on the adjusted $R^{2}$, which is approximately the percentage of total variability in $\ln$ (Loss) accounted for by the fit. The "sd(Resid)" column is the standard deviation of the residuals, [e in the model of Equation D.1]. The smaller "sd(Resid)" is, the more precise the fit. The last column "df" has the degrees of freedom associated with "sd(Resid)" appropriate for the t-tests. Since the carriers are

MINITAB is a copyright of Thomas A. Ryan, Jr. 
intercorrelated and multicolinear, interpreting relative magnitudes of coefficients as being indicative of relative "importance" of the carrier variables can be highly misleading.

Two equations are summarized for Group 1. The second is recommended for use since it provides a slightly better fit (based on the $R^{2}$ and sd(Resid) statistics). For the carrier variable, the first equation used the natural logarithm of the MWh sold to domestic customers and the second used the natural logarithm of the total fiwh sold.

Groups 2 and 3 have LDOM and LIRG as significant carriers, with LIN contributing in Group 2 and LOTR in Group 3. Group 4 is the only group with transmission data (for 16 of the 27 utilities; 4 of the 16 had $M 3$ of zero). This carrier, M3, is significant, along with LDOM in the full model.

It will be noted in Table 0.2 that the adjusted $R^{2}$ is smaller for the group regression than for the regression using all 117 data points from the utilities. (a) Despite this, it can be shown that the group fits will provide better precision of estimation when applied to utilities that satisfy the group definitions.

Percentage Loss

A similar set of estimation equations was developed for estimating the percentage loss from the transmission index normalized by number of customers (M2), and the percentage of total sales sold in each customer sector. This model is expressed as

$$
\begin{aligned}
\text { sL }= & a+b_{1} M 2+b_{2} \text { PDOM }+b_{3} \text { PIRG }+b_{4} \text { PCDM } \\
& \left.+b_{5} \text { (PIND or POTR }\right)+e
\end{aligned}
$$

\footnotetext{
(a) The adjustment in the "Adj. $R^{2 n}$ is for the number of carriers as well as the number of data points, so that comparisons for different data sets and restricted models are more meaningful.
} 
where $M 2=$ (Circuit Miles $/ N$ Customers $) \times(\%$ Self-Generation $)$

PDOM, ..., POTR are the percentages of total sales to each customer sector

$\% \mathrm{~L}=100$ (GWh Required - GWh Sold)/GWh Required.

The coefficients $\left(a, B_{1}, \ldots, b_{5}\right)$ and the residual (e) were as defined for Equation (D.1). Since the percentages are colinear, either POTR or PIND was removed so that the full model had only 6 carriers, including the vector of ones for the intercept.

The results are given in Table D.3. The same "Notes" as for Table 0.2 apply, except that t-values are usually not given for a full model, since any of the five percentage-in-sector carriers could be removed to define a full model. The results are not as good, in terms of $R^{2}$, as the results for the $\ln \left(\right.$ MWh) data (summarized in Table 0.3 ). The best overall fit has an $R^{2}$ of $27.4 \%$ compared with $91.5 \%$ for the fit of $\ln$ (Loss) for the 117 utilities. The

TABLE D.3. Summary of Fits of Percent Loss to Percent of Sale in Customer Sector and (CMI *\% S.G.)/NCUST

\begin{tabular}{|c|c|c|c|c|c|c|c|c|c|c|c|}
\hline Croup & $s$ & & a & $\mathrm{M} 2$ & PDOH & PIRC & PCOM & Plito & PDTR & $\begin{array}{l}\text { Adj. } \\
R^{2} \\
\end{array}$ & sci(Res:d) \\
\hline ALL & 117 & $\begin{array}{l}\text { Coeff. } \\
t\end{array}$ & $\begin{array}{l}2.720 \\
2.53\end{array}$ & $\begin{array}{l}4.0606 \\
5.34\end{array}$ & $\begin{array}{l}0.06564 \\
3.77\end{array}$ & $\begin{array}{l}0.08591 \\
4.56\end{array}$ & $(0.24)$ & {$[0.37]$} & $(-0.31)$ & $\begin{array}{l}27.37 \\
26.17\end{array}$ & $\begin{array}{l}3.11 z_{b} \\
3.143\end{array}$ \\
\hline 1 & 26 & ${ }_{t}^{\text {Coeff. }}$ & - & $*$ & $\begin{array}{l}0.0766 \\
6.11\end{array}$ & $\star$ & - & - & $\begin{array}{l}0.1132 \\
1.86\end{array}$ & $9.04^{\mathrm{a}}$ & 3.189 \\
\hline 2 & 43 & ${ }_{t}^{\text {Coeif. }}$ & $\begin{array}{l}9.29 \\
11.41\end{array}$ & * & - & - & $\begin{array}{l}0.08371 \\
1.43\end{array}$ & $\begin{array}{l}-0.04740 \\
-1.63\end{array}$ & $\begin{array}{l}-0.8484 \\
-2.39\end{array}$ & 12.41 & 2.977 \\
\hline 3 & 21 & $\begin{array}{l}\text { Coeff. } \\
t\end{array}$ & $\begin{array}{l}9.38 \\
7.27\end{array}$ & $\star$ & - & - & - & $\begin{array}{l}-0.097 i 8 \\
-1.94\end{array}$ & $\begin{array}{l}-0.4361 \\
-1.92\end{array}$ & $2 C .96$ & 2.896 \\
\hline 4 & 27 & $\begin{array}{l}\text { Coeff. } \\
t\end{array}$ & $\begin{array}{l}2.939 \\
1.67\end{array}$ & $\begin{array}{l}4.4134 \\
6.22\end{array}$ & $\begin{array}{l}0.06407 \\
1.67\end{array}$ & $(1.03)$ & $(-0.51)$ & - & $(0.74)$ & $\begin{array}{l}58.62 \\
55.97\end{array}$ & $\begin{array}{l}2.686 \\
2.771\end{array}$ \\
\hline
\end{tabular}

Notes

a. The $R^{2}$ is for the fit with an intercept since $R^{2}$ is not defined for the no intercept case. (The intercept was -0.051 with a $t$-value of -0.02 .)

b. The statistics for the fuil model are for the fit eliminating PIND, except for the t-value for PIND wich was for the fit omitting POTR. 
best fit is for Group 4, with an $R^{2}$ of $58.6 \%$. But the residuals from this fit have a strong linear relationship with \% Loss, for the 22 loss values less than $10 \%$, indicating that the relatively high $R^{2}$ is spurious as an indicator of the degree of fit. 


\section{DISTRIBUTION}

No. of

Copies

OFFSITE

30 W. M. Warwick MS/KES

Bonneville Power Administration P.0. Box 3621

Portland, OR 97208

30 DOE Technical Information Center

ONSITE

DOE Richland Operations Office

J. J. Sutey/D. R. Segna
No. of

Copies

66 Pacific Northwest Laboratory

W. B. Ashton

J. W. Callaway (4D)

C. A. Counts

R. F. Darwin

J. G. DeSteese (5)

W. H. Doggett

J. E. Engl in

C. A. Geffen

P. L. Hendrickson

J. W. Johnston

M. S. Klan

A. D. Lee

R. J. Nesse

R. G. Rivera

T. J. Secrest

R. C. Tepel

Publishing Coordination $\mathrm{MH}$ (2)

Technical Information (5) 


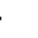

